\title{
Auswirkungen kardiovaskulärer Risikofaktoren sowie verschiedener Vor- und Begleiterkrankungen auf den Verlauf der Alzheimer-Demenz
}

\author{
INAUGURAL-DISSERTATION \\ zur Erlangung des Doktorgrades \\ der Medizinischen Fakultät der \\ Georg-August-Universität zu Göttingen
}

vorgelegt von

Marilis Fricke

aus

Aurich 
Dekan:

\section{Betreuungsausschuss}

Betreuer/in

Ko-Betreuer/in:

\section{Prüfungskommission}

Referent/in

Ko-Referent/in:

Drittreferent/in:

Datum der mündlichen Prüfung: 29.06.2021
Prof. Dr. med. I. Zerr

Prof. Dr. sc. hum. T. Friede

PD Dr. rer. nat. S. Unkel

Prof. Dr. med. M. Oppermann 
Hiermit erkläre ich, die Dissertation mit dem Titel "Auswirkungen kardiovaskulärer Risikofaktoren sowie verschiedener Vor- und Begleiterkrankungen auf den Verlauf der Alzheimer-Demenz" eigenständig angefertigt und keine anderen als die von mir angegebenen Quellen und Hilfsmittel verwendet zu haben.

Göttingen, den 


\section{Inhaltsverzeichnis}

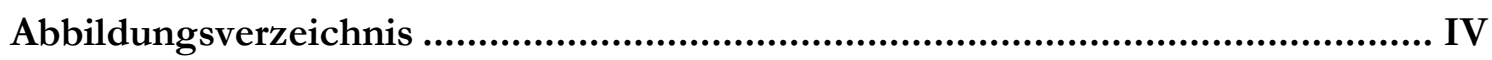

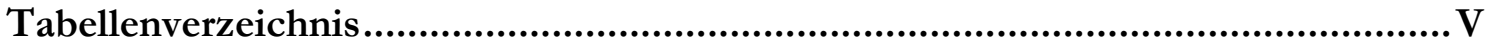

Abkürzungsverzeichnis ................................................................................... VII

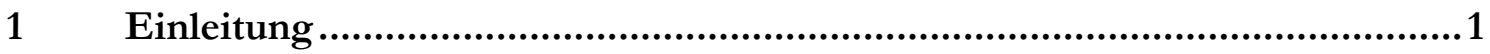

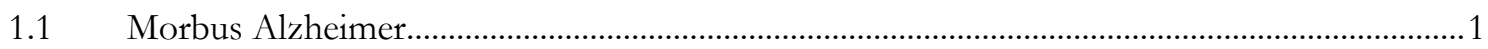

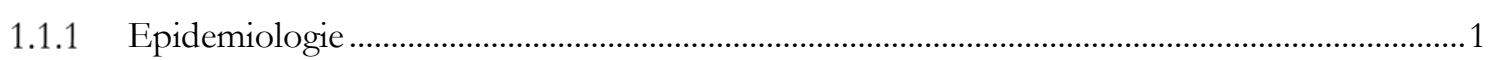

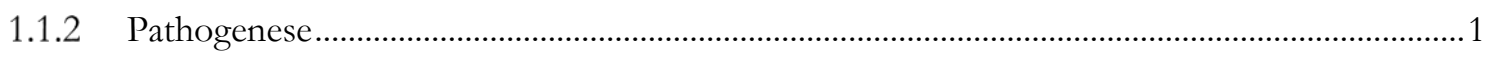

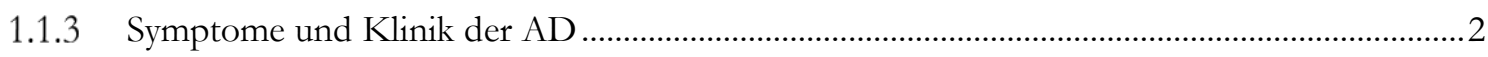

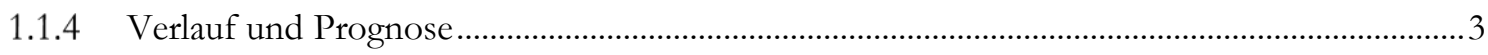

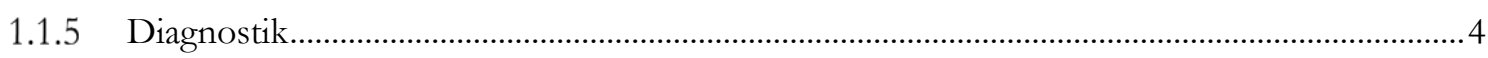

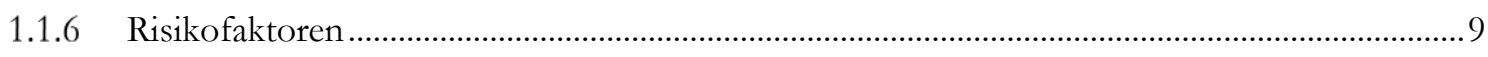

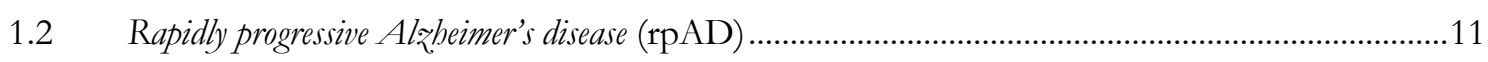

$1.3 \quad$ Fragestellung der Doktorarbeit .................................................................................................. 14

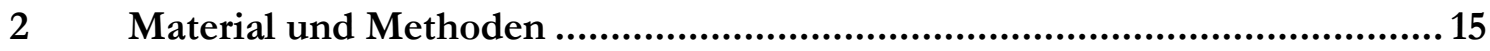

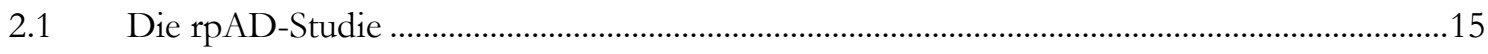

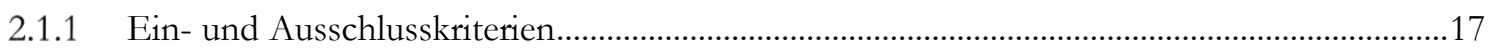

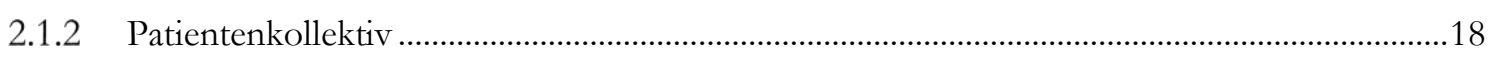

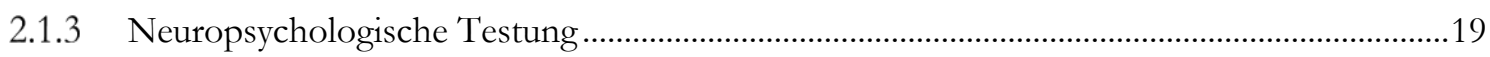

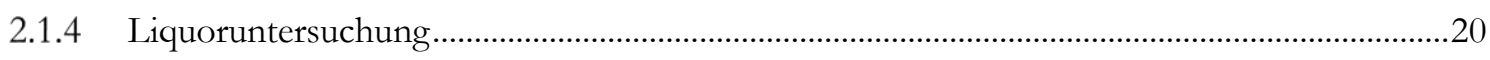

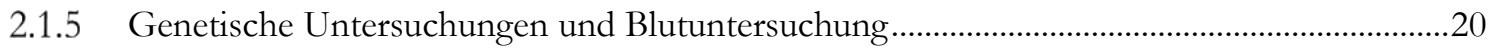

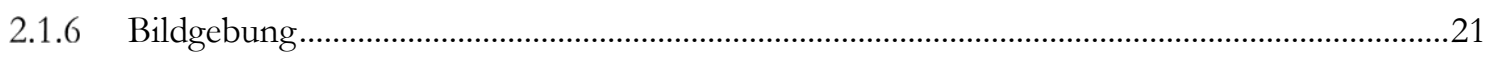

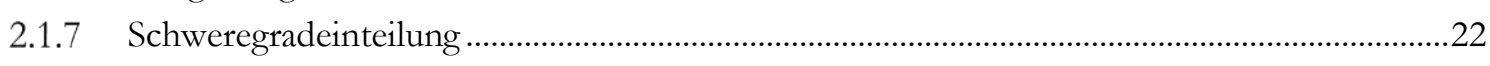

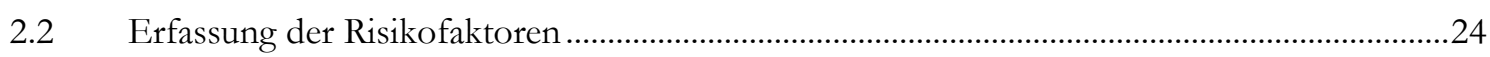

2.2.1 Kardiovaskuläre Risikofaktoren und Malignome...................................................................25

2.2.2 Chirurgische Eingriffe und andere Vor- und Begleiterkrankungen ..........................................26

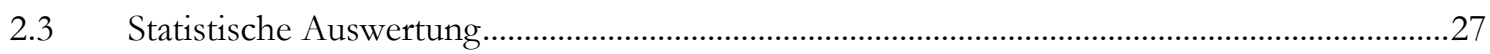

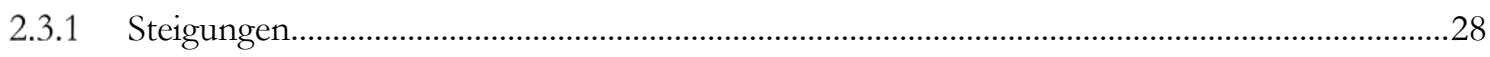

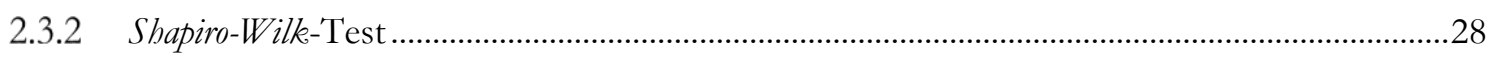

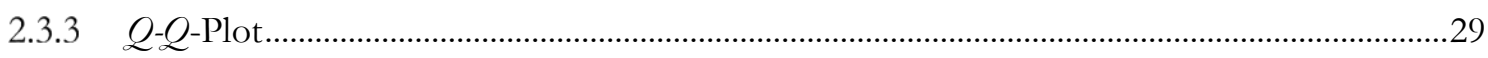

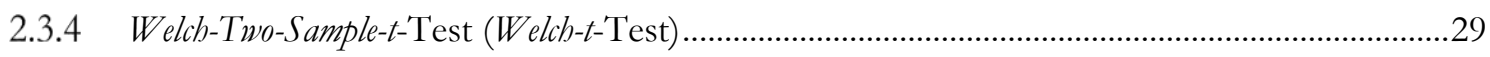

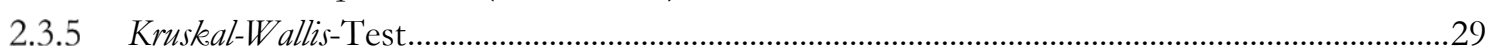

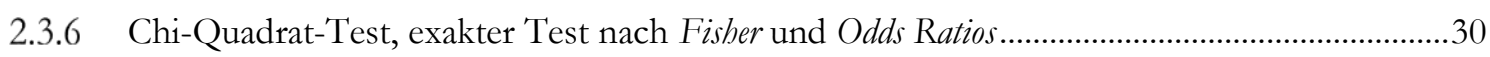

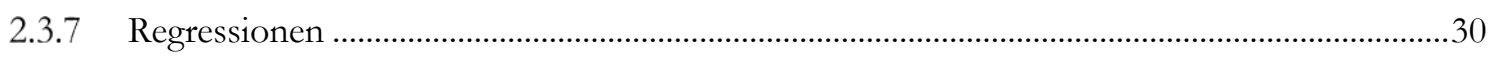

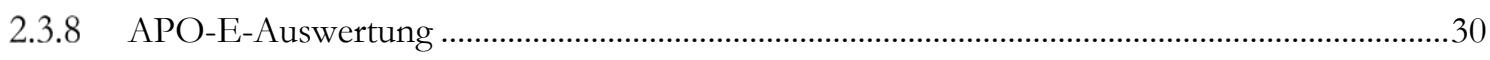

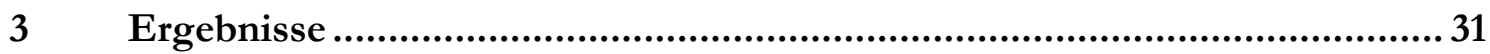

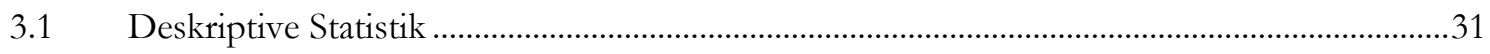

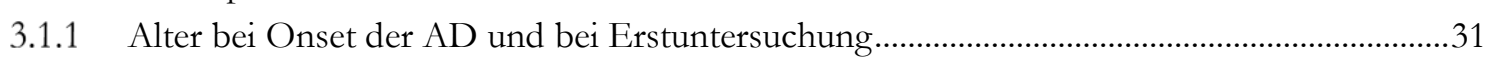




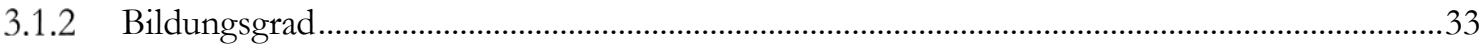

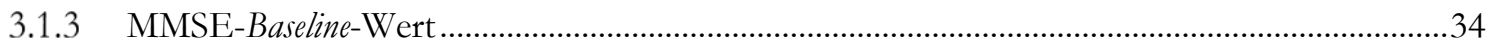

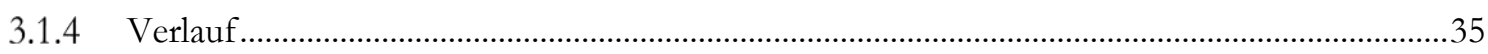

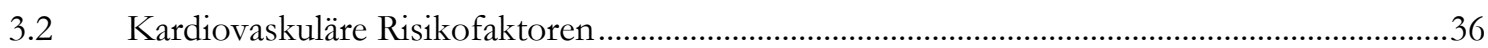

3.2.1 Deskriptive Statistik der Steigungen der „,kardiovaskulären Risikofaktoren“.............................37

3.2.2 p-Werte des Welch-t-Tests der „,kardiovaskulären Risikofaktoren“ “............................................38

3.2.3 p-Werte des Chi-Quadrat-Tests und des exakten Tests nach Fisher mit Odds Ratios der „kardiovaskulären Risikofaktoren“...............................................................................................39

3.2.4 Regressionsanalyse von Diabetes mellitus als prognostischer Faktor für den Gedächtnisverfall im Rahmen einer AD

3.2.5 Regressionsanalyse von KHK als prognostischer Faktor für den Gedächtnisverfall im Rahmen einer AD..

3.2.6 Regressionsanalyse mit KHK und Diabetes mellitus als Kovariablen ......................................42

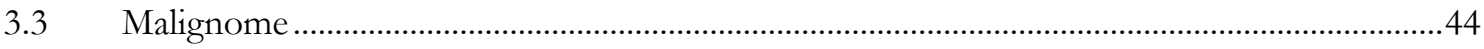

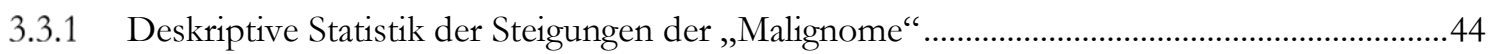

3.3.2 p-Werte des Welch-t-Tests der „Malignome“ im Allgemeinen und der Subgruppen der

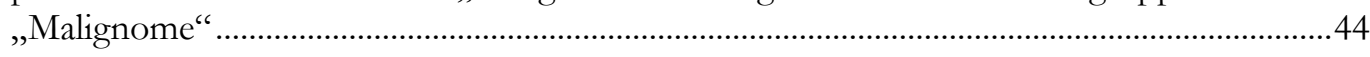

3.3.3 p-Werte des Chi-Quadrat-Tests und des exakten Tests nach Fisher mit Odds Ratios der

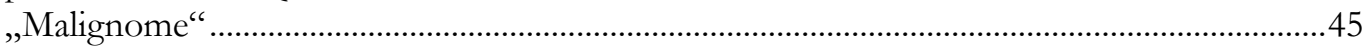

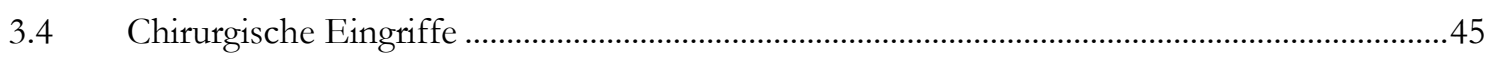

3.4.1 Deskriptive Statistik der Steigungen der „,chirurgischen Eingriffe“ “..........................................45

3.4.2 p-Werte des Welch-t-Tests der „chirurgischen Eingriffe“ im Allgemeinen und der einzelne Eingriffe ................................................................................................................................. 46

3.4.3 p-Werte des Chi-Quadrat-Tests und des exakten Tests nach Fisher mit Odds Ratios der „,chirurgischen Eingriffe“

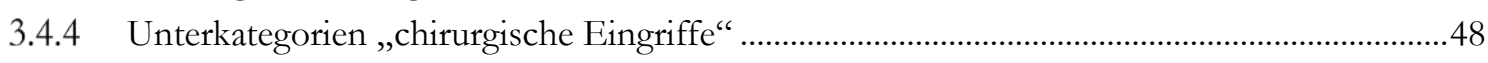

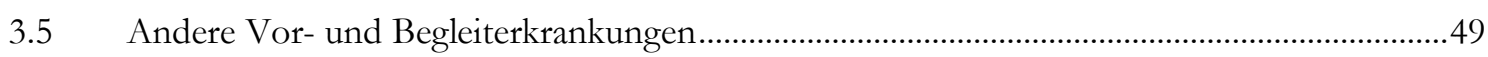

3.5.1 Deskriptive Statistik der Steigungen der ,anderen Vor- und Begleiterkrankungen“ “.............49

3.5.2 p-Werte des Welch-t-Tests der ,anderen Vor- und Begleiterkrankungen“...............................50

3.5.3 p-Werte des Chi-Quadrat-Tests und des exakten Tests nach Fisher mit Odds Ratios der „anderen Vor- und Begleiterkrankungen“.......................................................................................51

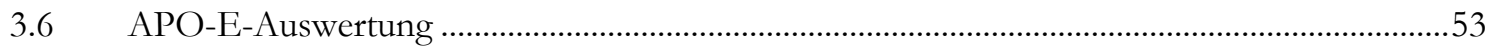

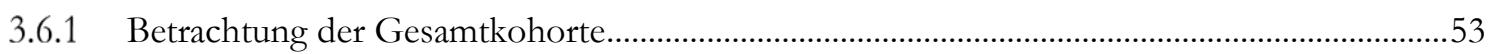

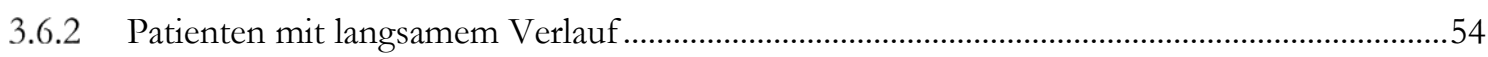

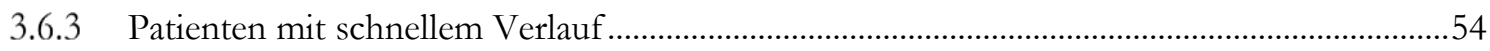

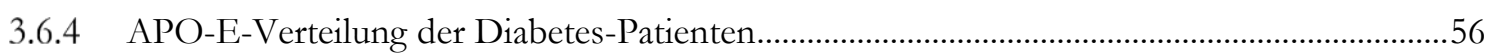

3.6.5 APO-E-Verteilung der KHK-Patienten ..................................................................................

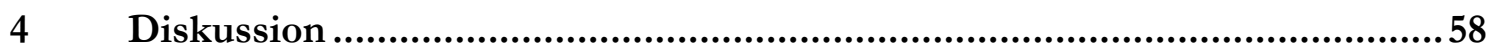

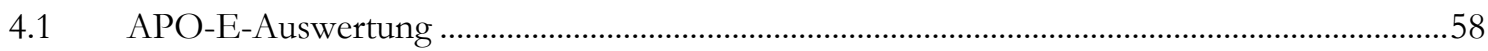

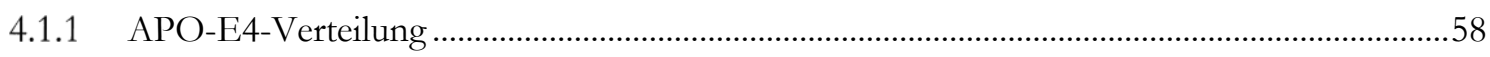

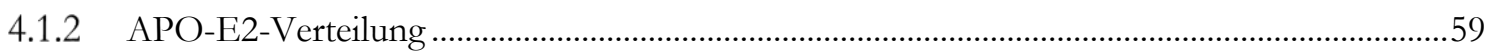

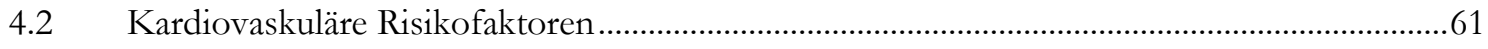

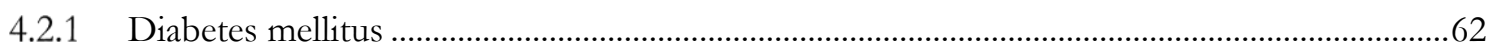

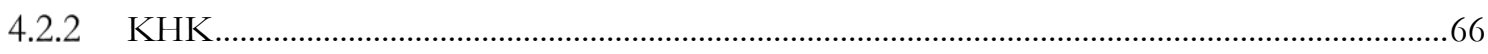

4.2.3 KHK und Diabetes mellitus als Komorbiditäten .....................................................................69 


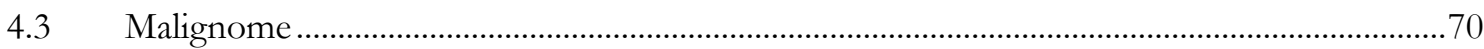

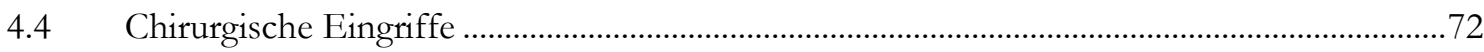

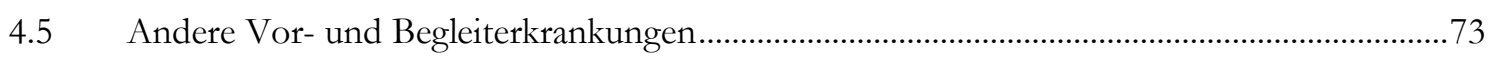

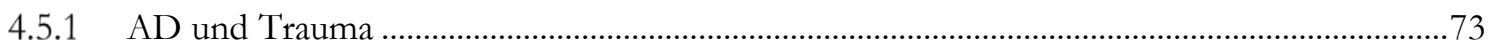

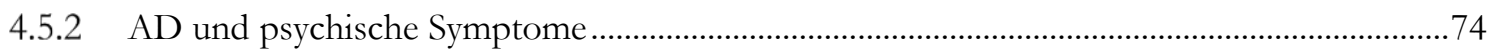

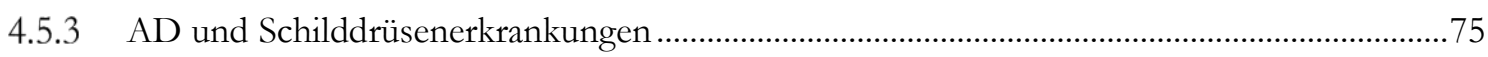

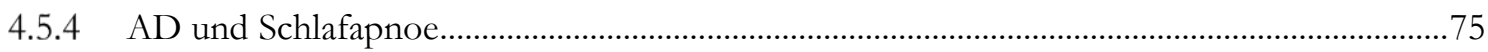

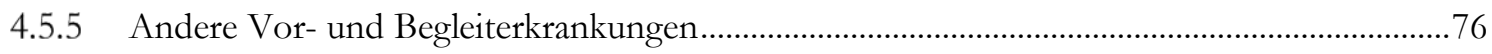

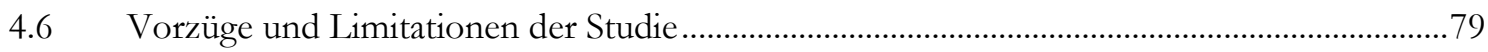

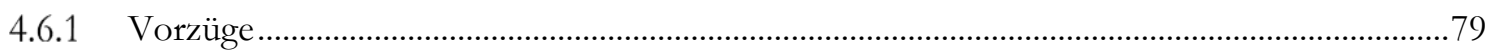

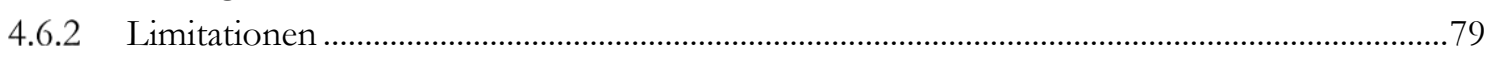

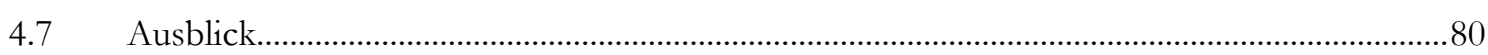

$5 \quad$ Zusammenfassung.................................................................... 81

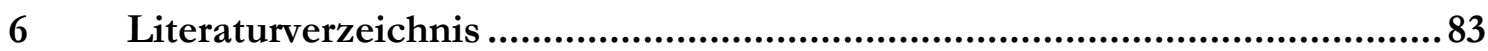




\section{Abbildungsverzeichnis}

Abbildung 1: Schematische Darstellung des Studienkonzepts der rpAD-Studie....... .16

Abbildung 2: PRISMA-Flussdiagramm zur Selektion der rpAD-Patienten

Abbildung 3: Zwei MRT-Aufnahmen mit typischen AD-Läsionen

Abbildung 4: Beispielhafte Darstellung zur Berechnung einer Steigung...........................................28

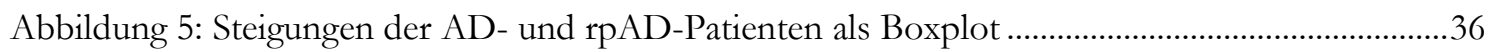

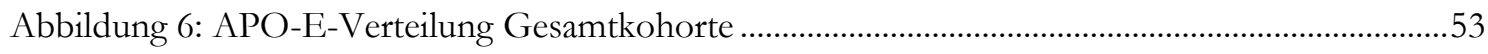

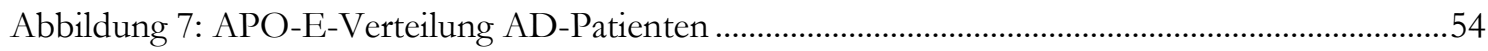

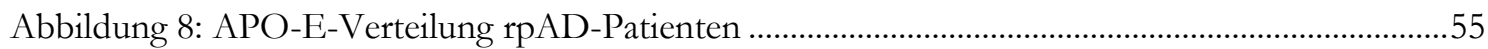




\section{Tabellenverzeichnis}

Tabelle 1: Beeinträchtigungen bei Verdacht auf eine AD ................................................................

Tabelle 2: Diagnostikkriterien für die AD modifiziert nach McKhann et al. (2011).............................5

Tabelle 3: Diagnostikkriterien für die AD modifiziert nach Dubois et al. (2014) .................................5

Tabelle 4: Ausschlusskriterien für die Diagnose einer AD modifiziert nach Dubois et al. (2014) ......6

Tabelle 5: Vergleich von klassischer AD und rpAD modifiziert nach Schmidt et al. (2011) .............13

Tabelle 6: Notwendige Einschlusskriterien der rpAD-Studie .............................................................17

Tabelle 7: Ergänzende Einschlusskriterien der rpAD-Studie...............................................................17

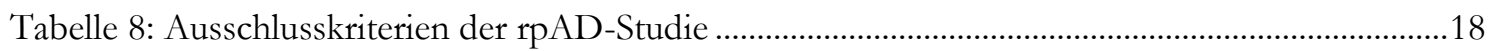

Tabelle 9: Ranking der Studienpatienten aus dem Studienbericht der rpAD-Studie.........................23

Tabelle 10: Untersuchte Faktoren in den Gruppen ,kardiovaskuläre Risikofaktoren“ und „,Malignome “ ......................................................................................................................25

Tabelle 11: Untersuchte Faktoren in den Gruppen „chirurgische Eingriffe“ und „andere Vor- und

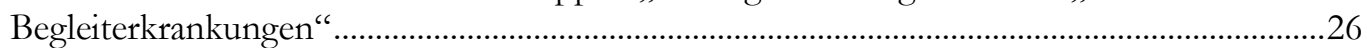

Tabelle 12: Geschlechterverteilung der AD- und rpAD-Gruppe......................................................31

Tabelle 13: Alter der AD- und rpAD-Patienten bei Onset der AD .......................................................32

Tabelle 14: Alter der AD- und rpAD-Patienten bei Erstuntersuchung ..............................................33

Tabelle 15: Bildungsjahre der AD- und rpAD-Patienten ...................................................................34

Tabelle 16: MMSE-Baseline-Wert der AD- und rpAD-Patienten..........................................................35

Tabelle 17: Deskriptive Statistik der Steigungen der „,kardiovaskulären Risikofaktoren“ ...................37

Tabelle 18: p-Werte des Welch-t-Tests der „,kardiovaskulären Risikofaktoren“...................................38

Tabelle 19: p-Werte des Chi-Quadrat-Tests und des exakten Tests nach Fisher mit Odds Ratios der „kardiovaskulären Risikofaktoren“....

Tabelle 20: Regressionskoeffizienten mit Standardfehlern und p-Werten der linearen Regression von Diabetes mellitus.

Tabelle 21: Regressionskoeffizienten mit Standardfehlern und p-Werten der logistischen Regression von KHK

Tabelle 22: Regressionsmodell mit KHK und Diabetes mellitus als Kovariablen ............................43

Tabelle 23: Deskriptive Statistik der Steigungen der „Malignome“ ........................................................44

Tabelle 24: p-Werte des Welch-t-Tests für „Malignome“ im Allgemeinen und Subgruppen der „Malignome“

Tabelle 25: p-Werte des Chi-Quadrat-Tests und des exakten Tests nach Fisher mit Odds Ratios der „Malignome“.

Tabelle 26: Deskriptive Statistik der Steigungen der „,chirurgischen Eingriffe“ “.................................46

Tabelle 27: p-Werte des Welch-t-Tests der einzelnen ,chirurgischen Eingriffe“ ................................47

Tabelle 28: p-Werte des Chi-Quadrat-Tests und des exakten Tests nach Fisher mit Odds Ratios der „,chirurgischen Eingriffe“

Tabelle 29: Gruppenvergleich der Untergruppen „Herzoperationen“ und „orthopädische Eingriffe"

Tabelle 30: Deskriptive Statistik der Steigungen der „,anderen Vor- und Begleiterkrankungen“.......49

Tabelle 31: Deskriptive Statistik der Steigungen der ,, anderen Vor- und Begleiterkrankungen“ mit

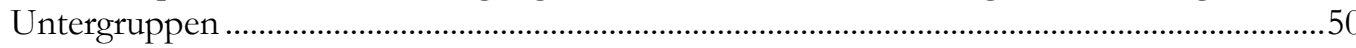

Tabelle 32: p-Werte des Welch-t-Tests der ,anderen Vor- und Begleiterkrankungen“.........................51

Tabelle 33: p-Werte des Chi-Quadrat-Tests und des exakten Tests nach Fisher mit Odds Ratios der ,anderen Vor- und Begleiterkrankungen“.....

Tabelle 34: p-Werte der Gruppenvergleiche der Unterkategorien „Trauma“, ,andere neurologische Erkrankungen“, „Schilddrüse“ und „psychische Vorerkrankungen“

Tabelle 35: APO-E-Verteilung von Patienten der rpAD-Studie 
Tabelle 36: Häufigkeit der einzelnen Allele in der Studienkohorte ....................................................56

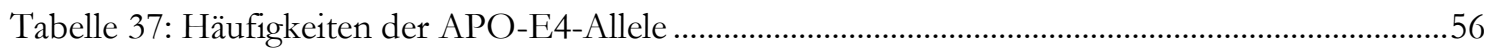

Tabelle 38: APO-E-Verteilung der Diabetes-Patienten im Vergleich zu Nicht-Diabetes-Patienten. 57

Tabelle 39: APO-E-Verteilung der KHK im Vergleich zu Nicht-KHK-Patienten

Tabelle 40: Übersicht über die Referenzen geordnet nach dem Kriterium „Risikofaktor für AD” und ,,kein Risikofaktor für AD"

Tabelle 41: Übersicht über die Referenzen geordnet nach „Risikofaktor für klassische AD" und „Risikofaktor für rapid progressive AD" .78 


\section{Abkürzungsverzeichnis}

$\begin{array}{ll}\text { AD } & \text { Alzheimer-Demenz } \\ \text { ADL } & \text { Activities of daily living } \\ \text { APO-E } & \text { Apolipoprotein-E } \\ \text { APP } & \text { Amyloid precursor protein } \\ \text { A } 1-42 & \text { Amyloid-beta-1-42 } \\ \text { CERAD } & \text { Consortium to establish a registry for Alzheimer's disease } \\ \text { DNA } & \text { Desoxyribonukleinsäure } \\ \text { DGN } & \text { Deutsche Gesellschaft für Neurologie e.V. } \\ \text { ELISA } & \text { Ensyme-linked immunosorbent assay } \\ \text { FLAIR } & \text { Fluid attenuated inversion recovery } \\ \text { HNO } & \text { Hals-Nasen-Ohren } \\ \text { KHK } & \text { Koronare Herzkrankheit } \\ \text { MMSE } & \text { Mini mental status examination } \\ \text { MRT } & \text { Magnet-Resonanz-Tomographie } \\ \text { NIA-AA } & \text { National Institute on Aging and Alzheimers's Association } \\ \text { OSAS } & \text { Obstruktives Schlafapnoesyndrom } \\ \text { pAVK } & \text { Periphere arterielle Verschlusskrankheit } \\ \text { PET } & \text { Positronen-Emissions-Tomographie } \\ \text { PD } & \text { Parkinson-Demenz } \\ \text { pTau } & \text { Phosphoryliertes Tau } \\ \text { rpAD } & \text { Rapidly Progressive Alzheimer's Disease } \\ \text { TEP } & \text { Totale Endoprothese } \\ \text { UMG } & \text { Universitätsmedizin Göttingen } \\ \text { UPDRS } & \text { Unified Parkinson's disease rating scale } \\ & \end{array}$




\section{$1 \quad$ Einleitung}

\subsection{Morbus Alzheimer}

\subsubsection{Epidemiologie}

Mit einer geschätzten Prävalenz von 36 Millionen Patienten weltweit gilt der Morbus Alzheimer als die häufigste Form der demenziellen Erkrankungen. Die weltweiten Kosten, die durch Diagnostik, Therapie und Pflege der Betroffenen entstehen, machen die Erkrankung zu einem sozioökonomischen Problem. Es wird vermutet, dass sich die Patientenzahl aufgrund des demographischen Wandels bis 2050 sogar verdreifachen wird (Querfurth und LaFerla 2010; Wimo et al. 2013; Ferri et al. 2005; Goldberg 2007).

\subsubsection{Pathogenese}

Die Atrophie des Hirngewebes ist ein entscheidender pathologischer Faktor in der Entstehung der Alzheimer-Demenz (AD). Die Atrophie betrifft den gesamten cerebralen Kortex, wobei der Temporallappen am stärksten betroffen ist. Nach heutiger wissenschaftlicher Erkenntnis entsteht die Atrophie aufgrund der neurofibrillären Degeneration und dem Verlust von intrinsischen Pyramidalzellen, einschließlich ihrer Axone. Der Verlust von aufsteigenden subkortikalen Fasern vom Nucleus basalis Meynert und dem Locus coeruleus könnte ebenfalls dazu beitragen. Erste Veränderungen, die auf eine beginnende AD hindeuten, sind am hippocampalen und entorhinalen Cortex beschrieben und betreffen gleichermaßen die graue und die weiße Substanz (Mann 1991; deToledo-Morrell et al. 2004).

Zeitgleich zu dem Verlust des Hirnvolumens akkumulieren intrazelluläre neurofibrilläre Bündel (tangles) im Laufe der Erkrankung (Gomez-Isla et al. 1997). Die Hauptkomponente der intrazellulären tangles ist ein abnormal hyperphosphoryliertes und aggregiertes Tau-Protein. Diese Form von Tau besitzt andere Eigenschaften als das Protein gesunder Personen. Es ist unlöslich und kann aufgrund fehlender Affinität keine Mikrotubuli mehr stabilisieren. Somit kann Tau seiner zentralen Funktion nicht mehr nachkommen. Des Weiteren assoziiert es sich $\mathrm{zu}$ paarigen helikalen Strukturen, wodurch weiterhin die Akkumulation begünstigt wird (Querfurth und LaFerla 2010; Iqbal et al. 2010). 
Erhöhte Konzentrationen von phosphoryliertem Tau (pTau) oder seine generelle Erhöhung im Liquor sind mögliche Marker für die Schwere der demenziellen Symptomatik und korrelieren mit der Verschlechterung der kognitiven Leistung (Wallin et al. 2006).

Laut der sogenannten „Amyloid-Hypothese“ besteht ein Ungleichgewicht zwischen Produktion, Abbau und Aggregation von Peptiden. Neben dem Tau-Protein akkumuliert auch Amyloid- $\beta$ (Hardy und Allsop 1991; Barage und Sonawane 2015). Das abnorme Amyloid- $\beta$ kann dabei in verschiedenen Strukturformen auftreten, in denen entweder 30 bis 100 Monomere oder unter 30 Monomere enthalten sind (Cohen et al. 2015).

Die Kombination aus neuronalem Verlust und der Ausfällung der genannten Proteine zu Plaques und tangles führt zu einem diffusen Funktionsverlust vieler Hirnareale, der sich in den verschiedenen Symptomen der AD-Patienten widerspiegelt.

Nach dem gegenwärtigen Stand der Forschung spielen in der Pathogenese der Erkrankung noch weitere komplexe molekulare Mechanismen eine Rolle, von denen einige durch biochemische, molekulare, zellbiologische und transgenetische Modelle näher untersucht werden konnten (Huang und Mucke 2012).

\subsubsection{Symptome und Klinik der AD}

Die durch Alois Alzheimer im Jahre 1907 erstmals beschriebene Erkrankung ist gekennzeichnet durch einen Gedächtnisverlust mit progressiver Demenz und Funktionsausfällen in verschiedenen kognitiven Bereichen.

Als frühe Symptome manifestieren sich oft subtile intermittierende Defizite des episodischen Gedächtnisses (Walsh und Selkoe 2004). Dies zeigt sich durch den Verlust kürzlich aufgenommener Informationen und die Unfähigkeit Alltagstätigkeiten strukturiert zu erledigen. Bei Progredienz der Erkrankung zeigten sich bei 88 \% der Betroffenen Verhaltensauffälligkeiten wie Apathie, Unruhe, Angstzustände, Reizbarkeit, Dysphorie, Enthemmung, Wahn und Halluzinationen (Mega et al. 1996).

Der Rückgang der kognitiven Leistung ist assoziiert mit schlechten Ergebnissen in neuropsychologischen Tests, bei denen die visuell-räumliche Interaktionsfähigkeit getestet wird. Ein Defizit in diesem Bereich korrelierte auch mit einer Verschlechterung in den Aktivitäten des täglichen Lebens (ADL) (Mortimer et al. 1992).

Dabei unterscheiden sich die Symptome bei Patienten mit Early- und Late-Onset-AD. Patienten, die vor dem 65. Lebensjahr erkranken, werden in die Gruppe Early-Onset-AD eingeordnet, diejenigen, die nach dem 65. Lebensjahr erkranken, sind als Late-Onset-AD-Patienten zu 
klassifizieren. Bature et al. (2017) beobachteten, dass Early-Onset-AD-Patienten vornehmlich an kognitiven Einschränkungen litten, während Late-Onset-AD-Patienten Depressionen sowie Einschränkungen des semantischen Gedächtnisses und der konzeptionellen Fähigkeiten zeigten.

Es zeigten sich auch atypische Verläufe, die darauf hindeuten, dass eine Einteilung in Early-und Late-Onset-AD nicht ausreicht. Wahrscheinlich existieren weitere Subgruppen, die aufgrund unzureichender Datenlage jedoch noch keinen Einzug in Leitlinien oder Behandlungsschemata gefunden haben. Im Folgenden sollen zwei Beispiele für mögliche Subtypen aufgezeigt werden. Diverse Faktoren aus Murrays Daten, unter anderem demografische, genetische und klinische Unterschiede, erlauben eine Differenzierung von typischer und atypischer AD-Erkrankung. Er differenzierte mit dem „hippocampussparenden“ und dem „limbisch-prädominanten“'Typ zwei Subtypen, die zusammen 25\% der AD-Patienten ausmachen. Die Patienten, welche am hippocampussparenden Typen litten, waren jünger, mehrheitlich männlich und wiesen signifikant weniger Apolipoprotein-E4-Allele (APO-E4) als jene Patienten mit limbischprädominantem Typ auf (Murray et al. 2011). Insbesondere das Fehlen der APO-E4-Allele unterscheidet diesen möglichen Subtyp von der klassischen AD.

Eine andere Studie ließ ebenfalls auf zwei verschiedene Untergruppen der AD schließen. Die eine ist charakterisiert durch langsame klinische Progression und Parietallappendysfunktion, die andere durch schnelle Progression und funktionelle Abnormalitäten in Parietal- und Frontallappen (Mann et al. 1989).

\subsubsection{Verlauf und Prognose}

Besonders die initiale Phase der Erkrankung stellt für die Betroffenen eine Belastung dar, da sie sich ihres kognitiven Verfalls bewusst sind. Nach dem ursprünglich langsam fortschreitenden Verlauf der Erkrankung verlieren die Patienten immer mehr Alltagsfertigkeiten und kognitive Fähigkeiten. Sie sind zunehmend auf Pflege angewiesen, da die Ausführung der ADL selbstständig nicht mehr möglich ist. Im Laufe der Jahre ist eine enge Zusammenarbeit von Familienmitgliedern, Pflegepersonal und Sozialarbeitern vonnöten, um die Patienten bestmöglich zu unterstützen und zu versorgen. Nach im Mittel drei bis neun Jahren endet die Erkrankung mit dem Tod (Hampel et al. 2004; Huang und Mucke 2012; Querfurth und LaFerla 2010). 


\subsubsection{Diagnostik}

Häufig ist die sporadische Form der AD. Die seltenere, zu 0,5 \% innerhalb aller AD-Erkrankten auftretende familiäre Variante der Erkrankung ist mit speziellen autosomal-dominant vererbten Mutationen vergesellschaftet. Diese werden mit hoher Penetranz weitervererbt (Nikisch et al. 2008; Xie und Tanzi 2006). In der Diagnostik wird sich anhand der ICD-10-Kodierung an den bereits erwähnten Subgruppen der Early- und Late-Onset-AD orientiert. Die Grenze ist dabei laut der Deutschen Gesellschaft für Neurologie e.V. (DGN) das 65. Lebensjahr, wobei beide Formen sich nach derzeitigem Stand der Wissenschaft in der Symptomatik, allerdings nicht in Pathogenese und Therapie unterscheiden (DGN 2016; Bature et al. 2017). Bei Verdacht auf eine genetische Form der Erkrankung wird nach Einteilung in Early- oder Late-Onset-AD eine genetische Untersuchung angeschlossen.

Laut der Arbeitsgruppe des „National Institute on Aging“ und der "Alz̧heimer's Association" (NIA-AA) müssen mindestens zwei der Fähigkeiten aus Tabelle 1 beeinträchtigt sein, um das Vorliegen einer AD zu belegen (DGN 2016).

Tabelle 1: Beeinträchtigungen bei Verdacht auf eine AD

\section{Beeinträchtigungen}

Gedächtnisfunktionen

Verstehen und Durchführen komplexer Aufgaben, Urteilsfähigkeit

Räumlich-visuelle Funktionen

Sprachfunktionen

Veränderung im Verhalten („Persönlichkeitsveränderungen“)

(DGN 2016) Die Verwendung erfolgt mit freundlicher Genehmigung von Prof. Dr. Frank Jessen.

Bei Betrachtung der möglichen pathophysiologischen Prozesse der Erkrankung wird sich an den von McKhann et al. (1984; 2011) veröffentlichen Diagnostikkriterien orientiert, welche in Tabelle 2 dargestellt sind. 
Tabelle 2: Diagnostikkriterien für die AD modifiziert nach McKhann et al. (2011)

\begin{tabular}{lll}
\hline Amyloid-Marker & Marker für neuronale Schädigung \\
\hline $\begin{array}{l}\text { Erniedrigung von } \\
\text { (Aß1-42) im Liquor }\end{array}$ & Amyloid-beta-1-42 & Erhöhung von Tau und/oder pTau im Liquor \\
Amyloid-Nachweis mittels Positronen- & Atrophie des medialen Temporallappens, darge- \\
Emissions-Tomographie (PET) & stellt mittels Magnetresonanz-Tomographie \\
& (MRT) \\
& Parietotemporaler Hypometabolismus, darge- \\
& stellt mittels Fluorodesoxyglukose-Positronen- \\
& Emissions-Tomographie (FDG-PET) \\
\hline
\end{tabular}

(DGN 2016) Die Verwendung erfolgt mit freundlicher Genehmigung von Prof. Dr. Frank Jessen.

Dubois et al. (2014) schlagen im Rahmen ihrer Arbeit der „International Working Group“(IWG) vor, die $\mathrm{AD}$ anhand einer über sechs Monate andauernden episodischen Gedächtnisstörung zu diagnostizieren. Mindestens eines der folgenden Kriterien aus Tabelle 3 muss ebenfalls erfüllt sein.

Tabelle 3: Diagnostikkriterien für die AD modifiziert nach Dubois et al. (2014)

Hinweise für die Pathologie der AD durch mindestens eines der folgenden Kriterien

Erniedrigtes A $\beta 1-42$ im Liquor und erhöhtes Tau-Protein bzw. pTau im Liquor

Positiver Amyloid-Nachweis mit PET

Mutation, die zu einer monogen vermittelten AD führt (Mutation auf den Genen Presenilin-1, Presenilin-2 oder auf dem Gen des Amyloid-Precursor-Proteins (APP))

(DGN 2016) Die Verwendung erfolgt mit freundlicher Genehmigung von Prof. Dr. Frank Jessen.

Zusätzlich ergänzen Dubois et al. Kriterien, die das Vorliegen einer AD unwahrscheinlich machen (siehe Tabelle 4). 
Tabelle 4: Ausschlusskriterien für die Diagnose einer AD modifiziert nach Dubois et al. (2014)

\section{Ausschlusskriterien}

Plötzlicher Beginn der Symptomatik

Frühe Gangstörung, frühe Krampfanfälle, schwere frühe Verhaltensänderungen, frühe extrapyramidalmotorische Zeichen oder frühe Halluzinationen

Fokale neurologische Zeichen

Fluktuationen der kognitiven Störungen

Andere Erkrankungen, die die kognitive Störung erklären können

(DGN 2016) Die Verwendung erfolgt mit freundlicher Genehmigung von Prof. Dr. Frank Jessen.

\subsubsection{MRT}

Die MRT-Bildgebung ist ein wichtiges Werkzeug in der AD-Diagnostik mittels Bildgebung. Mit der MRT können neuroanatomische Atrophien, Hypointensitäten und Mikroinfarkte dargestellt werden, welche für die AD typisch sind (Ali et al. 2015). Dabei sind bezüglich der neuroanatomischen Atrophien vor allem die Hippocampusformationen betroffen, die sich bei AD-Patienten bis zu $35 \%$ kleiner darstellten verglichen mit gesunden Vergleichspersonen (Desikan et al. 2010; Frisoni et al. 2008).

\subsubsection{PET}

Für die AD-Diagnostik wird die PET in Kombination mit einem radioaktiv markierten Glukose-Präparat eingesetzt, um den Glukosemetabolismus in den verschiedenen Regionen des Gehirns darstellen zu können. Mithilfe der 18[F]-fluoro-2-Deoxyglukose kann ein verringerter Metabolismus im Gehirn von AD-Patienten detektiert werden (Cutler 1986).

Dabei sind insbesondere Einbußen in der funktionellen Aktivität und Kommunikation zwischen den Hemisphären und zwischen den Strukturen des Parietal- und Frontallappen auffällig (Horwitz et al. 1987). Anhand der Darstellung vieler verschiedener Regionen ist festzustellen, wie gut einzelne Bereiche ihre ursprünglichen Funktionen noch ausführen können. Gravierende kognitive Defizite in bestimmten Bereichen, waren auf diejenigen Regionen mit dem niedrigsten Glukosemetabolismus zurückzuführen (McGeer et al. 1990). Es ist ebenfalls möglich bei ausgewählten Patienten die Amyloid- $\beta$ - und Tau-Belastung im Gehirn mittels PET zu detektieren, was eine weitere nicht invasive Untersuchungsmethode darstellt. Als Radiopharmaka werden bei der Amyloid- $\beta$-Detektion unter anderem [18F]-Florbetapir, [18F]-Florbetaben oder [18F]-Flutemetamol zur Darstellung der Plaques 
verwendet. Ziel der Untersuchung ist es eine Aussage darüber zu treffen, ob das Gehirn eines Patienten als „Amyloid- $\beta$ positiv“ oder „Amyloid- $\beta$ negativ“ zu klassifizieren ist. Abhängig vom Radiopharmakon wird ein Befund als positiv ab einem oder zwei betroffenen Bereichen gewertet. Dabei wird bei Verdacht auf AD ein besonderes Augenmerk auf den frontalen, zingulären, temporalen, parietalen und okzipitalen Kortex gelegt. Im primär visuellen und im sensorimotorischen Kortex sind weniger Amyloidablagerungen zu beobachten (Barthel et al. 2015).

Die Detektion von Tau-Ablagerungen im Gehirn gestaltet sich dagegen etwas schwieriger, da der tracer sowohl die Bluthirnschranke überqueren als auch sich intrazellulär an die Tau-Tangles ablagern muss. Einige zugelassene tracer sind beispielsweise [11C]-PBB3, [18F]-THK523, [18F]THK5105, [18F]-THK5117, [18F]-T808 und [18F]-T807. Bisher gibt es wenige Studien, in denen die verschiedenen tracer am menschlichen Gehirn getestet wurden. Die Untersuchung der Tau-Belastung im Hirn kann helfen die AD-Diagnose weiter zu festigen und differentialdiagnostisch weitere Tauopathien auszuschließen. Des Weiteren ist geplant, zukünftig die Tau-Messung für Verlaufskontrollen zu nutzen (Shah und Catafau 2014).

\subsubsection{Blutuntersuchung und Genetik}

Im Blut von Patienten mit Verdacht auf AD wird vor allem das APO-E4 als ein Protein des Lipidstoffwechsels bestimmt, welches als eines der wichtigsten genetischen Risikofaktoren für die AD gilt (Kim et al. 2009).

Des Weiteren werden die schon erwähnten monogenetischen Mutationen des Presenilin-1- und Presenilin-2-Gens und des APP im Blut untersucht (Dubois et al. 2014).

Eine Studie aus dem Jahr 2018 entdeckte einen Zusammenhang zwischen der Strukturveränderung des Amyloid- $\beta$ im menschlichen Blut und den Liquor-AD-Biomarkern, sodass in Zukunft neuere diagnostische Pfade mittels Blutuntersuchung erhofft werden (Nabers et al. 2018).

\subsubsection{Liquoruntersuchung}

Mittels einer Liquorpunktion im Lumbalbereich wird Liquor entnommen, auf pathologische Veränderungen des A $\beta 1-42-P e p t i d s$, des Tau-Proteins oder des pTau-Proteins untersucht und asserviert. Dabei sprechen ein erniedrigtes A $\beta 1-42-P e p t i d$ im Liquor und ein erhöhtes TauProtein bzw. pTau im Liquor für eine AD (Dubois et al. 2014). 


\subsubsection{Neuropsychologische Testung}

Ergänzend zur bildgebenden Diagnostik und den Liquoruntersuchungen müssen neuropsychologische Tests durchgeführt werden, um die Diagnose zu festigen und Differentialdiagnosen auszuschließen. Mit Kurztests wie dem Mini-Mental-Status-Examination (MMSE)-Test nach Folstein et al. (1975), dem Montreal-Cognitive-Assessment(MoCa)-Test nach Nasreddine et al. (2005) oder dem Demenz-Detection (DemTect)-Test nach Kessler et al. (2000) können kognitive Defizite grob eingeschätzt werden, der Schweregrad bestimmt oder eine Verlaufsuntersuchung getätigt werden. Das „Consortium to establish a registry for Alzheimer's disease“ (CERAD) entwickelte eine Testbatterie, die es ermöglicht mehrere kognitive Domänen in einer Untersuchung zu testen und die Defizite speziellen Bereichen zuzuordnen (Morris et al. 1989).

\subsubsection{MMSE}

Der MMSE ist ein kurzer Test, der es ermöglicht kognitive Defizite bei Patienten zu detektieren. Dieser wurde auch genutzt, um die Patienten für diese Dissertation zu untersuchen. Anhand des Testes wurde im Verlauf im Rahmen der Rapidly-Progessive-Alzhbeimer's-Disease-Studie (rpADStudie) eine Einteilung unternommen, inwiefern es sich um eine rapid oder langsam progressive AD handelt. Der aus elf Aufgaben bestehende Test ermöglicht eine Maximalpunktzahl von 30 Punkten. Er nimmt etwa fünf bis zehn Minuten Zeit in Anspruch, sodass er schnell und einfach im klinischen Alltag eingesetzt werden kann. Fragen, welche die Stimmung oder Denkweise betreffen, sind nicht enthalten, sodass es bei Patienten mit depressiver Symptomatik zur Verfälschung der Punktzahl kommen kann (Folstein et al. 1975). Eine Punktzahl von 29 bis 30 Punkten stellt einen Normalbefund dar. Dabei gilt im Allgemeinen bei einer Punktzahl von unter 25 Punkten der Verdacht auf eine Demenz, wobei es allerdings viele verschiedene Einteilungsansätze gibt.

Besonders in nachfolgenden Untersuchungen kann bei Beobachtung der erzielten Punktzahlen oftmals ein Trend erkannt werden, der voraussagt, wie sich die Patienten in Zukunft entwickeln könnten. So scheint der Verlust von über vier Punkten im MMSE innerhalb der ersten sechs Monate der Follow-Up-Untersuchungen ein Vorbote von schwereren klinischen Verläufen zu sein. Die Patienten wurden schneller hospitalisiert und starben früher (Soto et al. 2008a).

Die erreichten Punkte im MMSE der Patienten mit rapid progressiver AD waren signifikant niedriger als die der Patienten mit langsam progressiver AD. Die allgemeine Einschränkung der rapid progressiven Gruppe war zudem signifikant höher, die Patienten zeigten einen gravierenderen jährlichen Abfall der Gedächtnisleistung und hatten eine kürzere mediane Überlebenszeit (Bhargava et al. 2006; Wilkosz et al. 2010; Hui et al. 2003). 


\subsubsection{Risikofaktoren}

Die mit der Entstehung oder dem Verlauf der AD zusammenhängenden Risikofaktoren waren Gegenstand intensiver Forschungsprojekte, da die genaue Pathogenese noch nicht abschließend geklärt ist und immer noch nach Therapiemöglichkeiten gesucht wird. In einer Metaanalyse von 2014 sind viele der Risikofaktoren zusammengefasst, die auch in dieser Arbeit untersucht wurden (Campdelacreu 2014).

\subsubsection{APO-E4}

Auf molekulargenetischer Ebene wurden bereits die genetischen Mutationen im Presenilin-1- und Presenilin-2-Gen sowie die des APP bei der familiären AD genannt. Ein weiterer genetischer Risikofaktor stellt das APO-E, insbesondere das APO-E4-Allel, dar. Dies spielt eine wichtige Rolle im Lipidmetabolismus und in der Neurobiologie (Jarvik et al. 1996; Slooter et al. 1998; Huang 2006). Vor allem in der homozygoten Form und in Kombination mit kardiovaskulären Risikofaktoren beeinflusst das APO-E den Gedächtnisverlust bei älteren Patienten (Caselli et al. 2011). APO-E4 soll bei der Late-Onset-AD daran beteiligt sein, die Amyloid- $\beta$ Oligomerisierung und Clearance zu steuern (Tanzi und Bertram 2005).

Das APO-E4-Allel wurde ebenfalls in Zusammenhang mit anderen Risikofaktoren untersucht. So fanden Mayeux et al. (1995) heraus, dass ein Synergismus aus APO-E4 und einer traumatischen Kopfverletzung eine zehnfache Erhöhung des AD-Risikos bedeutet.

\subsubsection{Psychische Symptome}

Depressionen treten vermehrt bei Patienten mit Late-Onset-AD auf (Bature et al. 2017). Sie können die kognitiven Domänen bei älteren Patienten beeinträchtigen und die Symptome einer Demenz hervorrufen oder verschlimmern. Im Risikoprofil der AD-Patienten ist die Depression allerdings nur eine von vielen psychischen Erkrankungen, welche die Patienten und ihr soziales Umfeld belasten können. Forschungsergebnisse zeigen auch, dass sich psychische Symptome direkt auf den Krankheitsverlauf auswirken. Delir und Halluzinationen gelten als Prädiktoren für einen schnelleren Krankheitsprogress (Buccione et al. 2007).

\subsubsection{Vaskuläre- und kardiovaskuläre Erkrankungen}

Die Prävalenz von vaskulären Risikofaktoren und kardiovaskulären Erkrankungen ist bei ADPatienten hoch, was einen negativen Effekt auf die Kognition im hohen Alter haben kann (Duthie et al. 2011; Laukka et al. 2010).

Silvestrini et al. (2006) fanden heraus, dass die beeinträchtigte Funktion cerebraler Mikrogefäße zu einer ungünstigen Entwicklung der kognitiven Funktionen bei AD Patienten führte. Bei 
älteren Individuen konnte passend dazu eine Assoziation zwischen AD und Schlaganfällen beobachtet werden, wobei dieser Zusammenhang am stärksten bei bekannten vaskulären Risikofaktoren bestand. Dies könnte durch einen Progress der bereits bestehenden vaskulären Krankheit oder durch den gemeinsamen Effekt von Schlaganfall und AD-ähnlichen Symptomen erklärbar sein, was im Endeffekt zu einem früheren Beginn der Erkrankung führt. Die jährliche Inzidenz für eine AD war bei Patienten mit vorangegangenem Schlaganfall 5,2 \% und für diejenigen ohne ein solches Ereignis 4,0 \% (Honig et al. 2003).

Newman et al. (2005) entdeckten ebenfalls, dass ältere Erwachsene mit kardiovaskulären Risikofaktoren gefährdet waren, eine Demenz beziehungsweise eine $\mathrm{AD}$ zu entwickeln. Insbesondere Patienten mit peripherer arterieller Verschlusskrankheit (pAVK) waren betroffen, wobei vermutet wird, dass starke periphere Arteriosklerose ebenfalls einen direkten Risikofaktor darstellt.

Bhargava et al. (2006) benannten zusammenfassend folgende häufige kardiovaskuläre Risikofaktoren der AD-Patienten: kardiale Erkrankungen, Myokardinfarkt, Schlaganfall, Bluthochdruck, Diabetes mellitus, aktive Raucher und ehemalige Raucher.

\subsubsection{Diabetes mellitus}

Auch der Diabetes mellitus ist ein häufig diskutierter Risikofaktor der AD. Es wird vermutet, dass die Erkrankung mit dem Risiko vergesellschaftet ist, im hohen Alter eine AD zu entwickeln. Hohe Serumglukoselevel sowie erhöhte Serumcholesterolwerte führen zu einer Schädigung hippocampaler Strukturen (Arvanitakis et al. 2004).

Ein besonderes Risiko gilt dabei für die Patienten mit insulinpflichtigem Diabetes mellitus. Diese Gruppe von Diabetikern hat ein um $65 \%$ erhöhtes Risiko an einer AD zu erkranken (Ott et al. 1996; Arvanitakis et al. 2004). Diskutiert wird hierbei unter anderem der zentrale Effekt, den die periphere Insulinresistenz im Gehirn auslöst, welcher den Insulinsignalweg im Gehirn beeinträchtigt. Es hat sich gezeigt, dass Insulin im zentralen Nervensystem eine der Schlüsselkomponenten im Gedächtnisprozess ist und eine Blockade dieses hippocampalen Signalweges zu tiefgreifenden kognitiven Defiziten führt (McNay und Recknagel 2011; Wu et al. 2008).

Auf der Gegenseite konnten Hassing et al. (2002) nicht bestätigen, dass Patienten mit Diabetes mellitus ein erhöhtes Risiko für eine AD aufweisen. Der Diabetes mellitus Typ 2 ist zwar mit verschiedenen Subtypen der Demenz assoziierbar, es zeigte sich allerdings nur ein zweifach erhöhtes Risiko für vaskuläre Demenz bei Diabetikern. Untersuchungen aus dem Jahre 2017 befassten sich mit dem Risiko an Early-Onset-AD bei einem bereits bestehenden Diabetes 
mellitus zu erkranken. Die Ergebnisse der 40 bis 64 Jahre alten Probanden gaben ebenfalls keinen Anhalt dafür, dass Diabetes mellitus einen Risikofaktor für die Entwicklung einer AD darstellt (Kadohara et al. 2017).

Es existieren somit verschiedene Standpunkte und eine Fülle an Studienergebnissen, deren Ergebnisse nicht kongruent sind. Es bleibt weiterhin offen, ob und inwiefern Diabetes mellitus einen Risikofaktor darstellt.

\subsection{Rapidly progressive Alzheimer's disease (rpAD)}

Viele Studien der letzten Jahre beschäftigten sich mit der Differenzierung und Klassifizierung möglicher Subtypen der AD, unter ihnen auch die rpAD. Es wurde deutlich, dass sich in manchen Fällen die kognitiven Funktionen der Betroffenen rasch verschlechterten und die AD schneller als bei anderen Patienten voranschritt (Jayaratnam et al. 2008). Um diese Vermutung tiefergehend zu untersuchen, wurden die Ergebnisse des MMSE-Tests der Patienten verglichen. Soto et al. (2008b) kamen zu dem Schluss, dass der Verlust von drei oder mehr Punkten in sechs Monaten im MMSE einen gravierenderen Verlauf voraussagt, was als Gruppeneinteilung für die rpAD genutzt wurde. Bezogen auf ein ganzes Jahr Beobachtung liegt der Grenzwert zur rpAD bei sechs verlorenen Punkten im MMSE (Schmidt et al. 2011).

Ein anderer Punkt, in dem sich die rpAD von der typischen AD unterscheidet, sind verschiedene Symptome, die bei den rpAD-Patienten früher und vermehrt auftraten. Patienten mit rpAD zeigten im Laufe der Erkrankung eine Vielzahl unterschiedlicher Symptome, wobei sie häufig an Myokloni (75\%), Gangstörungen (66\%), positivem Babinski-Zeichen (66\%), Rigidität (50\%), Aphasie (66\%) und Halluzinationen (44\%) litten. Die Krankheit ist überdies in der Lage eine Creutzfeldt-Jakob-Erkrankung zu imitieren (Schmidt et al. 2010).

Die schnellen Verläufe bei den Patienten wirkten sich ebenfalls auf die Überlebenszeit der Gruppe aus. Bhargava et al. (2006) teilten in ihrer Studie AD-Patienten in rapid und langsam progressive Patienten ein, die sich signifikant in ihren Überlebenskurven unterschieden. Die mediane Überlebenszeit zwischen Beginn der Erkrankung und dem Tod betrugen 8,7 Jahre bei den rapid progressiven und 10,8 Jahre bei den langsam progressiven Patienten. In anderen Studien wurden erheblich kürzere Überlebenszeiten von 26 bis 48 Monaten dokumentiert (Schmidt et al. 2011; Josephs et al. 2009). 
Bei neurobiologischen Untersuchungen zeigte sich als weiteres Unterscheidungsmerkmal ein veränderter Aufbau der Amyloidplaques bei Patienten mit rpAD (Drummond et al. 2017). Auch Cohen et al. (2015) untersuchten die Amyloidplaques von AD-Patienten und entdeckten eine Strukturheterogenität des A $\beta 1-42$ und dazu höhere Spiegel von unterschiedlich strukturiertem A $\beta 1-42$.

In einer neueren Studie von 2018 wurden im Liquor von Patienten mit rapid progressiver Demenz die leichten Neurofilamente als Bestandteil des Axons gemessen. Diese sind für den Strukturerhalt der Axone zuständig (Petzold 2005). Bei 37 von 73 getesteten AD-Patienten zeigte sich ein atypischer oder rapid progressiver Verlauf, wobei die Patienten der rapid progressiven Gruppe im Median viel höhere Werte von leichten Neurofilamenten im Liquor aufwiesen. Die klassischen AD-Patienten hatten im Median 1933 pg/ml vorzuweisen und die rapid progressiven $2521 \mathrm{pg} / \mathrm{ml}$. Es wird vermutet, dass die leichten Neurofilamente ein direkter Marker für Neurodegeneration sind und sie vor allem in der Differenzierung zwischen klassischer und atypischer AD diagnostisch hilfreich sein könnten (Abu-Rumeileh et al. 2018).

Die Frequenz des APO-E4-Allels wurde ebenfalls in einem Gruppenvergleich untersucht. Die APO-E4-Frequenz bei den rapid progressiven Patienten war mit $38 \%$ niedrig, was sich mit den Ergebnissen einer weiteren Studie deckt (Schmidt et al. 2010; Cohen et al. 2015).

Das Spektrum der wichtigen Differentialdiagnosen verschiebt sich somit in Richtung rapid progressiver Erkrankungen mit neuropsychiatrischen Symptomen wie bei der CreutzfeldtJakob-Erkrankung oder Enzephalitiden autoimmuner Ursache (Schmidt et al. 2010; Zerr und Hermann 2018).

Die bisherigen Ergebnisse weisen auf einige Unterschiede der beiden Gruppen rapid und langsam progressiver AD in Bezug auf die kognitive Leistung, die Symptome, die Überlebenszeit, die Amyloid-Beschaffenheit und die APO-E4-Frequenz hin, sodass es sinnvoll ist weitere Untersuchungen anzuschließen. Um die Erkrankung genauer zu erforschen ist es wichtig weitere Unterscheidungsmerkmale sowohl im klinischen als auch im molekularbiologischen Bereich zu entdecken. Die bisher beobachteten Unterschiede sind in Tabelle 5 nachzuvollziehen. 
Tabelle 5: Vergleich von klassischer AD und rpAD modifiziert nach Schmidt et al. (2011)

\begin{tabular}{lll}
\hline Variable & rpAD & Klassische AD \\
\hline Überlebenszeit & Kurz (2 bis 3 Jahre) & 8 bis 10 Jahre
\end{tabular}

Alter bei Beginn der

Ungefähr mit 65 Jahren $(<65$

Erkrankung Jahren ist Early-Onset-, $>65$ Jahren ist Late-Onset-AD)

Rate des kognitiven Verfalls > 6 MMSE-Punkte/Jahr 3 bis 6 MMSE-Punkte/Jahr

Fokal neurologische Zeichen Kommen in frühen Stadien Kommen in späten Stadien vor, multipel (vor allem vor extrapyramidale Zeichen)

Liquormarker Sehr hohes gesamt Tau- und Hohe gesamt Tau- und p'Taup'Tau-Level, sehr niedriges Level, niedriges A $\beta 1-42$ LeA 1-42 Level, 14-3-3 Pro- vel, 14-3-3 Protein üblichertein manchmal vorhanden weise abwesend (exakte Werte unklar)

APO-E4-Genotyp

Relativ geringes Vorkom- Wird als Risikofaktor angesemen bei rapid progressiven hen Fällen

(Schmidt et al. 2011) Die Verwendung erfolgt mit freundlicher Genehmigung der American Medical Association. 


\subsection{Fragestellung der Doktorarbeit}

Viele weitere Risikofaktoren, von denen vermutet wird, dass sie mit der Verschlechterung in kognitiven Domänen vergesellschaftet sind, wurden in Studien untersucht. Dazu gehören Psychopharmaka-Einnahme, Antidementiva-Einnahme, weibliches Geschlecht, die Präprogressionsrate, Vitamin B12-Mangel, Schilddrüsenfunktionsstörungen, obstruktives Schlafapnoesyndrom (OSAS) und das Glaukom. Um genauere Aussagen zu treffen, müssten diese weiter untersucht werden (Schmidt et al. 2013; Knopman et al. 2001; Duthie et al. 2011).

In dieser Arbeit soll im Rahmen einer Studie mit rapid progressiven AD-Patienten untersucht werden, inwiefern sich spezifische Risikofaktoren bei bestehender AD auf die Progressionsrate auswirken. Die Fragestellungen lauten:

- Sind Unterschiede der Gedächtnisleistung zwischen den Gruppen (klassische AD und rpAD) bezüglich der Präsenz von „kardiovaskulären Risikofaktoren, Malignomen, chirurgischen Eingriffen sowie anderen Vor- und Begleiterkrankungen“ zu erkennen?

- Wirken sich die genannten Merkmale „kardiovaskuläre Risikofaktoren“, „Malignome“, „,chirurgische Eingriffe“ und „,andere Vor- und Begleiterkrankungen“ bei Bestehen einer AD auf die Progressionsrate aus?

- Sind die genannten Merkmale mit einem beschleunigten oder verlangsamten Verlauf $\operatorname{der} \mathrm{AD}$ assoziiert?

Die Risikofaktoren sollen untersucht werden, um eventuell Prävention zu leisten oder die bestehenden Therapieoptionen zu erweitern. Zudem tragen die Untersuchungen dazu bei die beiden Gruppen AD und rpAD genauer zu betrachten, um Unterschiede oder Gemeinsamkeiten herauszuarbeiten. 


\section{Material und Methoden}

\subsection{Die rpAD-Studie}

Die rpAD-Studie aus der Abteilung für Neurologie der Universitätsmedizin Göttingen (UMG) ist eine vom Bundesministerium für Bildung und Forschung (BMBF) im Rahmen des Kompetenznetzes degenerative Demenzen (KNDD) geförderte Studie, auf deren Daten sich diese Dissertation stützt. Mithilfe der Studie soll ein möglicher Subtyp der AD untersucht werden, die rapid progressive AD. Es wird untersucht, inwiefern sich Patienten mit langsamem Krankheitsverlauf von jenen mit einem rapiden Verlauf unterscheiden, um die Diagnosesicherung zu vereinfachen und biologische Marker für diesen Subtyp zu etablieren. Die verschiedenen Marker sollen außerdem dazu beitragen den Verlauf der Erkrankung einschätzen zu können. Mit den erhobenen Daten aus der neuropsychologischen Testung, der Anamnese, der Blutentnahme und der Liquorpunktion sind verschiedene bildgebende und molekularbiologische Untersuchungen möglich, die auf eventuelle Unterschiede zwischen den beiden Gruppen hinweisen könnten. Sollte sich die rpAD deutlich von der AD unterscheiden, könnte ein anderes Therapiekonzept entwickelt werden, um betroffene Patienten bestmöglich zu unterstützen.

Die Studie wurde von der Ethikkommission der UMG unter der Leitung von Prof. Dr. Brockmöller am 21.12.2009 unter der Nummer 9/6/08 genehmigt.

Seit 2009 wurden Patienten, bei denen eine AD diagnostiziert wurde oder Verdacht auf eine AD bestand, in die rpAD-Studie an der UMG aufgenommen. Die Patienten wurden entweder über die Demenz-Ambulanz der UMG eingeschlossen oder wurden durch das Nationale Referenzzentrum für Transmissible Spongiforme Enzephalopathien (NRZ-TSE) auf die Studie hingewiesen, falls sich der initiale Verdacht auf eine Creutzfeldt-Jakob Erkrankung nicht bestätigte.

Bei Erstkontakt wurde neben der Eigenanamnese auch eine Fremdanamnese erhoben, die erfassen sollte, zu welchem Zeitpunkt die Gedächtnisprobleme zuerst auftraten und ob eine Wesensveränderung deutlich wurde. Dies geschah auf der Basis des Fragebogens „Informant questionnaire on cognitive decline in the elderly"(IQCODE) (Jorm et al. 1991).

In der weiteren Anamnese wurden Gewicht und eventuelle Gewichtsveränderungen, die Bildungsjahre und die genauen Symptome erhoben. Darüber hinaus wurde eine Familienanamnese dokumentiert, die sowohl demenzielle Erkrankungen als auch andere Vorerkrankungen der Verwandten abfragte. Der Patient wurde ebenfalls nach diversen 
Risikofaktoren und zur individuellen Medikamenteneinnahme befragt. Diese Angaben konnten anhand vorhandener Arztberichte ergänzt werden.

Nach Aufklärung über die Studie und dem Einschluss gemäß definierten Kriterien erfolgte die körperliche Untersuchung, eine Blutentnahme und die neuropsychologische Testung.

Halbjährlich erfolgte wechselweise eine Nachuntersuchung oder eine telefonische Follow-UpUntersuchung.

Die Patienten schieden aus der Studie aus, wenn sie die neuropsychologischen Tests nicht mehr adäquat bewältigen konnten, was sich beispielsweise in einem MMSE von null bis zwei Punkten zeigte. Trat der Tod eines Patienten ein, konnte bei Einwilligung der Angehörigen eine Autopsie stattfinden, um die Diagnose der AD endgültig zu prüfen. Abbildung 1 zeigt einen Überblick über das Studiendesign.

\begin{tabular}{l}
\hline \multicolumn{1}{|c|}{ Krankheitsbeginn } \\
1. Kontakt -> Einwilligung, Einschluss/Ausschluss \\
Anamnese, körperliche Untersuchung \\
Blutentnahme \\
neuropsychologische Testung \\
R 6 Monate \\
2. Kontakt -> telefonisch o. UMG: Anamnese, KU, BE, Testung \\
R 6 Monate
\end{tabular}

3. Kontakt -> telefonisch o. UMG: Anamnese, KU, BE, Testung

- - Weiterführung der halbjährlichen Follow-Ups

Tod des Patienten + : neuropath. Untersuchung nach Einwilligung

Abbildung 1: Schematische Darstellung des Studienkonzepts der rpAD-Studie, UMG: Universitätsmedizin Göttingen, KU: körperliche Untersuchung, BE: Blutentnahme 


\subsubsection{Ein- und Ausschlusskriterien}

Die Ein- und Ausschlusskriterien der rpAD-Studie entsprechen den modifizierten Kriterien nach Dubois et al. (2007). Sie sind in den Tabellen 6, 7 und 8 dargestellt. Seit 2011 wurden die Diagnosen der Patienten zusätzlich anhand der aktuellen Kriterien für die klinische Diagnose der AD gestellt (McKhann et al. 2011).

Tabelle 6: Notwendige Einschlusskriterien der rpAD-Studie

Einschlusskriterien - alle müssen erfüllt sein

Vorliegen einer frühen und signifikanten Störung des episodischen Gedächtnisses, die zudem die folgenden drei Kriterien erfüllt:

Progressive Änderung der Gedächtnisfunktion seit über sechs Monaten (berichtet durch Patienten und Angehörige)

Objektive Beweise der Störung des episodischen Gedächtnisses in Tests: Erinnerungsstörung, die sich nicht durch Wiederholung bessert (Verstehen der Aufgabe und des zu erinnernden Inhaltes vorausgesetzt)

Die episodische Gedächtnisstörung kann isoliert oder in Assoziation mit anderen kognitiven Veränderungen zu Beginn oder im Verlauf der AD auftreten

(Dubois et al. 2007) Die Verwendung erfolgt mit freundlicher Genehmigung des Elsevier-Verlags.

\section{Tabelle 7: Ergänzende Einschlusskriterien der rpAD-Studie}

\section{Einschlusskriterien - mindestens eines muss erfüllt sein}

Atrophie des medialen temporalen Lappens, Volumenverlust der Hippocampi, des entorhinalen Cortex und der Amygdala im MRT: qualitative Einschätzung mittels visuellem Scoring (Vergleich zu altersnormierter Population) oder Volumetrie dieser Regionen Abnormale Liquormarker: niedrige Aß1-42 Konzentration, erhöhte gesamt Tau-Konzentration oder erhöhte pTau-Konzentration oder Kombination dieser drei Marker Spezifische Muster im PET/funktionelle Bildgebung, bilateral temporoparietal reduzierter Glukosemetabolismus

Fluktuationen der kognitiven Störungen

Gesicherte AD, autosomal-dominante Mutation in der näheren Familie

(Dubois et al. 2007) Die Verwendung erfolgt mit freundlicher Genehmigung des Elsevier-Verlags. 


\section{Tabelle 8: Ausschlusskriterien der rpAD-Studie}

\section{Ausschlusskriterien - alle müssen erfüllt sein}

Kein apoplektiformer Beginn der Demenz

Kein frühes Auftreten von Gangstörung, Anfällen, Verhaltensänderung*

Keine frühen fokalneurologischen Defizite wie Hemiparese, Sensibilitätsstörungen, Gesichtsfelddefekte*

Keine frühen extrapyramidalen Zeichen*

Keine non-AD-Demenz (Lewy-Körperchen-Demenz, frontotemporale Demenz, Creutzfeldt-Jakob-Erkrankung, Strahlendemenz, paraneoplastische Demenz)

Keine ausgeprägte Depression (Pseudodemenz)

Keine ausgeprägte Herz-Kreislauf-Krankheit

Keine toxisch, metabolisch oder durch Bestrahlung bedingte Abnormalitäten, die weiterer Abklärung bedürfen

Keine MRT-Fluid-Attenuated-Inversion-Recovery (FLAIR)- oder T2-Signal-Abnormitäten im medialen temporalen Lappen, die auf infektiöse oder vaskuläre Insulte hinweisen

(Dubois et al. 2007) Die Verwendung erfolgt mit freundlicher Genehmigung des Elsevier-Verlags.

*Da nicht sicher ist, ob diese Kriterien auf die rapid progressive AD-Form anwendbar sind, ist bei diesen Punkten abzuwägen, ob sie einen Ausschlussgrund darstellen. Eventuell sind diese Symptome auch Symptome einer rpAD.

\subsubsection{Patientenkollektiv}

In die Studie wurden seit 2009351 Patienten aufgenommen (Stand 14.05.2018). Im Rahmen der Dissertation wurden die Daten von 90 Probanden ausgewertet, wobei die Anzahl der Patienten in der Auswertung der einzelnen statistischen Tests leicht variieren kann. Die Auswahl der Patienten erfolgte anhand der Anzahl der Follow-Up-Untersuchungen, wobei eine Mindestanzahl von zwei bis maximal sechs gefordert war. In Abbildung 2 ist die Selektion der rpAD-Patienten für die statistische Berechnung mittels PRISMA-Flussdiagramm dargestellt (Moher et al. 2009). 


\section{Selektion der rpAD-Patienten für die statistische Berechnung}

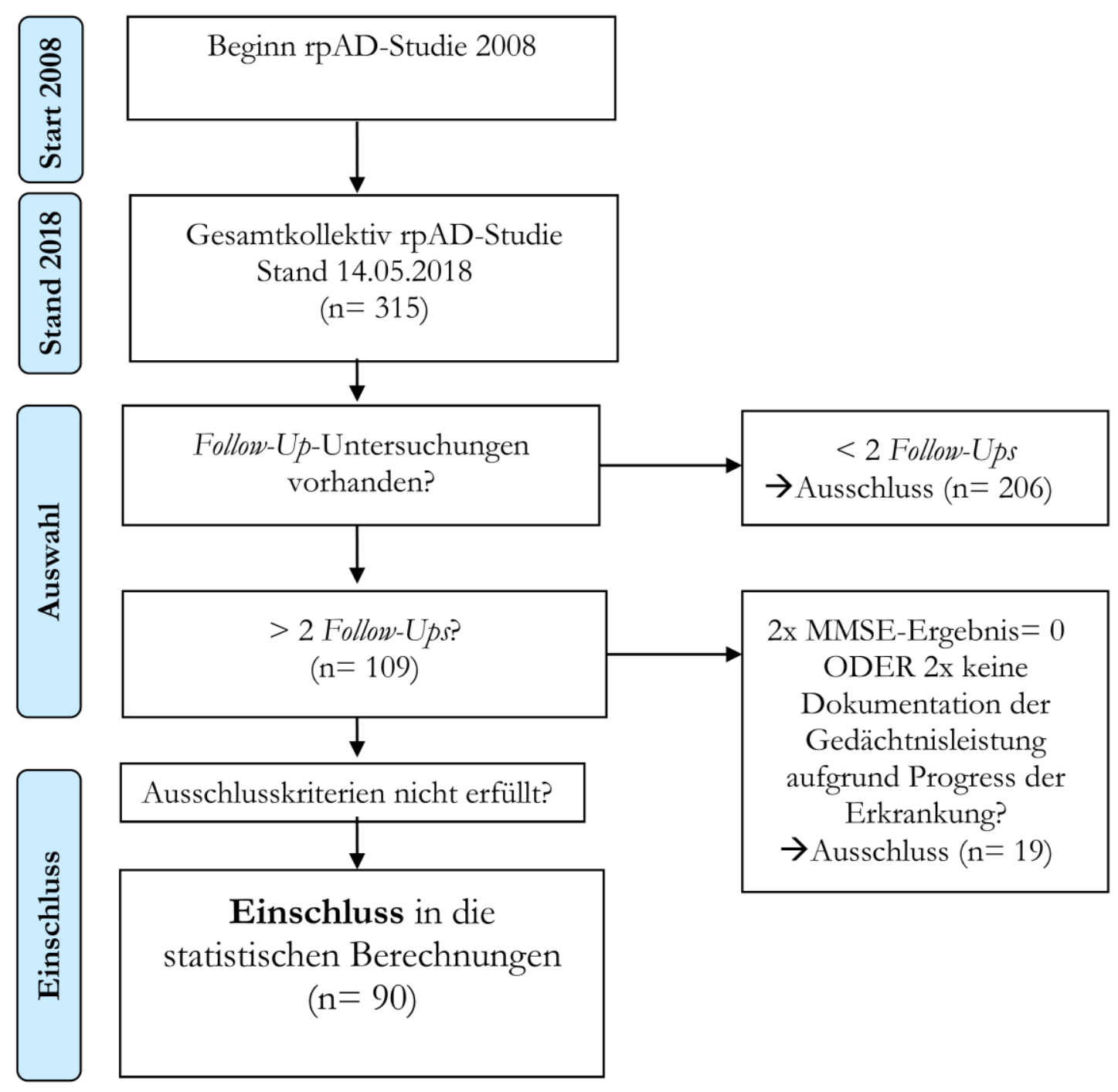

\section{Abbildung 2: PRISMA-Flussdiagramm zur Selektion der rpAD-Patienten}

(Moher et al. 2009) Die Verwendung erfolgt mit freundlicher Genehmigung von Dr. David Moher.

\subsubsection{Neuropsychologische Testung}

Die neuropsychologische Testung wurde durchgeführt, um die verschiedenen kognitiven Domänen der Patienten zu testen und stellte einen fundamentalen Bestandteil der Diagnostik dar. Die Testung dauerte je nach Patienten etwa 90 Minuten und wurde in den Räumen der UMG in ruhiger Atmosphäre durchgeführt, wobei sichergestellt wurde, dass die Patienten zur aktiven Mitarbeit bereit waren und die Aufgabenstellung verstanden.

$\mathrm{Zu}$ den Tests gehörten der „Development and validation of a test for early diagnosis of dementia with differentiation from depression” (TFDD) modifiziert nach Ihl et al. (2000), die „Global deterioration scale” (GDE) nach Reisberg et al. (1982), die „Instrumental activities of daily living” (iADL) nach Lawton und Brody (1969), die „Basic activities of daily living”(bADL) nach Katz (1983), die „Unified 
Parkinson's disease rating scale" (UPDRS) (Movement Disorder Society Task Force on Rating Scales for Parkinson's Disease 2003) und die CERAD-Plus-Testbatterie nach Morris et al. (1989).

Die CERAD-Batterie enthält die Tests „Verbale Flüssigkeit“ (Tiere), „Boston-Naming-Test“ nach Kaplan et al. (1983), den MMSE nach Folstein et al. (1975), die „Wortliste Lernen, Abrufen, Wiedererkennen“ und „Figuren Abzeichnen, Abrufen“.

Die erweiternden Tests, die zur CERAD plus Batterie gehören, sind der „Trail-Making-Test A und B“ nach Oswald (1979), die „Phonematische Flüssigkeit“ (S-Wörter) und der „Uhrentest“ nach Shulman (1993). Nach Berechnung der Testergebnisse wurden diese archiviert und halbjährlich ergänzt. So konnten durch direkten Vergleich mit den Vorergebnissen Verschlechterungen oder Verbesserungen in bestimmten kognitiven Domänen objektiviert werden.

\subsubsection{Liquoruntersuchung}

Nach Einschluss in die Studie wurden im Liquor das Gesamtprotein, der Serum/LiquorAlbumin-Quotient, $A \beta 1-40$ und $A \beta 1-42$, der $A \beta$-Quotient (A $\beta 1-42 / A \beta 1-40)$, die Zellzahl pro $\mathrm{mm}^{3}$, das gesamt Tau und das p'Tau bestimmt.

Tau, pTau und Aß1-42 wurden mittels eines Standard-Enzyme-Linked-Immunosorbent-Assay (ELISA)-Kits der Firma Innogenetics gemessen (Innogenetics N.V., Ghent, Belgium; Tau: Innotest hTAU ELISA, pTau: Innotest pTau (p181), A $\beta 1-42$ : Innotest $\beta$-Amyloid (1-42)). Mittels ELISA wurde ebenfalls das 14-3-3-Protein im Liquor bestimmt. Zur Fehlervermeidung wurde jede Probe zwei Mal überprüft.

Die Zellzahl wurde mittels Fuchs-Rosenthal-Zählkammer bestimmt. Das Gesamtprotein und das Albumin wurden in der Nephelometrie nach Reiber gemessen (Reiber und Peter 2001).

\subsubsection{Genetische Untersuchungen und Blutuntersuchung}

Die Mutationen, die zur familiären Early-Onset-AD führen (Presenilin-1-, Presenilin-2- und APPMutation), wurden analysiert, wenn sich Hinweise auf eine familiäre AD durch einen frühen Beginn der Symptome abzeichneten. Es wurde ebenfalls die Codon-129-Bestimmung und Prp (platelet rich plasma) molekulargenetische Diagnostik mittels Sanger Sequenzierung durchgeführt. 
Bei der Einschlussuntersuchung fand ebenfalls eine Blutentnahme statt, die bei den Follow-UpUntersuchungen wiederholt wurde. Lehnte ein Patient die Blutentnahme ab, war trotzdem ein Einschluss in die Studie möglich.

Es wurden verschiedene Proberöhrchen für die stationären Labordaten und die genetischen Untersuchungen entnommen. Dabei wurde den Patienten Blut in Monovetten mit 1x9 ml Serum, 2x3 ml Citrat, 2x9 ml und 2x2,7 ml Ethylendiaminotetraacetat-Röhrchen (EDTA) entnommen.

Die Standarduntersuchungen umfassten die Gerinnungswerte, das Blutbild, die Elektrolyte, die Blutfette, Leber- und Nierenwerte, Entzündungswerte, Schilddrüsenwerte, Vitamin B12, Folsäure und den Homocysteinspiegel.

Das APO-E-Allel wurde mittels der Desoxyribonukleinsäure(DNA)-Strip-Technologie der Firma Hain Lifescience bestimmt. Die DNA wurde aus Vollblut isoliert, amplifiziert und hybridisiert. Auf Teststreifen mit komplementären Sonden band die DNA nach Denaturierung. Die Reaktion wurde mit verschiedenen enzymatischen Farbreaktionen sichtbar gemacht, sodass am Ende ein Allel-spezifisches Bandenmuster ablesbar war.

\subsubsection{Bildgebung}

Um vaskuläre Läsionen und Atrophiezeichen zu detektieren, wurden die im Rahmen der Diagnostik durchgeführten MRT-Untersuchungen ausgewertet. Die Aufnahmen wurden auf verschiedenen Geräten (in der Regel 1,5 Tesla) angefertigt.

Die vaskulären Läsionen (white matter hyperintensities - WMH) wurden anhand der T2- oder der FLAIR-Wichtung nach dem Scheltensscore und der ARWMC-Skala (age related white matter changes) eingeteilt und umfassen periventrikuläre Hyperintensitäten, subkortikale Hyperintensitäten der weißen Substanz, Hyperintensitäten der Basalganglien und infratentorielle Foci mit Hyperdensitäten (Wahlund et al. 2001; Scheltens et al. 1993).

Die Beurteilung und Lokalisation von Hirnatrophien erfolgte anhand der T1-Gewichtung. Es wurde beurteilt, ob sie global, frontal, temporal, parietal, okzipital oder hippocampal betont waren. Abbildung 3 zeigt zwei MRT-Aufnahmen mit typischen AD-Läsionen. 

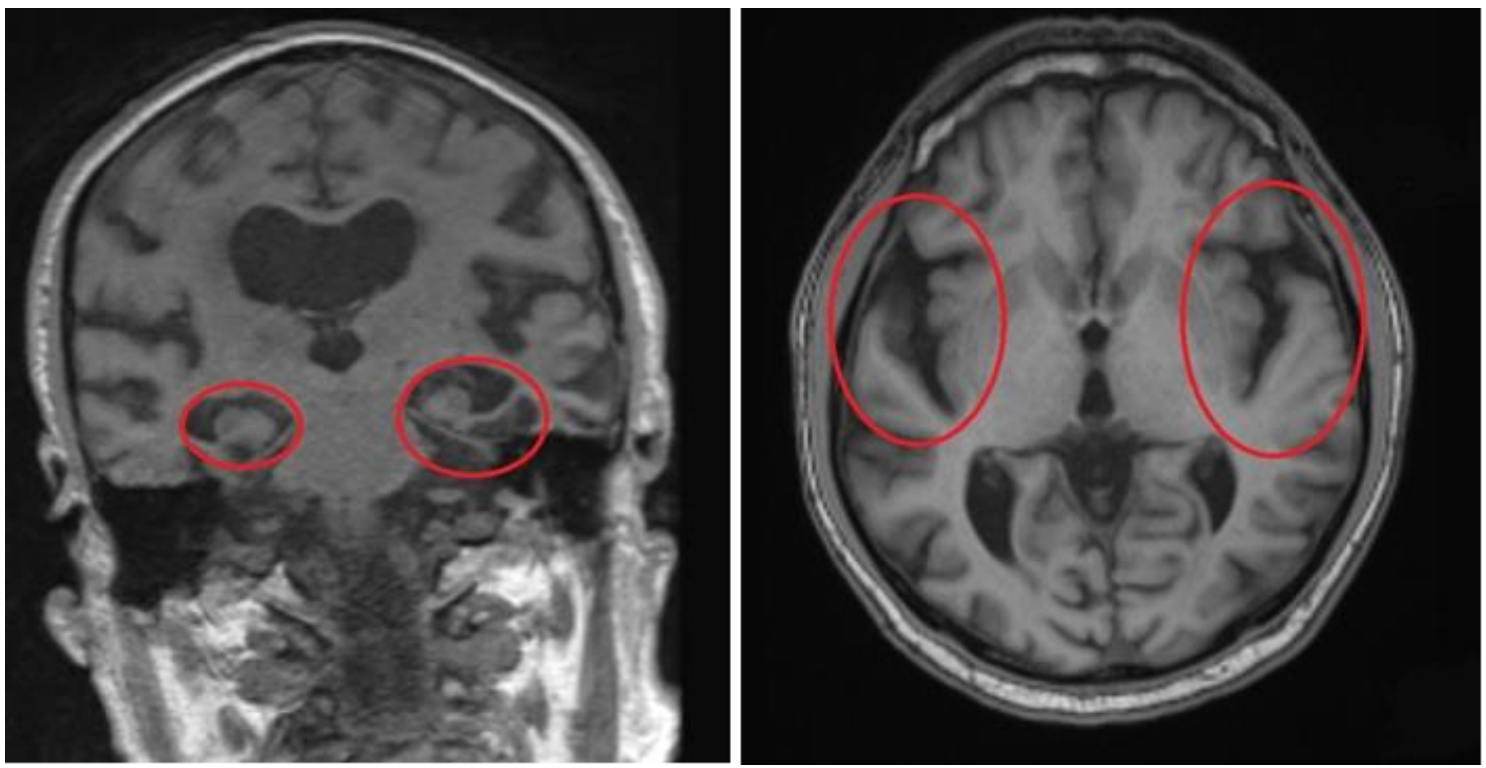

Abbildung 3: Zwei MRT-Aufnahmen mit typischen AD-Läsionen links: hippocampal betonte Atrophie beidseits; rechts: temporal betonte Atrophie beidseits mit stärkerem Schwund auf der linken Seite, Quelle: UMG, Neuroradiologie, Patienten der Studie rpAD

\subsubsection{Schweregradeinteilung}

Nachdem die Patienten ein Jahr in die Studie eingeschlossen waren und dementsprechend mindestens zwei Follow-Up Untersuchungen vorlagen, war es möglich eine Aussage über die Verlaufsgeschwindigkeit ihrer Erkrankung zu treffen. Die Patienten wurden anhand des jährlichen Abfalls des MMSE und des Erstmanifestationsalters in verschiedene Gruppen eingeteilt. Dabei wurde festgelegt, diejenigen Patienten mit einem MMSE-Verlust von sechs oder mehr Punkten pro Jahr oder über drei Punkten pro halbem Jahr in die „rapid progressive“ Gruppe einzuteilen (Soto et al. 2008b; Schmidt et al. 2011). In die Kategorie „langsamer Verlauf“"gehören Patienten mit einem MMSE-Abfall von weniger als sechs Punkten pro Jahr. Darüber hinaus wurde im Verlauf die klinische Diagnose der AD wiederholt überprüft. Die genaue Einteilung ist Tabelle 9 nachzuvollziehen. 
Tabelle 9: Ranking der Studienpatienten aus dem Studienbericht der rpAD-Studie

\begin{tabular}{|c|c|}
\hline Ranking & Bedeutung \\
\hline A & $\begin{array}{l}\text { AD (positive Einschlusskriterien) UND schneller Verlauf („,rapidly } \\
\text { progressive“) }^{6}\end{array}$ \\
\hline A1 & UND early onset $<65$ Jahre alt \\
\hline $\mathrm{A} 2$ & UND late onset $>65$ Jahre alt \\
\hline B & $\begin{array}{l}\text { AD (positive Einschlusskriterien) UND langsamer Verlauf („,non } \\
\text { rapidly progressive }{ }^{6} \text { ) }\end{array}$ \\
\hline B1 & UND early onset $<65$ Jahre alt \\
\hline B2 & UND late onset $>65$ Jahre alt \\
\hline $\mathrm{C}$ & $\begin{array}{l}\text { AD (positive Einschlusskriterien) ABER Verlauf noch nicht } \\
\text { einschätzbar (v.a. bei Neueinschlüssen) }\end{array}$ \\
\hline $\mathrm{C} 1$ & UND early onset $<65$ Jahre alt \\
\hline $\mathrm{C} 2$ & UND late onset $>65$ Jahre alt \\
\hline $\mathrm{D}$ & $\begin{array}{l}\text { AD fraglich trotz positiver Einschlusskriterien DESHALB } \\
\text { Differentialdiagnosen beachten (z. B. Pseudodemenz, FTD) }\end{array}$ \\
\hline D1 & UND early onset $<65$ Jahre alt \\
\hline $\mathrm{D} 2$ & UND late onset $>65$ Jahre alt \\
\hline $\mathrm{E}$ & Keine AD (negative Einschlusskriterien) = „Kontrollgruppe“ \\
\hline E1 & UND early onset $<65$ Jahre alt \\
\hline E2 & UND late onset $>65$ Jahre alt \\
\hline $\mathrm{X}$ & Keine Daten vorhanden ODER Patient ausgeschlossen! \\
\hline$+\mathrm{p}$ & AD neurohistopathologisch nachgewiesen \\
\hline$\dagger$ & Patient bereits verstorben \\
\hline
\end{tabular}

Die Verwendung dieser modifizierten Tabelle erfolgt mit freundlicher Genehmigung von Stefan Göbel (ärztlicher Mitarbeiter der rpAD-Studie). 
Bei dem in dieser Arbeit untersuchten Patientenkollektiv handelte es sich vor allem um Patienten der Gruppen „A“ und „B“, da bei diesen Patienten aufgrund mehrerer Follow-UpUntersuchungen bereits ein Verlauf der AD absehbar war. Die Unterteilung in early onset (Beginn der Demenz vor dem 65. Lebensjahr) und late onset (Beginn der Demenz nach dem 65. Lebensjahr) wurde in der statistischen Auswertung vernachlässigt, weil die genaue Abgrenzung nach dem Alter eine Störvariable im Sinne eines Selektionsbias in den statistischen Berechnungen dargestellt hätte.

\subsection{Erfassung der Risikofaktoren}

Bei den erfassten Risikofaktoren wurde überprüft, ob und inwiefern sie einen Einfluss auf den Verlauf der AD ausüben. Sie wurden retrospektiv aus den asservierten Daten der Patienten erhoben. Dabei konnten die Vorerkrankungen aus den Einschlussdokumenten der Studie, Befunden und Arztbriefen, der Datenbank der UMG (ixserv) und aus telefonischen Interviews mit behandelnden Haus- und Fachärzten erhoben werden. Die Daten wurden digital und anonymisiert archiviert.

Zunächst erfolgte die Erfassung von Geburtsdatum, Alter, Geschlecht, Bildungsgrad und APO-E-Status. Die weiteren Risikofaktoren lassen sich in die Gruppen „kardiovaskuläre Risikofaktoren“, „,chirurgische Eingriffe“, „Malignome“ und „,andere Vor- und Begleiterkrankungen“ einteilen. In Tabelle 10 sind die einzelnen Risikofaktoren in den Gruppen „kardiovaskuläre Risikofaktoren“ und „Malignome“ nachzuvollziehen. 


\subsubsection{Kardiovaskuläre Risikofaktoren und Malignome}

Tabelle 10: Untersuchte Faktoren in den Gruppen „kardiovaskuläre Risikofaktoren“ und „Malignome“

\begin{tabular}{ll}
\hline Kardiovaskuläre Risikofaktoren & Malignome \\
\hline Diabetes mellitus & Zentrales Nervensystem \\
Hypertonus & Gastrointestinal \\
Rauchen & Niere \\
Hyperlipoproteinämie & Mamma \\
Herzrhytmusstörungen (HRS) & Blut \\
Schlaganfall & Urologisch \\
Myokardinfarkt & Knochen \\
pAVK & Lunge \\
Thrombose & \\
Lungenembolie & \\
Herzinsuffizienz & \\
Koronare Herzkrankheit (KHK) & \\
\hline
\end{tabular}

In der Kategorie „kardiovaskuläre Risikofaktoren“ konnte in Ermangelung an Detailangaben nur erhoben werden, ob die Erkrankung oder der Risikofaktor vorhanden war oder nicht. In der Anamnese wurde lediglich das Vorliegen der Erkrankung abgefragt, wobei keine vertiefenden Fragen bezüglich der einzelnen Erkrankungen gestellt wurden. Verlässliche Daten zu Symptombeginn oder Therapien konnten nur vereinzelt erhoben werden, sodass diese Informationen nicht in die statistische Berechnung miteinbezogen wurden.

Die verschiedenen Untergruppen in der Kategorie Malignome konnten nur grob erfasst werden. Die genaue Histologie, die Eindringtiefe oder die Differenzierung des Tumors waren oft in den Befunden nicht nachzuvollziehen, ebenso wenig wie stattgefundene Therapien. Zuerst wurde der MMSE mit dem Vorhandensein einer Krebserkrankung in Zusammenhang gebracht und im Folgenden die einzelnen malignen Erkrankungen.

In Tabelle 11 sind die einzelnen Risikofaktoren in den Gruppen „,chirurgische Eingriffe“ und „andere Vor- und Begleiterkrankungen“ dargestellt. 


\subsubsection{Chirurgische Eingriffe und andere Vor- und Begleiterkrankungen}

Tabelle 11: Untersuchte Faktoren in den Gruppen „chirurgische Eingriffe“ und „andere Vor- und Begleiterkrankungen"

\begin{tabular}{ll}
\hline Chirurgische Eingriffe & Andere Vor- und Begleiterkrankungen \\
\hline Gehirn & Epilepsie \\
Rückenmark & Depression \\
Nerven & Hypakusis \\
Wirbelsäule & Schlafapnoe \\
Auge & Arthrose \\
Hals-Nasen-Ohren (HNO) & Autoimmunerkrankung \\
Tonsillen & Trauma \\
Appendix & Schilddrüse \\
Lunge & Chronische Infektionen \\
Herz & Glaukom \\
Gallenblase & Psychische Vorerkrankung \\
Gastrointestinal & Asthma \\
Leistenhernie & \\
Urologisch & \\
Orthopädisch & \\
\hline
\end{tabular}

Bei der statistischen Auswertung wurde zunächst überprüft, ob ein genereller Zusammenhang zwischen einem Eingriff und dem Abfall im MMSE bestand. Anschließend wurden die einzelnen Eingriffe mit dem Verlauf der AD verglichen. Dabei sollte überprüft werden, ob bestimmte Operationen das Risiko für einen rapiden Verlauf erhöhen.

\subsubsection{Subgruppen der Operationen}

Die Eingriffe in den Fachbereichen Orthopädie und Kardiologie konnten des Weiteren in einzelne zu der Hauptgruppe gehöriger Eingriffe unterteilt werden. Die Herzoperationen umfassten Schrittmacherimplantationen, Katheteruntersuchungen und Stentimplantationen und die orthopädischen Operationen umfassten Knie-Totalendoprothesen (TEP), Hüft-TEPs und Weitere. Dabei wurde bei der Akquirierung der Daten per Anamnese erhoben, welche Operationen durchgeführt wurden, sodass keine genaueren Daten zum Zeitpunkt oder zur Narkose vorlagen. Es wurde ebenfalls nicht unterschieden, ob der Eingriff vor oder nach Beginn der AD stattfand. 


\subsubsection{Subgruppen der ,anderen Vor- und Begleiterkrankungen“}

Die Kategorie „andere Vor- und Begleiterkrankungen“ umfasst Erkrankungen oder Normabweichungen, die bei Sichtung der Daten auffällig wurden. Die Einbeziehung in die statistischen Berechnungen erfolgte nur bei mindestens zwei Betroffenen in der Kohorte.

In den Kategorien „Trauma, Schilddrüse, chronische Infektionen und andere neurologische Erkrankungen“" gab es weitere Subgruppen, die ebenfalls eingehender untersucht wurden.

In der Kategorie „Trauma“ wurde in Traumata des Kopf- oder Halsbereichs und Traumata jeder anderen Körperregion unterteilt. Des Weiteren gibt es in der Kategorie „Schilddrüse“ die Unterteilung in Hypothyreose, Hyperthyreose, Morbus Hashimoto und weitere Schilddrüsenerkrankungen, die Morbus Basedow oder Hypoparathyreodismus enthalten. Die „chronischen Infektionen“ wurden in Hepatitis B und/oder C und weitere chronische Infektionen wie Borreliose und Tuberkulose unterteilt. Bei ,andere neurologische Erkrankungen“ gab es die Unterteilung in vaskuläre Demenz oder Demenz vom Parkinson-Typ (PD).

\subsection{Statistische Auswertung}

Die statistische Auswertung der Daten erfolgte in enger Zusammenarbeit mit dem Institut für Medizinische Statistik an der UMG unter der Leitung von Prof. Dr. Tim Friede.

Die Daten wurden mithilfe des Programms R (Version 1.1.383) ausgewertet. Grafiken und Tabellen wurden mit IBM SPSS (Statistical Package for the Social Sciences, Version 25) erstellt. Herr Heiko Rembowski leistete bei den Berechnungen als studentische Hilfskraft Unterstützung bei Problemen.

Es galt zwei Zusammenhänge zu betrachten. Mittels t-Test wurde auf Unterschiede der Mittelwerte von Steigungen (abhängige Variable) getestet, wobei die unabhängige Variable die Erkrankungen als binäre Variable darstellte $(0=$ erkrankt, $1=$ nicht erkrankt). Die Steigungen wurden aus den MMSE-Ergebnissen der Patienten berechnet und stellen deren Gedächtnisabfall im Verlauf der Zeit dar. Es sollte der Einfluss der einzelnen Erkrankungen auf den Gedächtnisabfall beurteilt werden.

Die Anwendung des Chi-Quadrat-Tests und des exakten Tests nach Fisher erfolgte zur Beurteilung einer Auswirkung der Risikofaktoren auf die Verlaufsklasse (AD= langsamer Verlauf, $\mathrm{rpAD}=$ rapider Verlauf), wobei die Steigungen für die Berechnung in der Verlaufsklasse dichotomisiert wurden $(0=\mathrm{AD}, 1=\mathrm{rpAD})$. 
Nach Variablenselektion durch die genannten Tests wurden Variablen mit signifikanten p-Werten $(\mathrm{p}=<0,05)$ in Regressionsmodelle aufgenommen.

Die einzelnen Tests und statistischen Mittel werden im Folgenden näher beschrieben.

\subsubsection{Steigungen}

Mittels der MMSE-Ergebnisse in den halbjährlichen Follow-Up-Untersuchungen wurde eine Steigung für jeden Patienten erstellt.

Der Verlauf der Erkrankung wurde mittels linearer Regression modelliert, wobei der Abfall der Geraden (Steigung bzw. slope) als Maß für den Gedächtnisabfall steht. Als unabhängige Variable dienten die Zeitpunkte der Follow-Up-Untersuchungen in Monaten und als abhängige Variable die MMSE-Testwerte.

In Abbildung 4 ist eine solche Steigung, erstellt mit dem Programm R, dargestellt.

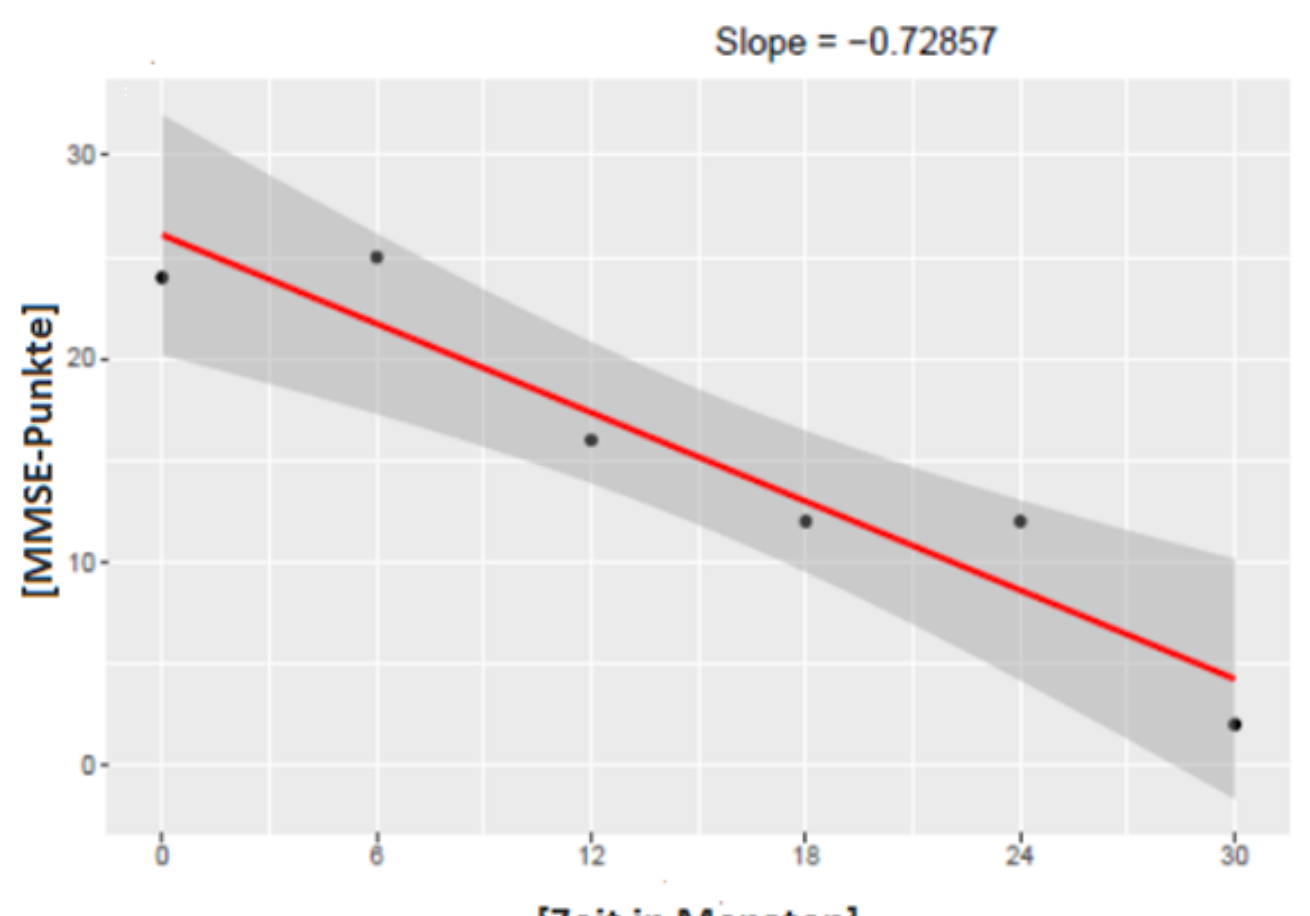

[Zeit in Monaten]

\section{Abbildung 4: Beispielhafte Darstellung zur Berechnung einer Steigung}

\subsubsection{Shapiro-Wilk-Test}

Der Shapiro-Wilk-Test testet alle klinischen Parameter auf Normalverteilung, wobei die Nullhypothese annimmt, dass eine Normalverteilung vorliegt. Wenn der klinische Parameter nicht normal verteilt ist, kann kein parametrischer Test in der weiteren Berechnung angewandt werden. 
Die Ergebnisse des Shapiro-Wilk-Tests sind nicht aufgeführt. Wurde ein parametrischer Test durchgeführt, ist anzunehmen, dass der Test eine Normalverteilung ergeben hat.

\subsubsection{Q-Q-Plot}

Der Q-Q-Plot ist eine visuelle Prüfung auf Normalverteilung. Es werden die theoretischen und empirischen Quantile verglichen, wobei eine Gerade die ideale Normalverteilung darstellt. Weichen eine Vielzahl der Werte systematisch von der Geraden ab, liegt keine Normalverteilung vor.

\subsubsection{Welch-Two-Sample-t-Test (Welch-t-Test)}

Der Welch-Two-Sample-t-Test vergleicht die Mittelwerte der Steigungen in Abhängigkeit von den einzelnen Risikofaktoren. Es handelt sich um einen parametrischen Test, der als Nullhypothese annimmt, dass die zwei Stichproben aus derselben Grundgesamtheit stammen.

Die Steigungen dienten als abhängige Variable und die Risikofaktoren als unabhängige, binäre Variable ( $0=$ Risikofaktor nicht vorhanden, $1=$ Risikofaktor vorhanden). Bei Nutzung dieses Tests wird eine Normalverteilung der Werte vorausgesetzt. Als Unterschied zu einem gewöhnlichen t-Test findet der Test auch bei Daten Anwendung, in denen sich wie in dieser Stichprobe die Gruppengröße und die Varianzen unterscheiden. Nach Durchführung des Welch-Two-Samplet-t-Tests kann anhand der p-Werte eine Aussage getroffen werden, ob sich einzelne Risikofaktoren auf die Steigungen der Patienten auswirken.

\subsubsection{Kruskal-Wallis-Test}

Der Kruskal-Wallis-Test ist ein nicht parametrischer Test, der dem Gruppenvergleich von zwei oder mehr Gruppen dient, was für den Vergleich der Variablen mit mehreren Unterkategorien von Bedeutung war. Die Nullhypothese nimmt an, dass die Gruppen aus derselben Grundgesamtheit stammen und sich die Mediane nicht unterscheiden. Es können nicht normalverteilte Daten mit unterschiedlichen Gruppengrößen und Varianzen genutzt werden. Ergibt der Kruskal-Wallis-Test einen signifikanten p-Wert, unterscheiden sich die Gruppen voneinander, wobei nicht zu erkennen ist, in welcher Gruppe der Median von den Medianen der anderen Gruppen statistisch signifikant abweicht. 


\subsubsection{Chi-Quadrat-Test, exakter Test nach Fisher und Odds Ratios}

Im Folgenden wurden die Risikofaktoren und die Verlaufsklasse (AD, rpAD) auf stochastische Unabhängigkeit mittels Chi-Quadrat-Tests getestet. Die Risikofaktoren dienten als binäre Variable $(0=$ Risikofaktor nicht vorhanden, $1=$ Risikofaktor vorhanden), die Verlaufsklasse $(0=\mathrm{AD}, 1=\mathrm{rpAD})$ wurde durch die dichotomen Steigungen dargestellt. Dabei nimmt die Nullhypothese an, dass die Gruppen voneinander statistisch unabhängig sind. Da einige Gruppen weniger als fünf Patienten mit einer bestimmten Krankheit oder einem Risikofaktor enthielten, bot sich der exakte Test nach Fisher an, mit dem kleinere Gruppen verglichen werden konnten.

Mithilfe dieser Tests sollte eruiert werden, inwiefern bestimmte Risikofaktoren und Erkrankungen die Einteilung in die Gruppen AD und rpAD beeinflussen.

Die Odds Ratio oder das Chancenverhältnis kann dazu verwendet werden, Aussagen zu der Stärke des Zusammenhangs zwischen $\mathrm{AD}$ und Risikofaktor zu treffen. Es kann beurteilt werden, wie wahrscheinlich es ist in die Gruppe rpAD eingeordnet zu werden, wenn der Patient am getesteten Risikofaktor erkrankt ist, verglichen mit den Patienten ohne Risikofaktor.

\subsubsection{Regressionen}

Durch signifikante p-Werte in den vorangegangenen Tests wurden einige Risikofaktoren zusammen mit möglichen Störvariablen wie Alter, Geschlecht und Bildungsgrad in Regressionsmodelle aufgenommen, um die Zusammenhänge in Bezug auf die AD detaillierter $\mathrm{zu}$ untersuchen. Es wurden lineare und logistische Regressionsmodelle angewandt. In der linearen Regression diente die Steigung als abhängige Variable und die Variablen Alter, Geschlecht, Bildungsgrad, MMSE-Baseline-Wert, Achsenabschnitt und der zu untersuchende Risikofaktor als unabhängige Variable, um den Einfluss des Risikofaktors auf die Steigung zu untersuchen. Bei der logistischen Regression dienten ebenfalls die zuvor genannten Variablen als unabhängige Variable, jedoch sollte der Einfluss des Risikofaktors auf die dichotomisierte Verlaufsklasse $(0=\mathrm{AD}, 1=\mathrm{rpAD})$ beobachtet werden, weshalb eine logistische Regression verwendet werden musste.

\subsubsection{APO-E-Auswertung}

Die APO-E-Auswertung erfolgte deskriptiv. Es wurde untersucht, wie oft die sechs AllelKombinationen in der Gesamtkohorte vorkamen. Im Anschluss wurde ausgewertet, ob sich die prozentuale Verteilung zwischen den Patienten mit rapidem oder langsamem Verlauf unterscheidet. 


\section{Ergebnisse}

\subsection{Deskriptive Statistik}

Es konnten die Daten von 90 AD-Patienten statistisch untersucht werden, da diese Patienten mindestens zwei Follow-Up-Untersuchungen aufwiesen. In den Gruppen Diabetes mellitus, Hypertonus, Schlaganfall und Autoimmunerkrankung konnten nur die Daten von 89 Patienten verwendet werden, da bei jeweils einem Patienten keine genauen Angaben über die Erkrankung oder den Risikofaktor zu eruieren waren.

Im Folgenden wird in Tabelle 12 die Geschlechterverteilung der Patientenkohorte dargestellt. Die AD-Patienten waren zu 42,5\% männlich und zu 57,5\% weiblich. In der rpAD-Kohorte waren $40 \%$ der Patienten männlich und $60 \%$ weiblich.

Tabelle 12: Geschlechterverteilung der AD- und rpAD-Gruppe

\begin{tabular}{llll}
\hline Verlauf & Geschlecht & Anzahl Patienten & $\begin{array}{l}\text { Anzahl } \\
\text { Patienten (\%) }\end{array}$ \\
\hline AD & $\mathrm{m}$ & 17 & 42,5 \\
& $\mathrm{w}$ & 23 & 57,5 \\
\hline gesamt & - & 40 & 100 \\
\hline rpAD & $\mathrm{m}$ & 20 & 40,0 \\
\hline gesamt & w & 30 & 60,0 \\
\hline
\end{tabular}

Weiterhin wurden die Parameter Alter, Bildungsgrad und MMSE-Baseline-Wert untersucht, da vermutet wird, dass sie einen modellierenden Einfluss auf die Steigungen haben könnten.

\subsubsection{Alter bei Onset der AD und bei Erstuntersuchung}

Um die Altersverteilung besser zu veranschaulichen, wurden die Daten der Variable Alter gruppiert dargestellt (siehe Tabelle 13, 14).

Keine AD-Patienten waren zu Beginn der Erkrankung unter 50 Jahre alt, während dies auf $8 \%$ der rpAD-Patienten zutraf. Der größte Teil der AD-Patienten war bei Onset 66 bis 70 Jahre $(20 \%)$ und zwischen 71 und 75 Jahren alt (27,5\%), während es in der rpAD-Gruppe Patienten im Alter von 50 bis 55 Jahren $(24 \%)$ und 66 bis 70 Jahren waren (22\%). Die rpAD- 
Patienten waren zu Beginn der Erkrankung im Schnitt jünger. Der älteste Patient befand sich in der AD-Gruppe und war älter als 86 Jahre.

Tabelle 13: Alter der AD- und rpAD-Patienten bei Onset der AD

\begin{tabular}{lllll}
\hline Jahre & Anzahl AD & Anzahl rpAD & AD (\%) & rpAD (\%) \\
\hline $45-49$ & - & 4 & - & 8 \\
$50-55$ & 4 & 12 & 10 & 24 \\
$56-60$ & 4 & 8 & 10 & 16 \\
$61-65$ & 5 & 6 & 12,5 & 12 \\
$66-70$ & 8 & 11 & 20 & 22 \\
$71-75$ & 11 & 5 & 27,5 & 10 \\
$76-80$ & 2 & 3 & 5 & 6 \\
$81-85$ & 5 & 1 & 12,5 & 2 \\
$86-90$ & 1 & - & 2,5 & - \\
\hline gesamt & 40 & 50 & 100 & 100 \\
\hline
\end{tabular}

Als die Erstvorstellung im Rahmen der rpAD-Studie erfolgte, war bei den AD-Patienten keiner jünger als 50 Jahre. Bei den rpAD-Patienten war ein Patient zu finden, der mit unter 50 Jahren in die Studie eingeschlossen wurde. Der Großteil der AD-Patienten war zwischen 61 und 65 Jahren (17,5\%) und 76 bis 80 Jahren (17,5\%) alt. Bei den rpAD-Patienten nahmen den größten Anteil die Patienten im Alter von 56 bis 60 Jahren (22\%) und zwischen 66 und 70 Jahren (20\%) ein. Die ältesten Patienten waren wieder in der AD-Gruppe im Alter von 86 bis 90 Jahren zu finden $(7,5 \%)$. 
Tabelle 14: Alter der AD- und rpAD-Patienten bei Erstuntersuchung

\begin{tabular}{lllll}
\hline Jahre & Anzahl AD & Anzahl rpAD & AD (\%) & rpAD (\%) \\
\hline $45-49$ & - & 1 & 0 & 2 \\
$50-55$ & 2 & 7 & 5 & 14 \\
$56-60$ & 6 & 11 & 15 & 22 \\
$61-65$ & 7 & 7 & 17,5 & 14 \\
$66-70$ & 2 & 10 & 5 & 20 \\
$71-75$ & 10 & 8 & 25 & 16 \\
$76-80$ & 7 & 3 & 17,5 & 6 \\
$81-85$ & 3 & 3 & 7,5 & 6 \\
$86-90$ & 3 & - & 7,5 & - \\
\hline gesamt & 40 & 50 & 100 & 100 \\
\hline
\end{tabular}

\subsubsection{Bildungsgrad}

Die in der Anamnese erhobenen Bildungsjahre befanden sich in einer Spanne von 7 bis 20 Jahren. Dabei wurden Schuljahre und sämtliche Ausbildungs- oder Studienjahre zusammengerechnet.

Die Bildungsjahre der AD-Patienten erstreckten sich zwischen 7 und 20 Jahren. Der größte Anteil der Patienten wurde zehn bis zwölf Jahre lang ausgebildet (32,5 \%).

Die Bildungsjahre der rpAD-Patienten entsprachen der Spanne der AD-Kohorte von ebenfalls 7 bis 20 Jahren. Der größte Patientenanteil besuchte für sieben bis acht Jahre eine Lehranstalt (32\%). Im Weiteren ist die Verteilung der Bildungsjahre in den Kohorten AD und rpAD relativ ähnlich.

Es ließ sich kein signifikanter Unterschied bezüglich der Bildungsjahre in den Gruppen AD und rpAD erkennen (siehe Tabelle 15). 
Tabelle 15: Bildungsjahre der AD- und rpAD-Patienten

\begin{tabular}{lllll}
\hline Bildungsjahre & Anzahl AD & Anzahl rpAD & AD (\%) & rpAD (\%) \\
\hline $7-8$ & 10 & 16 & 25 & 32 \\
$9-10$ & 5 & 5 & 12,5 & 10 \\
$11-12$ & 13 & 10 & 32,5 & 20 \\
$13-14$ & 2 & 8 & 5 & 16 \\
$15-16$ & 5 & 4 & 12,5 & 8 \\
$17-18$ & 4 & 5 & 10 & 10 \\
$19-20$ & 1 & 2 & 2,5 & 4 \\
\hline gesamt & 40 & 50 & 100 & 100 \\
\hline
\end{tabular}

\subsubsection{MMSE-Baseline-Wert}

Der MMSE-Baseline-Wert entspricht dem Wert im MMSE-Test, der bei Aufnahme des Patienten in die Studie erhoben wurde.

Der größte Anteil der AD-Patienten zeigte ein Ergebnis zwischen 20 und 25 MMSE-Punkten bei der Erstuntersuchung (35\%).

Die rpAD-Patienten umfassten eine Spanne von 0 bis 30 Punkten im MMSE-Test, wobei 29 bis 30 Punkte den Normalwert darstellen, den gesunde Probanden ohne AD erreichen sollten. Einige Patienten, die zu Beginn geringe kognitive Beeinträchtigungen im MMSE zeigten, zeichneten sich jedoch durch Defizite in anderen Testungen wie der CERAD-Testbatterie oder Auffälligkeiten im MRT aus. Sie wurden in die Berechnungen eingeschlossen, wenn sich während des Beobachtungszeitraums eine manifeste $\mathrm{AD}$ zeigte. Bei einem rpAD-Patienten wurde kein MMSE-Baseline-Wert dokumentiert.

Der größte Patientenanteil der rpAD-Kohorte erzielte ebenfalls zwischen 20 und 25 Punkten (26,5\%). Bei Patienten mit einem MMSE von unter fünf Punkten bei Studienbeginn kann nur eine zweifelhafte Aussage bezüglich des Verlaufs getroffen werden, da die Grenze für rpAD ein MMSE-Abfall von sechs Punkten pro Jahr darstellt. Die Patienten wurden allerdings aufgrund eindeutiger Klinik und zur Untersuchung des Risikoprofils in die Berechnungen miteinbezogen. Tabelle 16 fasst die MMSE-Baseline-Werte der AD- und rpAD-Patienten zusammen. 
Tabelle 16: MMSE-Baseline-Wert der AD- und rpAD-Patienten

\begin{tabular}{lllll}
\hline $\begin{array}{l}\text { MMSE- } \\
\text { Baseline-Werte }\end{array}$ & Anzahl AD & Anzahl rpAD & AD (\%) & rpAD (\%) \\
\hline 0 & - & 1 & - & 2 \\
$1-5$ & - & 6 & - & 12,2 \\
$6-10$ & - & 2 & - & 4 \\
$11-15$ & 8 & 8 & 20 & 16,3 \\
$16-20$ & 5 & 12 & 12,5 & 24,4 \\
$21-25$ & 14 & 13 & 35 & 26,5 \\
$26-30$ & 13 & 7 & 32,5 & 14,2 \\
\hline gesamt & 40 & 49 & 100 & 100 \\
\hline
\end{tabular}

\subsubsection{Verlauf}

Für jeden Patienten wurde ein Graph erstellt, der die individuelle Gedächtnisleistung in einer Regressionsgeraden darstellte. Die Steigungen der einzelnen Geraden wurden in Abbildung 5 in einem Boxplot dargestellt. Die einzelnen Steigungswerte befinden sich fast alle im negativen Bereich, da die AD-Patienten aufgrund ihrer degenerativen Erkrankung einen stetigen Abfall ihrer Gedächtnisleistung zeigten. Erkennbar ist, dass die AD-Patienten mit ihren Werten näher Richtung null tendierten, während die rpAD-Steigungswerte weiter im negativen Bereich zu finden sind. Die negativen Steigungswerte der rpAD-Patienten sind das Korrelat des stärkeren Gedächtnisabfalls im Vergleich zu den AD-Patienten. Diese Ergebnisse sind durch eine Vorauswahl der Patienten beeinflusst, da alle Patienten mit einem MMSE-Punkteabfall von über sechs Punkten pro Jahr in die Gruppe rpAD eingeteilt wurden. 


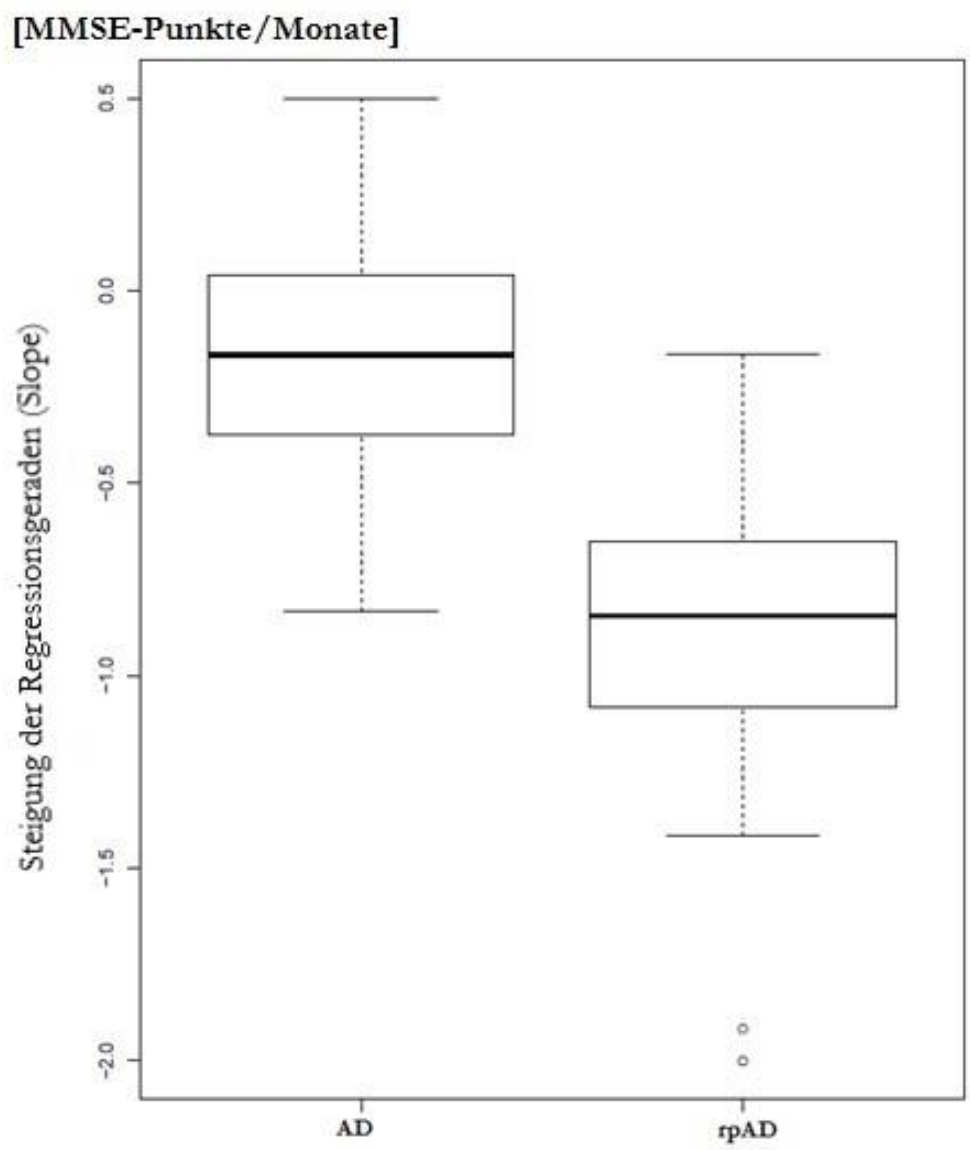

Abbildung 5: Steigungen der AD- und rpAD-Patienten als Boxplot

\subsection{Kardiovaskuläre Risikofaktoren}

Im Folgenden werden die statistischen Berechnungen der vier Risikofaktor-Gruppen dargestellt, beginnend mit den „kardiovaskulären Risikofaktoren“. Die statistischen Tests wurden im Kapitel 2.3 (vgl. S. 27) genauer erläutert. Zu Beginn wird die deskriptive Statistik dargestellt, dann die Berechnung des Welch-t-Tests. Anschließend werden die Ergebnisse des Chi-Quadrat- und des exakten Tests nach Fisher gezeigt. In Tabelle 17 ist die deskriptive Statistik der Steigungen der „kardiovaskulären Risikofaktoren“ nachzuvollziehen. Es wurden die Steigungen von allen beobachteten Patienten abhängig von den einzelnen Risikofaktoren in die Gruppen „erkrankt“ und „nicht-erkrankt“ eingeteilt und Mittelwert, Standardabweichung und Median erstellt. 


\subsubsection{Deskriptive Statistik der Steigungen der „kardiovaskulären Risikofaktoren“}

Tabelle 17: Deskriptive Statistik der Steigungen der „kardiovaskulären Risikofaktoren“

\begin{tabular}{|c|c|c|c|c|c|c|}
\hline \multicolumn{2}{|l|}{ Parameter * } & Mittelwert & $\mathrm{SD}$ & Median & $\begin{array}{l}\text { Anzahl } \\
\text { Patienten }\end{array}$ & $\begin{array}{l}\text { Anteil } \\
\text { Patienten (\%) }\end{array}$ \\
\hline Diabetes mellitus & 0 & $-0,565$ & 0,51 & $-0,500$ & 79 & 88,8 \\
\hline Diabetes mellitus & 1 & 0,017 & 0,43 & 0,042 & 10 & 11,2 \\
\hline Hypertonus & 0 & $-0,466$ & 0,55 & $-0,492$ & 44 & 49,5 \\
\hline Hypertonus & 1 & $-0,531$ & 0,52 & $-0,500$ & 45 & 50,5 \\
\hline Rauchen & 0 & $-0,427$ & 0,48 & $-0,450$ & 61 & 67,8 \\
\hline Rauchen & 1 & $-0,655$ & 0,60 & $-0,583$ & 29 & 32,2 \\
\hline $\begin{array}{l}\text { Hyperlipoprotein } \\
\text { ämie }\end{array}$ & 0 & $-0,548$ & 0,52 & $-0,500$ & 39 & 43,4 \\
\hline $\begin{array}{l}\text { Hyperlipoprotein } \\
\text { ämie }\end{array}$ & 1 & $-0,464$ & 0,55 & $-0,417$ & 51 & 56,6 \\
\hline HRS & 0 & $-0,483$ & 0,52 & $-0,500$ & 79 & 87,8 \\
\hline HRS & 1 & $-0,624$ & 0,61 & $-0,667$ & 11 & 12,2 \\
\hline Schlaganfall & 0 & $-0,513$ & 0,53 & $-0,500$ & 82 & 93 \\
\hline Schlaganfall & 1 & $-0,298$ & 0,57 & $-0,083$ & 7 & 7 \\
\hline Myokardinfarkt & 0 & $-0,508$ & 0,53 & $-0,500$ & 88 & 97,8 \\
\hline Myokardinfarkt & 1 & $-0,167$ & 0,94 & $-0,167$ & 2 & 2,2 \\
\hline pAVK & 0 & $-0,495$ & 0,50 & $-0,50$ & 88 & 97,8 \\
\hline pAVK & 1 & $-0,750$ & 1,77 & $-0,75$ & 2 & 2,2 \\
\hline Thrombose & 0 & $-0,490$ & 0,54 & $-0,483$ & 85 & 94,5 \\
\hline Thrombose & 1 & $-0,670$ & 0,23 & $-0,517$ & 5 & 5,5 \\
\hline Lungenembolie & 0 & $-0,491$ & 0,54 & $-0,500$ & 87 & 96,7 \\
\hline Lungenembolie & 1 & $-0,778$ & 0,25 & $-0,833$ & 3 & 3,3 \\
\hline Herzinsuffizienz & 0 & $-0,514$ & 0,53 & $-0,500$ & 88 & 97,8 \\
\hline Herzinsuffizienz & 1 & 0,125 & 0,53 & 0,125 & 2 & 2,2 \\
\hline $\mathrm{KHK}$ & 0 & $-0,526$ & 0,52 & $-0,50$ & 85 & 94,5 \\
\hline KHK & 1 & $-0,067$ & 0,57 & $-0,25$ & 5 & 5,5 \\
\hline
\end{tabular}

$* 0=$ nicht erkrankt, $1=$ erkrankt 


\subsection{2 p-Werte des Welch-t-Tests der „kardiovaskulären Risikofaktoren“}

Jede der vier Gruppen wurde mittels des Shapiro-Wilk-Tests und des Q-Q-Plots auf Normalverteilung getestet, wobei sich eine Normalverteilung aller Gruppen ergab. Die Ergebnisse des Shapiro-Wilk-Tests und des Q-Q-Plots wurden nicht dargestellt.

Der Welch-t-Test berechnete, ob sich die Mittelwerte der Steigungen in Abhängigkeit von den Risikofaktoren unterscheiden. War der p-Wert des Welch-t-Test nicht signifikant, zeigten die Mittelwerte der Steigungen keine signifikanten Abweichungen zwischen den Gruppen, unabhängig davon ob der Risikofaktor vorhanden war oder nicht.

Die Ergebnisse zeigten einen signifikanten p-Wert bei der Erkrankung Diabetes mellitus ( $\mathrm{p}$-Wert $=0,002$, siehe Tabelle 18), wobei das Signifikanzniveau bei $\mathrm{p}=<0,05$ festgelegt wurde. Die Erkrankung wird im Kapitel 3.2.4 detaillierter untersucht (vgl. Kapitel 3.2.4). Mittels Regressionsanalyse wurde untersucht, inwiefern sich Diabetes mellitus auf den Verlauf der AD auswirkt. Es sollte unterschieden werden, ob die Erkrankung einen Gedächtnisverfall begünstigt oder verlangsamt.

Tabelle 18: p-Werte des Welch-t-Tests der „kardiovaskulären Risikofaktoren“

\begin{tabular}{ll}
\hline Parameter & $\begin{array}{l}\text { Welch- } \\
\text { Test }\end{array}$ \\
\hline Diabetes mellitus & $\mathbf{0 , 0 0 2}$ \\
Hypertonus & 0,570 \\
Rauchen & 0,082 \\
Hyperlipoproteinämie & 0,456 \\
HRS & 0,477 \\
Schlaganfall & 0,368 \\
Myokardinfarkt & 0,699 \\
pAVK & 0,872 \\
Thrombose & 0,177 \\
Lungenembolie & 0,178 \\
Herzinsuffizienz & 0,333 \\
KHK & 0,147 \\
\hline
\end{tabular}




\subsection{3 p-Werte des Chi-Quadrat-Tests und des exakten Tests nach Fisher mit Odds Ratios der „kardiovaskulären Risikofaktoren“}

Mittels Chi-Quadrat-Test und exaktem Test nach Fisher wurde der Einfluss der Risikofaktoren auf die dichotomen Steigungen (Verlaufsklasse) der AD- und rpAD-Patienten getestet. Es sollte untersucht werden, ob sich die Risikofaktoren auf die Einteilung der Patienten in die Gruppen $\mathrm{AD}$ oder rpAD auswirken.

Hier ergaben die Ergebnisse zwei signifikante p-Werte (siehe Tabelle 19). Der p-Wert des Chi-Quadrat-Tests der Variable KHK erwies sich mit $\mathrm{p}=0,010$ als signifikant. Die Steigungen der Patienten mit AD oder rpAD unterschieden sich demnach signifikant, wenn der Patient zusätzlich zu der AD an einer KHK erkrankt war.

Die Variable Diabetes mellitus war in diesem Zusammenhang ebenfalls mit einem $\mathrm{p}$-Wert $=0,019 \mathrm{im}$ Chi-Quadrat-Test signifikant. Auch hier unterschieden sich die Patienten mit $\mathrm{AD}$ in ihren Steigungen signifikant von denen mit rpAD. Beide Variablen wurden im Folgenden in ein Regressionsmodell aufgenommen.

Anhand der Odds Ratios ist es möglich Chancenverhältnisse abzulesen. Es wurde getestet wie hoch die Chance ist, bei Erkrankung mit einem bestimmten Risikofaktor in die Gruppe rpAD eingeordnet zu werden. Eine Odds Ratio von eins bedeutet, dass es keinen Unterschied im Chancenverhältnis zwischen den Gruppen gibt. Ein Wert kleiner als eins bedeutet, dass die Chance der Gruppe bei Erkrankung mit dem Risikofaktor kleiner ist eine rpAD zu bekommen als in der Gruppe ohne Risikofaktor. Ein Ergebnis größer als eins bedeutet, dass es wahrscheinlicher ist, dass die Patienten mit dem Risikofaktor in die Grupp rpAD eingeordnet werden. Dabei ist an der Odds Ratio von Diabetes $=0,183$ abzulesen, dass die Chance an einer rpAD zu erkranken unter Diabetikern kleiner als bei Nicht-Diabetikern war (in etwa fünfmal kleiner als bei Nicht-Diabetikern). Bei der Variable KHK mit einer Odds Ratio von null ist die Chance in die Gruppe rpAD eingeordnet zu werden, gleich null. 
Tabelle 19: p-Werte des Chi-Quadrat-Tests und des exakten Tests nach Fisher mit Odds Ratios der „kardiovaskulären Risikofaktoren“

\begin{tabular}{llll}
\hline Parameter & Chi-Quadrat-Test & $\begin{array}{l}\text { Exakter Test } \\
\text { nach Fisher }\end{array}$ & $\begin{array}{l}\text { Odds } \\
\text { Ratio }\end{array}$ \\
\hline Diabetes mellitus & $\mathbf{0 , 0 1 9}$ & $\mathbf{0 , 0 3 9}$ & 0,183 \\
Hypertonus & 0,449 & 0,397 & 0,665 \\
Rauchen & 0,391 & 0,506 & 1,398 \\
Hyperlipoproteinämie & 0,568 & 0,670 & 0,788 \\
HRS & 0,565 & 0,748 & 1,534 \\
Schlaganfall & 0,295 & 0,460 & 0,474 \\
Myokardinfarkt & 0,113 & 0,204 & 0 \\
pAVK & 0,873 & 1,000 & 0,835 \\
Thrombose & 0,837 & 1,000 & 1,268 \\
Lungenembolie & 0,694 & 1,000 & 1,692 \\
Herzinsuffizienz & 0,113 & 0,205 & 0 \\
KHK & $\mathbf{0 , 0 1 0}$ & $\mathbf{0 , 0 1 7}$ & 0 \\
\hline
\end{tabular}

\subsubsection{Regressionsanalyse von Diabetes mellitus als prognostischer Faktor für den Gedächtnisverfall im Rahmen einer AD}

Den Berechnungen wurde eine multiple lineare Regression angeschlossen, um den möglichen Einfluss von Geschlecht, Bildungsgrad, Alter und dem MMSE-Baseline-Wert auf die Ergebnisse zu betrachten. Dabei sollte ebenfalls eruiert werden, ob sich die Erkrankung positiv oder negativ auf den Gedächtnisverfall auswirkt. In der linearen Regression dienten die Steigungen als abhängige Variable und die Variablen Alter, Geschlecht, Bildungsgrad, MMSE-Baseline-Wert und der Achsenabschnitt als unabhängige Variable.

Anhand der Schätzer ist die Auswirkung von bestimmten Variablen auf die Steigungen ablesbar. Der p-Wert der linearen Regression für die Variable Diabetes mellitus war mit einem Ergebnis von $\mathrm{p}=0,001$ signifikant. Zu Beginn an Diabetes mellitus erkrankte Patienten wiesen verglichen mit Patienten ohne Diabetes mellitus durchschnittlich einen um 0,610 Punkte erhöhten MMSEWert vor (siehe Tabelle 20, Spalte Schätzer). Die Steigungsgeraden der Diabetes-Patienten bewegten sich flacher in Richtung $\mathrm{x}$-Achse, was für einen langsameren Verfall der Gedächtnisleistung steht. Eine Erkrankung mit Diabetes mellitus hatte in dieser Studienkohorte einen günstigen Effekt auf den Verlauf der AD. 
Des Weiteren war der p-Wert der Variable MMSE-Baseline-Wert signifikant ( $\mathrm{p}$-Wert=0,005). Sobald das Ergebnis des MMSE-Tests um einen Punkt in der initialen Untersuchung stieg, sank der slope der Patienten im Durchschnitt um -0,023 Punkte ab. Patienten mit einem höheren initialen MMSE-Wert zeigten einen rapideren Abfall der Gedächtnisleistung.

Die anderen aufgenommenen Variablen wirkten sich nicht signifikant auf die Steigungen der Patienten aus.

Tabelle 20: Regressionskoeffizienten mit Standardfehlern und p-Werten der linearen Regression von Diabetes mellitus

\begin{tabular}{llll}
\hline Koeffizient & Schätzer & Standardfehler & p-Wert \\
\hline Achsenabschnitt & $-0,143$ & 0,479 & 0,766 \\
Diabetes liegt vor & 0,610 & 0,170 & $\mathbf{0 , 0 0 1}$ \\
Geschlecht weiblich & $-0,175$ & 0,126 & 0,167 \\
Bildungsgrad [Jahre] & $-0,002$ & 0,016 & 0,912 \\
MMSE-Baseline-Wert & $-0,024$ & 0,008 & $\mathbf{0 , 0 0 5}$ \\
Alter [ahre] & 0,002 & 0,006 & 0,679 \\
\hline
\end{tabular}

\subsubsection{Regressionsanalyse von KHK als prognostischer Faktor für den Gedächtnisverfall im Rahmen einer AD}

Die Variable KHK zeigte mit einem $\mathrm{p}$-Wert $=0,010 \mathrm{im}$ Chi-Quadrat-Test und $\mathrm{p}=0,017 \mathrm{im}$ exakten Test nach Fisher signifikante Ergebnisse. Da die Steigungen für die Anwendung des Chi-Quadrat-Tests und des exakten Tests nach Fisher dichotomisiert wurden $(0=\mathrm{AD}, 1=\mathrm{rpAD})$, musste in diesem Falle die Variable KHK in eine logistische Regression aufgenommen werden. So konnte der Einfluss der unabhängigen Variablen KHK, Alter, Geschlecht, Bildungsgrad, MMSE-Baseline-Wert und Achsenabschnitt auf die abhängige Variable der dichotomisierten Verlaufsklasse $(0=\mathrm{AD}, 1=\mathrm{rpAD})$ beobachtet werden.

Bei Beobachtung der p-Werte der logistischen Regression fällt auf, dass der p-Wert der Variable MMSE-Baseline-Wert $(p=0,017)$ ein signifikantes Ergebnis zeigte (siehe Tabelle 21). Sie übte einen signifikant messbaren Einfluss auf den Verlauf der AD aus. Trotz Aufnahme der Variablen zeigte sich mit $\mathrm{p}=0,023$ ein signifikantes Ergebnis für den Risikofaktor KHK.

Die Interpretation der logistischen Regression unterscheidet sich von jener der linearen Regression dahingehend, dass hier kein linarer Zusammenhang betrachtet wird, sondern die 
Chance der Zuordnung in die Gruppen $0=\mathrm{AD}$ und $1=\mathrm{rpAD}$. Auch hier konnte anhand des Schätzers die Tendenz der Patienten abgelesen werden. In der logistischen Regression wurden die Regressionskoeffizienten als logarithmierte Odds Ratios interpretiert. Nach Anwendung der Exponentialfunktion ergab sich die Odds Ratio für die entsprechenden Variablen. Mit einem Schätzer von -2,685 für den Regressionskoeffizienten und somit einer Odds Ratio von 0,068 der Variable KHK kann abgelesen werden, dass KHK-Patienten zu langsamen Verläufen tendierten (Odds Ratio $<1=$ Tendenz zur langsam progressiven AD).

Der MMSE-Baseline-Wert zeigte sich mit einem p-Wert=0,017 ebenfalls als signifikant. Patienten mit einem um einen Punkt erhöhten MMSE-Baseline-Wert hatten verglichen mit Patienten mit einem Punkt weniger in der Testung eine um den Faktor 1,09 erhöhte Chance an einer rapid progressiven Form der AD zu leiden.

Bezüglich der Variable Alter ließ sich ebenfalls ein signifikanter Wert erkennen ( $\mathrm{p}$-Wert= 0,050). Es deutete anhand des Schätzers von -0,049 und der Odds Ratio von 0,95 pro Lebensjahr daraufhin, dass die Chance auf einen rapiden Verlauf der AD sank, je älter die Patienten wurden.

Tabelle 21: Regressionskoeffizienten mit Standardfehlern und p-Werten der logistischen Regression von KHK

\begin{tabular}{lllll}
\hline Koeffizient & Schätzer & Odds Ratio & Standardfehler & p-Wert \\
\hline Achsenabschnitt & 5,528 & 251,64 & 2,287 & $\mathbf{0 , 0 0 9}$ \\
KHK liegt vor & $-2,685$ & 0,068 & 1,698 & $\mathbf{0 , 0 2 3}$ \\
Geschlecht weiblich & 0,175 & 1,19 & 0,537 & 0,738 \\
Bildungsgrad [Jahre] & $-0,003$ & 0,99 & 0,071 & 0,964 \\
MMSE-Baseline-Wert & 0,087 & 1,09 & 0,039 & $\mathbf{0 , 0 1 7}$ \\
Alter [Jahre] & $-0,049$ & 0,95 & 0,026 & $\mathbf{0 , 0 5 0}$ \\
\hline
\end{tabular}

\subsubsection{Regressionsanalyse mit KHK und Diabetes mellitus als Kovariablen}

Da die Regressionen für die Risikofaktoren Diabetes mellitus und KHK signifikante p-Werte zeigten, sollte mit der folgenden Regression überprüft werden, ob sich die Erkrankungen wechselseitig beeinflussen. Drei Patienten waren sowohl an KHK als auch an Diabetes mellitus erkrankt. Mit einem $\mathrm{p}$-Wert= 0,144 für KHK und einem $\mathrm{p}$-Wert= 0,134 für Diabetes mellitus konnte sich die Vermutung eines Zusammenhangs nicht bestätigen. Die Variablen Achsenabschnitt $(p=0,014)$ und MMSE-Baseline-Wert $(p=0,035)$ übten einen signifikanten 
Einfluss auf die untersuchten Risikofaktoren aus (siehe Tabelle 22). Der MMSE-Baseline-Wert zeigte sich mit einem $\mathrm{p}$-Wert $=0,035$ als signifikant. Patienten mit einem um einen Punkt erhöhten MMSE-Baseline-Wert hatten eine um den Faktor 0,92 erhöhte Chance an einer langsam progressiven Form der AD zu leiden, verglichen mit Patienten mit einem Punkt weniger in der Testung. Obwohl sich keine Signifikanz bei beiden Erkrankungen in Kombination ergab, ist dennoch die Tendenz abzulesen, dass Patienten mit KHK und Diabetes mellitus immer noch eine höhere Chance auf einen langsamen Verlauf aufwiesen (Odds Ratios von Diabetes mellitus $(0,27)$ und $\operatorname{KHK}(0,12)$ jeweils $<1)$.

Tabelle 22: Regressionsmodell mit KHK und Diabetes mellitus als Kovariablen

\begin{tabular}{lllll}
\hline Koeffizient & Schätzer & Odds Ratio & Standardfehler & p-Wert \\
\hline Achsenabschnitt & 5,260 & 192,48 & 2,302 & $\mathbf{0 , 0 1 4}$ \\
KHK liegt vor & $-2,044$ & 0,12 & 1,697 & 0,114 \\
Diabetes liegt vor & $-1,287$ & 0,27 & 0,393 & 0,134 \\
Geschlecht weiblich & 0,321 & 1,37 & 0,548 & 0,548 \\
Bildungsgrad [Jahre] & $-0,008$ & 0,99 & 0,072 & 0,903 \\
MMSE-Baseline-Wert & $-0,077$ & 0,92 & 0,040 & $\mathbf{0 , 0 3 5}$ \\
Alter [Jahre] & $-0,047$ & 0,95 & 0,027 & 0,067 \\
\hline
\end{tabular}




\subsection{Malignome}

In Tabelle 23 ist die deskriptive Statistik für die Kategorie „Malignome“ und die Unterteilung in die verschiedenen Krebsarten aufgelistet.

\subsubsection{Deskriptive Statistik der Steigungen der „Malignome“}

Tabelle 23: Deskriptive Statistik der Steigungen der „Malignome“

\begin{tabular}{lllllll}
\hline Parameter * & & Mittelwert & SD & Median & $\begin{array}{l}\text { Anzahl } \\
\text { Patienten }\end{array}$ & $\begin{array}{l}\text { Anteil } \\
\text { Patienten (\%) }\end{array}$ \\
\hline Malignome & 0 & $-0,521$ & 0,54 & $-0,500$ & 84 & 93,4 \\
Malignome & 1 & $-0,208$ & 0,40 & $-0,292$ & 6 & 6,6 \\
\hline Gastrointestinal & 0 & $-0,499$ & 0,54 & $-0,500$ & 88 & 97,7 \\
Gastrointestinal & 1 & $-0,542$ & 0,18 & $-0,542$ & 2 & 2,2 \\
Niere & 0 & $-0,508$ & 0,54 & $-0,500$ & 88 & 97,7 \\
Niere & 1 & $-0,167$ & 0,12 & $-0,167$ & 2 & 2,2 \\
Mamma & 0 & $-0,51$ & 0,53 & $-0,500$ & 88 & 97,7 \\
Mamma & 1 & 0,042 & 0,65 & 0,042 & 2 & 2,2 \\
\hline
\end{tabular}

$*_{0}=$ nicht erkrankt, $1=$ erkrankt

\subsection{2 p-Werte des Welch-t-Tests der „Malignome“ im Allgemeinen und der Subgruppen der „Malignome“}

In den Gruppen „Malignome“ und „chirurgische Eingriffe“ wurden zunächst die Mittelwerte der Steigungen in Abhängigkeit von den einzelnen Erkrankungen und Eingriffen beobachtet. In der weiteren Berechnung wurden die einzelnen Subgruppen mittels Kruskal-Wallis-Test auf Gruppenunterschiede getestet, um eventuelle Effekte von einzelnen malignen Erkrankungen oder speziellen Eingriffen zu detektieren.

Der Welch-t-Test zeigte für die Variable „Malignome“ keinen signifikanten p-Wert.

Neben der Durchführung eines Welch-t-Tests für die Krebserkrankung im Allgemeinen wurde dieser Test ebenfalls bei drei Subgruppen durchgeführt.. Darunter fielen gastrointestinale Tumoren, Tumoren der Niere oder der Mamma, da dies die einzigen Krebserkrankungen in der untersuchten Kohorte waren.

Es zeigte sich kein signifikanter p-Wert für die Variablen der Subgruppen (siehe Tabelle 24). 
Tabelle 24: p-Werte des Welch-t-Tests für „Malignome“ im Allgemeinen und Subgruppen der „Malignome“

\begin{tabular}{ll}
\hline Parameter & Welch-t-Test \\
\hline Malignome & 0,122 \\
\hline Gastrointestinal & 0,796 \\
Niere & 0,070 \\
Mamma & 0,438 \\
\hline
\end{tabular}

\subsection{3 p-Werte des Chi-Quadrat-Tests und des exakten Tests nach Fisher mit Odds Ratios der „Malignome“}

Auch im Chi-Quadrat-Test und im exakten Test nach Fisher für die einzelnen Krebserkrankungen zeigte sich kein signifikanter p-Wert (siehe Tabelle 25).

Tabelle 25: p-Werte des Chi-Quadrat-Tests und des exakten Tests nach Fisher mit Odds Ratios der „Malignome“

\begin{tabular}{llll}
\hline Parameter & $\begin{array}{l}\text { Chi-Quadrat- } \\
\text { Test }\end{array}$ & $\begin{array}{l}\text { Exakter } \\
\text { nach Fisher }\end{array}$ & $\begin{array}{l}\text { Odds } \\
\text { Ratio }\end{array}$ \\
\hline Malignome & 0,797 & 1,000 & 0,828 \\
\hline Gastrointestinal & 0,873 & 1,000 & 0,835 \\
Niere & 0,873 & 1,000 & 1,692 \\
Mamma & 0,873 & 1,000 & 0,835 \\
\hline
\end{tabular}

\subsection{Chirurgische Eingriffe}

\subsubsection{Deskriptive Statistik der Steigungen der „chirurgischen Eingriffe“}

In der dritten Gruppe wurden die „chirurgischen Eingriffe“ untersucht. In Tabelle 26 ist die deskriptive Statistik der „chirurgischen Eingriffe“ und der einzelnen Eingriffe dargestellt. 
Tabelle 26: Deskriptive Statistik der Steigungen der „chirurgischen Eingriffe“

\begin{tabular}{lllllll}
\hline Parameter * & & Mittelwert & SD & Median & $\begin{array}{l}\text { Anzahl } \\
\text { Patienten }\end{array}$ & $\begin{array}{l}\text { Anteil } \\
\text { Patienten (\%) }\end{array}$ \\
\hline Chir. Eingriffe & 0 & $-0,541$ & 0,58 & $-0,500$ & 55 & 61,2 \\
Chir. Eingriffe & 1 & $-0,436$ & 0,44 & $-0,417$ & 35 & 38,8 \\
\hline Nerven & 0 & $-0,492$ & 0,54 & $-0,500$ & 87 & 96,6 \\
Nerven & 1 & $-0,726$ & 0,20 & $-0,833$ & 3 & 3,3 \\
HNO & 0 & $-0,490$ & 0,53 & $-0,500$ & 88 & 97,7 \\
HNO & 1 & $-0,917$ & 0,59 & $-0,917$ & 2 & 2,2 \\
Appendix & 0 & $-0,495$ & 0,54 & $-0,500$ & 84 & 93,3 \\
Appendix & 1 & $-0,574$ & 0,38 & $-0,508$ & 6 & 6,6 \\
Gallenblase & 0 & $-0,506$ & 0,55 & $-0,500$ & 85 & 94,4 \\
Gallenblase & 1 & $-0,400$ & 0,15 & $-0,417$ & 5 & 5,5 \\
Gastrointestinal & 0 & $-0,499$ & 0,54 & $-0,500$ & 88 & 97,7 \\
Gastrointestinal & 1 & $-0,542$ & 0,18 & $-0,542$ & 2 & 2,2 \\
Leistenhernie & 0 & $-0,480$ & 0,53 & $-0,492$ & 86 & 95,5 \\
Leistenhernie & 1 & $-0,920$ & 0,39 & $-0,917$ & 4 & 4,4 \\
Urologisch & 0 & $-0,499$ & 0,54 & $-0,50$ & 87 & 96,6 \\
Urologisch & 1 & $-0,528$ & 0,56 & $-0,25$ & 3 & 3,3 \\
\hline
\end{tabular}

$* 0=$ nicht erkrankt, $1=$ erkrankt

\subsection{2 p-Werte des Welch-t-Tests der „chirurgischen Eingriffe“ im Allgemeinen und der einzelne Eingriffe}

Der Welch-t-Test zeigte für die Variable „chirurgische Eingriffe“ keinen signifikanten p-Wert. In die Überkategorie „,chirurgische Eingriffe“ wurden auch Operationen eingeschlossen, die in den folgenden Berechnungen aufgrund mangelnder Patientenanzahlen nicht in die Untersuchung der Subgruppen miteinbezogen wurden.

Wie auch in der Gruppe „Malignome“ wurden bei den „chirugischen Eingriffen“ ebenfalls die Subgruppen untersucht (siehe Tabelle 27). Diese bestanden aus Eingriffen an Nerven, im HNO-Bereich, Appendix, Gallenblase, dem Gastrointestinaltrakt, Leistenhernien und den urologischen Organen. Die statistische Untersuchung der Subgruppen richtete sich nach Patientenanzahl der einzelnen Gruppen, wobei zwei Patienten die Minimalanzahl darstellten. Dabei ließen sich keine signifikanten p-Werte finden. 
Tabelle 27: p-Werte des Welch-t-Tests der einzelnen „chirurgischen Eingriffe“

\begin{tabular}{ll}
\hline Eingriffe & Welch-t-Test \\
\hline Chir. Eingriffe & 0,330 \\
\hline Nerven & 0,158 \\
HNO & 0,491 \\
Appendix & 0,645 \\
Gallenblase & 0,256 \\
Gastrointestinal & 0,796 \\
Leistenhernie & 0,106 \\
Urologisch & 0,938 \\
\hline
\end{tabular}

\subsection{3 p-Werte des Chi-Quadrat-Tests und des exakten Tests nach Fisher mit Odds Ratios der „chirurgischen Eingriffe“}

Der Chi-Quadrat-Test und der exakte Test nach Fisher zeigten für die Variablen der „chirurgischen Eingriffe“ keine signifikanten p-Werte (siehe Tabelle 28).

Tabelle 28: p-Werte des Chi-Quadrat-Tests und des exakten Tests nach Fisher mit Odds Ratios der ,chirurgischen Eingriffe“

\begin{tabular}{llll}
\hline Parameter & $\begin{array}{l}\text { Chi-Quadrat- } \\
\text { Test }\end{array}$ & $\begin{array}{l}\text { Exakter } \\
\text { Test nach } \\
\text { Fisher }\end{array}$ & Odds Ratio \\
\hline Chir. Eingriffe & 0,233 & 0,286 & 0,623 \\
\hline Nerven & 0,442 & 0,589 & 0,410 \\
HNO & 0,884 & 1,000 & 0,835 \\
Appendix & 0,554 & 0,685 & 1,723 \\
Gallenblase & 0,486 & 0,656 & 0,543 \\
Gastrointestinal & 0,884 & 1,000 & 0,835 \\
Leistenhernie & 0,412 & 0,624 & 2,519 \\
Urologisch & 0,442 & 0,586 & 0,410 \\
\hline
\end{tabular}

Da für die zwei Eingriffsarten „Herzoperationen“ und „orthopädische Eingriffe“ eine gute Datenlage bestand, konnten vertiefend einzelne Berechnungen bezüglich verschiedener Eingriffe innerhalb der Subgruppe durchgeführt werden (siehe Tabelle 29). 
Die Eingriffe am Herz bestanden aus Schrittmacher- oder Stentimplantationen und Katheteruntersuchungen (mit oder ohne Intervention) und die Eingriffe in der Orthopädie aus Knie-TEP, Hüft-TEP und Weiteren.

\subsubsection{Unterkategorien „chirurgische Eingriffe“}

Tabelle 29: Gruppenvergleich der Untergruppen „Herzoperationen“ und „orthopädische Eingriffe“

\begin{tabular}{lllll}
\hline Parameter & $\begin{array}{l}\text { Anzahl } \\
\text { Patienten }\end{array}$ & $\begin{array}{l}\text { Chi-Quadrat- } \\
\text { Test }\end{array}$ & $\begin{array}{l}\text { Exakter Test nach } \\
\text { Fisher }\end{array}$ & Kruskal-Wallis-Test \\
\hline Herzoperationen & & 0,270 & 0,244 & 0,753 \\
Kein Eingriff & 85 & & & \\
Schrittmacher & 1 & & \\
Stent & 2 & & 0,648 \\
Katheter- & 2 & & \\
Untersuchung & & & \\
\hline Orth. Eingriffe & & 0,282 & \\
Kein Eingriff & 78 & & & \\
Knie-TEP & 5 & & & \\
Hüft-TEP & 5 & & & \\
Weitere & 2 & & & \\
\hline
\end{tabular}




\subsection{Andere Vor- und Begleiterkrankungen}

Die letzte Gruppe stellen die „anderen Vor- und Begleiterkrankungen“ dar, für die ebenfalls zunächst die deskriptive Statistik erstellt wurde (siehe Tabelle 30).

\subsubsection{Deskriptive Statistik der Steigungen der „anderen Vor- und Begleiterkrankungen“"}

Tabelle 30: Deskriptive Statistik der Steigungen der „anderen Vor- und Begleiterkrankungen“

\begin{tabular}{|c|c|c|c|c|c|c|}
\hline \multicolumn{2}{|l|}{ Parameter * } & Mittelwert & SD & Median & $\begin{array}{l}\text { Anzahl } \\
\text { Patienten }\end{array}$ & $\begin{array}{l}\text { Anteil } \\
\text { Patienten (\%) }\end{array}$ \\
\hline Asthma & 0 & $-0,513$ & 0,523 & $-0,500$ & 88 & 97,7 \\
\hline Asthma & 1 & 0,041 & 0,883 & 0,0417 & 2 & 2,2 \\
\hline Epilepsie & 0 & $-0,502$ & 0,538 & $-0,500$ & 83 & 92,3 \\
\hline Epilepsie & 1 & $-0,481$ & 0,493 & $-0,667$ & 7 & 7,7 \\
\hline Depression & 0 & $-0,507$ & 0,541 & $-0,500$ & 74 & 82,3 \\
\hline Depression & 1 & $-0,471$ & 0,506 & $-0,417$ & 16 & 17,7 \\
\hline Hypakusis & 0 & $-0,489$ & 0,532 & $-0,5$ & 85 & 94,5 \\
\hline Hypakusis & 1 & $-0,700$ & 0,545 & $-0,5$ & 5 & 5,5 \\
\hline Schlafapnoe & 0 & $-0,508$ & 0,537 & $-0,500$ & 86 & 95,6 \\
\hline Schlafapnoe & 1 & $-0,342$ & 0,427 & $-0,292$ & 4 & 4,4 \\
\hline Arthrose & 0 & $-0,518$ & 0,529 & $-0,500$ & 87 & 96,7 \\
\hline Arthrose & 1 & 0,0278 & 0,337 & 0,083 & 3 & 3,3 \\
\hline Autoimmunerkrankung & 0 & $-0,509$ & 0,537 & $-0,500$ & 85 & 95,6 \\
\hline Autoimmunerkrankung & 1 & $-0,188$ & 0,329 & $-0,083$ & 4 & 4,4 \\
\hline Psych. Vorerkrankung & 0 & $-0,507$ & 0,527 & $-0,500$ & 86 & 95,5 \\
\hline Psych. Vorerkrankung & 1 & $-0,354$ & 0,712 & $-0,042$ & 4 & 4,4 \\
\hline
\end{tabular}

$*_{0}=$ nicht erkrankt, $1=$ erkrankt

In der untersuchten Gruppe „andere Vor- und Begleiterkrankungen“ fanden sich in den Kategorien „Trauma, Schilddrüse, chronische Infektionen und andere neurologische Erkrankungen“" weitere Untergruppen, deren deskriptive Statistik in Tabelle 31 dargestellt ist. 
Tabelle 31: Deskriptive Statistik der Steigungen der ,anderen Vor- und Begleiterkrankungen“ mit Untergruppen

\begin{tabular}{|c|c|c|c|c|c|c|}
\hline Parameter * & & Mittelwert & SD & Median & $\begin{array}{l}\text { Anzahl } \\
\text { Patienten }\end{array}$ & $\begin{array}{l}\text { Anteil } \\
\text { Patienten (\%) }\end{array}$ \\
\hline Trauma & 0 & $-0,515$ & 0,542 & $-0,500$ & 79 & 87,7 \\
\hline Kopf-/Halstrauma & 1 & $-0,363$ & 0,345 & $-0,250$ & 4 & 4,4 \\
\hline $\begin{array}{l}\text { Nicht Kopf- } \\
\text { /Halstrauma }\end{array}$ & 1 & $-0,407$ & 0,538 & $-0,417$ & 7 & 7,7 \\
\hline Schilddrüse & 0 & $-0,477$ & 0,523 & $-0,500$ & 81 & 90 \\
\hline Hypothyreose & 1 & $-0,796$ & 0,289 & $-0,758$ & 4 & 4,4 \\
\hline Hyperthyreose & 1 & $-0,250$ & - & $-0,250$ & 1 & 1,1 \\
\hline Hashimoto & 1 & $-0,306$ & 0,337 & $-0,250$ & 3 & 3,3 \\
\hline Weitere & 1 & $-2,000$ & - & $-2,000$ & 1 & 1,1 \\
\hline $\begin{array}{l}\text { Chronische } \\
\text { Infektionen }\end{array}$ & 0 & $-0,46$ & 0,530 & $-0,500$ & 86 & 95,5 \\
\hline Hepatitis-B oder -C & 1 & $-0,667$ & - & $-0,667$ & 1 & 1,1 \\
\hline $\begin{array}{l}\text { Andere chron. } \\
\text { Infektionen }\end{array}$ & 1 & $-0,578$ & 0,791 & $-0,983$ & 3 & 3,3 \\
\hline $\begin{array}{l}\text { Andere neurologische } \\
\text { Erkrankungen }\end{array}$ & 0 & $-0,503$ & 0,537 & $-0,50$ & 88 & 97,7 \\
\hline PD & 1 & $-0,500$ & - & $-0,50$ & 1 & 1,1 \\
\hline Vaskuläre Demenz & 1 & $-0,250$ & - & $-0,250$ & 1 & 1,1 \\
\hline
\end{tabular}

$*_{0}=$ nicht erkrankt, $1=$ erkrankt

\subsection{2 p-Werte des Welch-t-Tests der ,anderen Vor- und Begleiterkrankungen“}

Im $W$ elch-t-Test ergaben sich keine signifikanten p-Werte für die Variablen der ,anderen Vorund Begleiterkrankungen“" (siehe Tabelle 32). 
Tabelle 32: p-Werte des Welch-t-Tests der „anderen Vor- und Begleiterkrankungen“

\begin{tabular}{ll}
\hline Parameter & Welch-t- Test \\
\hline Asthma & 0,538 \\
Epilepsie & 0,918 \\
Depression & 0,802 \\
Hypakusis & 0,442 \\
Schlafapnoe & 0,501 \\
Arthrose & 0,096 \\
Autoimmunerkrankung & 0,143 \\
Psych. Vorerkrankung & 0,699 \\
\hline
\end{tabular}

\subsection{3 p-Werte des Chi-Quadrat-Tests und des exakten Tests nach Fisher mit Odds Ratios der „anderen Vor- und Begleiterkrankungen“}

Der Chi-Quadrat-Test und der exakte Test nach Fisher zeigten bei keinem der folgenden Variablen signifikante p-Werte (siehe Tabelle 33).

Tabelle 33: p-Werte des Chi-Quadrat-Tests und des exakten Tests nach Fisher mit Odds Ratios der ,anderen Vor- und Begleiterkrankungen“

\begin{tabular}{llll}
\hline Parameter & $\begin{array}{l}\text { Chi-Quadrat- } \\
\text { Test }\end{array}$ & $\begin{array}{l}\text { Exakter Test } \\
\text { nach Fisher }\end{array}$ & Odds Ratio \\
\hline Asthma & 0,196 & 0,498 & Inf. \\
Epilepsie & 0,907 & 1,000 & 1,124 \\
Depression & 0,315 & 0,411 & 0,596 \\
Hypakusis & 0,820 & 1,000 & 1,268 \\
Schlafapnoe & 0,216 & 0,327 & 0,268 \\
Arthrose & 0,051 & 0,090 & 0 \\
Autoimmunkrankung & 0,224 & 0,326 & 0,266 \\
Psych. Vorerkrankungen & 0,835 & 1,000 & 0,832 \\
\hline
\end{tabular}

Analog der Gruppe „chirurgische Eingriffe“ wurden einzelne Risikofaktoren oder Erkrankungen zusätzlich unterteilt (siehe Tabelle 34). Traumatische Ereignisse wurden unterteilt in Traumata des Kopf-/Halsbereiches und andere Traumata des Körpers, andere neurologische Erkrankungen in PD und vaskuläre Demenz, Schilddrüsenerkrankungen in 
Hypothyreose, Hyperthyreose, Morbus Hashimoto und weitere und chronische Infektionen in Hepatitis-B/-C und andere Infektionen. Keine der Variablen der Untergruppen zeigte signifikante p-Werte im Chi-Quadrat-Test, im exakten Test nach Fisher oder im Kruskal-WallisTest. In den mit Sternchen gekennzeichneten Feldern ist eine Berechnung des jeweiligen Tests aufgrund der kleinen Gruppengröße nicht möglich. In der Kategorie „chronische Infektionen“ konnte kein Kruskal-Wallis-Test zum Gruppenvergleich verwendet werden, da der Test nur bei mehr als zwei Gruppen mit mehr als einem Patienten angewandt werden kann. Aus diesem Grunde wurde mit dem Wilcoxon-Rangsummentest ein nicht parametrischer Test angewandt.

Tabelle 34: p-Werte der Gruppenvergleiche der Unterkategorien „Trauma“, „andere neurologische Erkrankungen“, „Schilddrüse“ und „psychische Vorerkrankungen“

\begin{tabular}{lllll}
\hline Parameter & $\begin{array}{l}\text { Anzahl } \\
\text { Patienten }\end{array}$ & $\begin{array}{l}\text { Chi-Quadrat- } \\
\text { Test }\end{array}$ & $\begin{array}{l}\text { Exakter } \\
\text { Test nach } \\
\text { Fisher }\end{array}$ & Kruskal-Wallis-Test \\
\hline Trauma & & 0,333 & 0,374 & 0,816 \\
Kein Trauma & 79 & & & \\
Kopf/Halstrauma & 4 & & \\
Nicht K./H.-Trauma & 7 & & 0,195 & $*$ \\
\hline $\begin{array}{l}\text { Andere } \\
\text { neurologische }\end{array}$ & 88 & & & \\
Erkrankungen & 1 & & & \\
Keine & 1 & & & \\
PD & & & 0,658 \\
Vask. Dem. & & & & \\
\hline Schilddrüse & & 0,666 & \\
Euthyreose & 81 & & & \\
Hypothyreose & 4 & & & \\
Hyperthyreose & 1 & & & \\
Hashimoto & 3 & & & \\
Weitere & 1 & & & \\
\hline Chron. Infektionen & & & & \\
Keine & 86 & & & \\
Hepatitis-B oder -C & 1 & & & \\
Andere Infektionen & 3 & & & \\
\hline
\end{tabular}




\subsection{APO-E-Auswertung}

Die APO-E-Auswertung erfolgte deskriptiv. Es wurde dargestellt, wie die sechs APO-E-Allele in der Gesamtkohorte, in der AD-Kohorte und in der rpAD-Kohorte verteilt sind.

\subsubsection{Betrachtung der Gesamtkohorte}

Es wurde die Allelverteilung von 104 Patienten der rpAD-Studie untersucht. Nicht alle diese Patienten konnten auch in die statistischen Berechnungen bezüglich der Risikofaktoren aufgenommen werden, da 14 von ihnen zu wenig Follow-Up-Untersuchungen aufwiesen. Es wurde sich dennoch dafür entschieden die Probanden in die Betrachtung der APO-EAllelverteilung aufzunehmen, da eine größere Kohorte möglicherweise ein repräsentativeres Ergebnis bezogen auf das Patientenkollektiv der gesamten rpAD-Studie liefern würde.

Insgesamt trugen $0,96 \%$ das Allel $2 / 2,42,31 \%$ das Allel 3/3, 10,47\% das Allel 4/4, 0,96\% das Allel 2/3, 4,8 \% das Allel 2/4 und 40,39 \% das Allel 3/4 (siehe Abbildung 6).

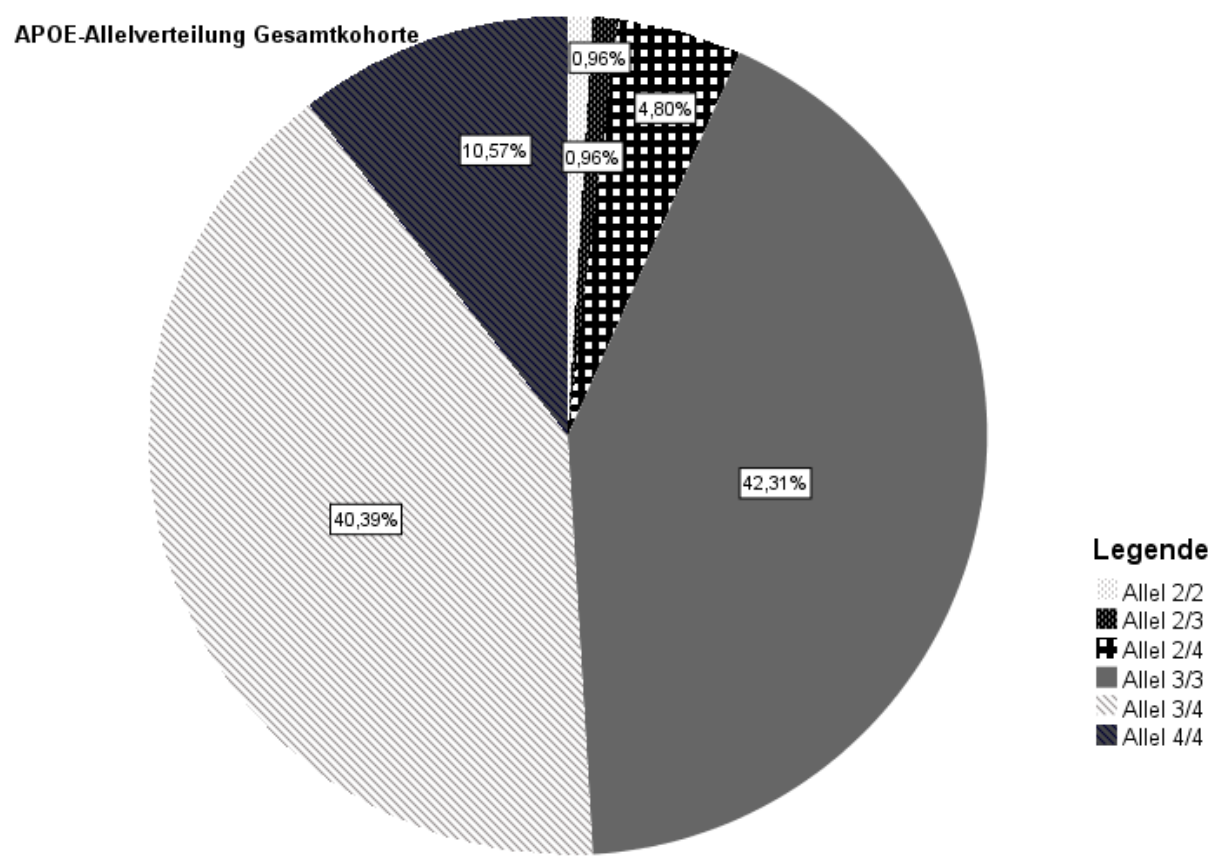

Abbildung 6: APO-E-Verteilung Gesamtkohorte 


\subsubsection{Patienten mit langsamem Verlauf}

Die 51 Patienten mit langsamem Verlauf wiesen im Vergleich zur Gesamtkohorte $1 \%$ mehr Allel 2/2 auf, hingegen $4 \%$ weniger 3/3. Das Allel 4/4 trug $1 \%$ mehr, $3 \%$ mehr das Allel 2/4. Das Allel 3/4 trugen $3 \%$ weniger (siehe Abbildung 7).

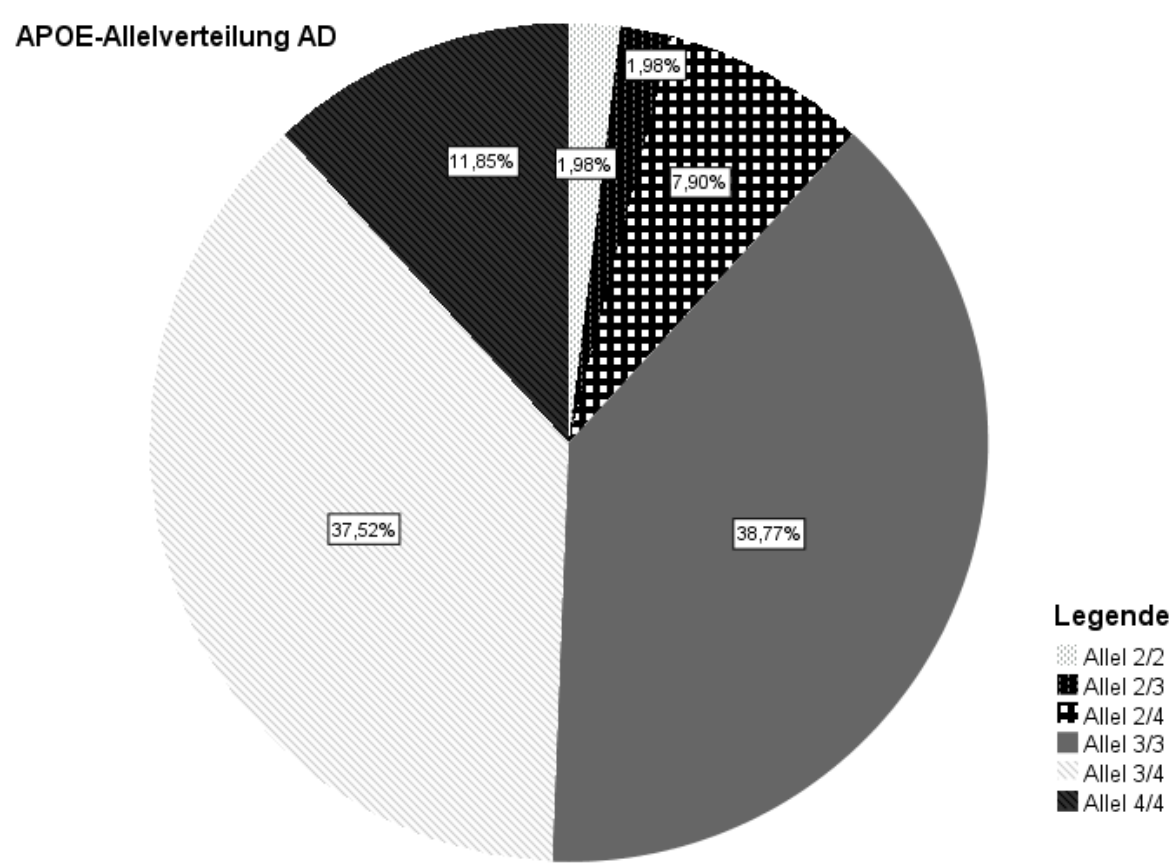

\section{Abbildung 7: APO-E-Verteilung AD-Patienten}

\subsubsection{Patienten mit schnellem Verlauf}

Die 53 Patienten mit schnellem Verlauf wiesen im Vergleich zur Gesamtkohorte kein Allel 2/2 auf. Das Allel 3/3 trugen $3 \%$ mehr, 1 \% weniger das Allel 4/4. Kein Patient trug das Allel 2/2, während hingegen $3 \%$ weniger das Allel 2/4 aufwiesen. Das Allel 3/4 war zu $3 \%$ mehr in der Gruppe mit schnellem Verlauf vorhanden.

Im Vergleich mit den Patienten mit langsamem Verlauf trug kein Patient das Allel 2/2, $7 \%$ mehr das Allel 3/3, $2 \%$ weniger das Allel 4/4. Kein Patient trug das Allel 2/3 und $5 \%$ weniger trugen das Allel 2/4. Das Allel 3/4 trugen $5 \%$ mehr.

Es fällt dabei auf, dass nur $2 \%$ der Patienten in der Kohorte rpAD überhaupt eine AllelKombination mit dem Allel 2 aufwiesen, während es in der Kategorie AD $12 \%$ waren (siehe Abbildung 8). 


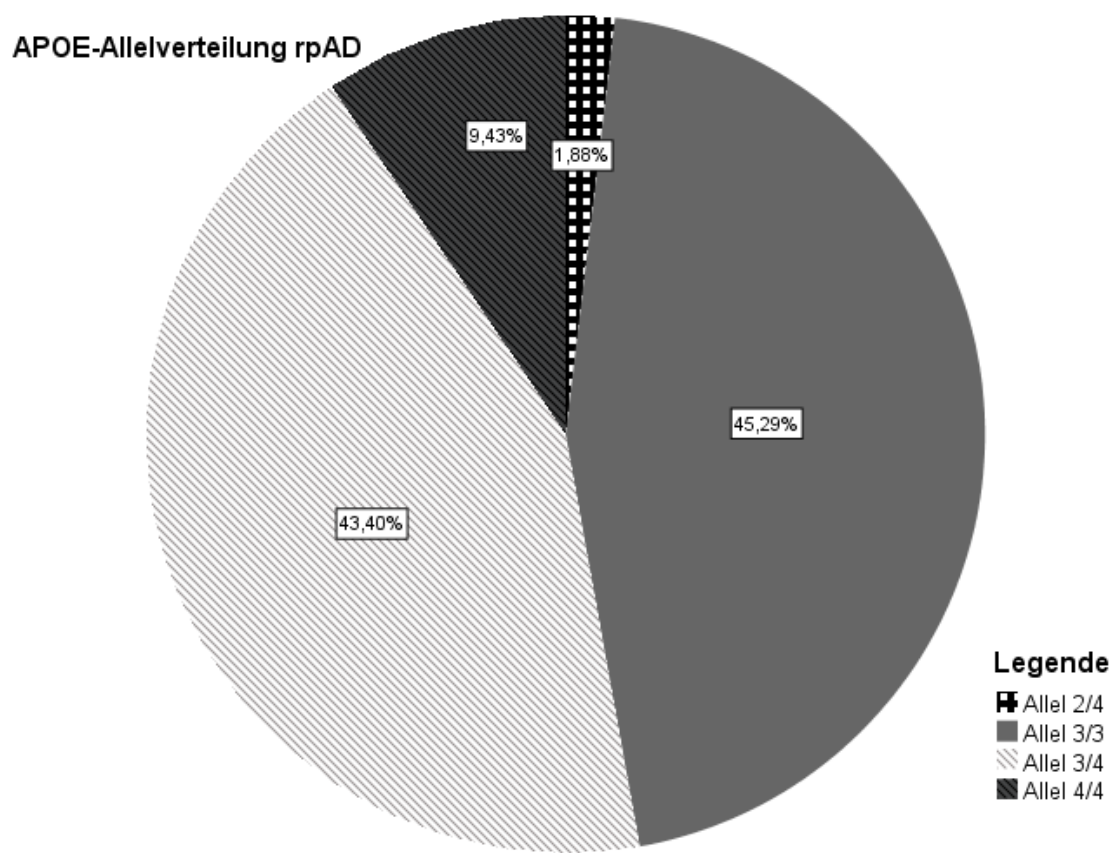

Abbildung 8: APO-E-Verteilung rpAD-Patienten

In Tabelle 35 sind die Ergebnisse zur Übersicht zusammengefasst.

Tabelle 35: APO-E-Verteilung von Patienten der rpAD-Studie

\begin{tabular}{lllllll}
\hline Allel & $\begin{array}{l}\text { Anzahl } \\
\text { insgesamt }\end{array}$ & Anzahl AD & Anzahl rpAD & $\begin{array}{l}\text { Insgesamt } \\
\mathbf{( \% )}\end{array}$ & AD (\%) & rpAD (\%) \\
\hline $\mathbf{2} / \mathbf{2}$ & 1 & 1 & 0 & 0,96 & 1,98 & 0 \\
$\mathbf{3 / 3}$ & 44 & 20 & 24 & 42,31 & 38,77 & 45,29 \\
$\mathbf{4} / \mathbf{4}$ & 11 & 6 & 5 & 10,57 & 11,85 & 9,43 \\
$\mathbf{2} / \mathbf{3}$ & 1 & 1 & 0 & 0,96 & 1,98 & 0 \\
$\mathbf{2 / 4}$ & 5 & 4 & 1 & 4,80 & 7,90 & 1,88 \\
$\mathbf{3 / 4}$ & 42 & 19 & 23 & 40,39 & 37,52 & 43,40 \\
\hline gesamt & 104 & 51 & 53 & 100 & 100 & 100 \\
\hline
\end{tabular}


In Tabelle 36 sind die Häufigkeiten der einzelnen Allele nachzuvollziehen.

Tabelle 36: Häufigkeit der einzelnen Allele in der Studienkohorte

\begin{tabular}{lllllll}
\hline Allel & Gesamtkohorte & AD & rpAD & Insgesamt (\%) & AD (\%) & rpAD (\%) \\
\hline APO-E2 & 8 & 7 & 1 & 3,8 & 6,8 & 0,9 \\
APO-E3 & 131 & 60 & 71 & 62,9 & 58,8 & 55,4 \\
APO-E4 & 69 & 35 & 34 & 33,1 & 34,3 & 32 \\
\hline gesamt & 208 & 208 & & 100 & 100 & 100 \\
\hline
\end{tabular}

In Tabelle 37 sind die Häufigkeiten der APO-E4-Allele nachzuvollziehen.

Tabelle 37: Häufigkeiten der APO-E4-Allele

\begin{tabular}{lllllll}
\hline $\begin{array}{l}\text { APO-E4- } \\
\text { Allele }\end{array}$ & Gesamtkohorte & AD & rpAD & Insgesamt (\%) & AD (\%) & rpAD (\%) \\
\hline 0 & 46 & 22 & 24 & 44,2 & 43,1 & 45,2 \\
1 & 47 & 23 & 24 & 45,1 & 45,0 & 43,3 \\
2 & 11 & 6 & 5 & 10,5 & 9,4 & 11,3 \\
\hline gesamt & 104 & 51 & 53 & 100 & 100 & 100 \\
\hline
\end{tabular}

\subsubsection{APO-E-Verteilung der Diabetes-Patienten}

Da sich der Risikofaktor Diabetes mellitus in unseren Berechnungen signifikant auf den Verlauf der AD auswirkte, wurde die APO-E-Verteilung der Diabetes-Patienten untersucht. Von den zehn Diabetes-Patienten wurde allerdings bei nur acht das APO-E-Allel bestimmt.

Es zeigte sich, dass 12,5\% der Patienten das Allel 3/3 trugen, $25 \%$ das Allel 4/4 und 62,5\% das Allel 3/4 (siehe Tabelle 38). 
Tabelle 38: APO-E-Verteilung der Diabetes-Patienten im Vergleich zu Nicht-DiabetesPatienten

\begin{tabular}{lllll}
\hline Allel & $\begin{array}{l}\text { Anzahl Patienten } \\
\text { Diabetes mellitus }\end{array}$ & $\begin{array}{l}\text { Anteil } \\
\text { Patienten (\%) }\end{array}$ & $\begin{array}{l}\text { Anzahl Patienten kein } \\
\text { Diabetes mellitus }\end{array}$ & $\begin{array}{l}\text { Anteil } \\
\text { Patienten (\%) }\end{array}$ \\
\hline $\mathbf{2} / \mathbf{2}$ & 0 & 0 & 1 & 1 \\
$\mathbf{3 / 3}$ & 1 & 12,5 & 43 & 44,7 \\
$\mathbf{4} / \mathbf{4}$ & 2 & 25 & 9 & 9,3 \\
$\mathbf{2} / 3$ & 0 & 0 & 1 & 1 \\
$\mathbf{2 / 4}$ & 0 & 0 & 5 & 5,2 \\
$\mathbf{3 / 4}$ & 5 & 62,5 & 37 & 38,5 \\
\hline gesamt & 8 & 100 & 96 & 100 \\
\hline
\end{tabular}

\subsubsection{APO-E-Verteilung der KHK-Patienten}

In Tabelle 39 ist die Verteilung der APO-E-Allele der KHK-Patienten nachzuvollziehen. Von einer KHK-Patientin wurde kein APO-E-Status bestimmt.

Tabelle 39: APO-E-Verteilung der KHK im Vergleich zu Nicht-KHK-Patienten

\begin{tabular}{lllll}
\hline Allel & $\begin{array}{l}\text { Anzahl } \\
\text { Patienten } \\
\text { KHK }\end{array}$ & $\begin{array}{l}\text { Anteil } \\
\text { Patienten KHK } \\
\mathbf{( \% )}\end{array}$ & $\begin{array}{l}\text { Anzahl Patienten KHK } \\
\text { kein }\end{array}$ & $\begin{array}{l}\text { Anteil Patienten } \\
\text { KHK (\%) }\end{array}$ \\
\hline $\mathbf{2} / \mathbf{2}$ & 0 & 0 & 1 & 1 \\
$\mathbf{3 / 3}$ & 1 & 25 & 43 & 43 \\
$\mathbf{4} / \mathbf{4}$ & 0 & 0 & 11 & 11 \\
$\mathbf{2} / \mathbf{3}$ & 0 & 0 & 1 & 1 \\
$\mathbf{2} / \mathbf{4}$ & 2 & 50 & 3 & 3 \\
$\mathbf{3 / 4}$ & 1 & 25 & 41 & 41 \\
\hline gesamt & 4 & 100 & 100 & 100 \\
\hline
\end{tabular}




\section{Diskussion}

\subsection{APO-E-Auswertung}

\subsubsection{APO-E4-Verteilung}

Das triallelische APO-E spielt eine wichtige Rolle im Lipidmetabolismus des menschlichen Körpers und ist auch in die Pathogenese der AD involviert (vgl. S. 9).

Das Auftreten mindestens eines APO-E4-Allels im Genom gilt schon seit langem als Risikofaktor für die Entwicklung einer AD. Dies gilt insbesondere für die sporadische LateOnset-AD (Chiappelli et al. 2006; Strittmatter und Roses 1996; Xie und Tanzi 2006).

Das Lebenszeitrisiko eine AD zu entwickeln liegt für Individuen mit zwei Kopien des APO-E4Allels (ca. $2 \%$ der Population) zwischen $50 \%$ und $60 \%$ im Alter von 85 Jahren und für diejenigen mit einer Kopie (25\% der Population) zwischen $23 \%$ und $30 \%$. Im Gegensatz dazu liegt das Lebenszeitrisiko eine $\mathrm{AD}$ zu entwickeln unabhängig des APO-E-Allels lediglich zwischen $11 \%$ und $14 \%$ (Genin et al. 2011). Dabei scheint die Demenz bei Trägern des APO-E4-Allels früher einzusetzen als bei Individuen ohne APO-E4-Allel (Blacker et al. 1997; Gomez-Isla et al. 1996). Auch bei bereits bestehender AD scheint sich die Allelkombination auf die Erkrankung auszuwirken. Cosentino et al. (2008) fanden heraus, dass die Präsenz von mindestens einem APO-E4-Allel mit einem rapideren kognitiven Verfall auch bei schon erkrankten Patienten zusammenhängt.

Die Entwickler der rpAD-Studie legten ein besonderes Augenmerk auf die APO-EGenbestimmung. Im Jahre 2010 lag die APO-E4-Frequenz der rapid progressiven Patienten bei $38 \%$, was im Vergleich zur Allgemeinbevölkerung als niedrig eingestuft wurde. Auffällig dabei war, dass homozygote Patienten in der Gruppe nicht zu finden waren (Schmidt et al. 2010). Dieses Ergebnis deckt sich auf den ersten Blick nicht mit vorher genannten Studienergebnissen, da dort in den Kohorten eine hohe Rate von APO-E4-Trägern zu finden war.

Die erhobenen Daten haben die Studie um einige Patienten vergrößert, sodass erneut eruiert wurde, wie sich die Verteilung der Allele entwickelt hat (vgl. S. 53). In der AD-Gruppe zeigte sich, dass über die Hälfte der Patienten mindestens ein APO-E4-Allel trugen (57,2 \%). Von den AD-Patienten trugen 7,9\% das Allel 2/4, 37,5\% trugen Allel 3/4 und 11,8\% trugen Allel 4/4. Diese Beobachtungen würde eher die Vermutung unterstützen, dass APO-E4 einen wichtigen Risikofaktor für die $\mathrm{AD}$ darstellt und häufiger bei $\mathrm{AD}$-Patienten vorkommt als in der Normalbevölkerung. 
In der rpAD-Gruppe sind es 54,6\% der Patienten, die mindestens ein APO-E4-Allel in sich trugen, was sich nur unwesentlich von der AD-Gruppe unterscheidet. Von den rpAD-Patienten trugen 1,8\% das Allel 2/4, 34,4\% trugen Allel 3/4 und 9,4\% trugen Allel 4/4.

Die von Schmidt et al. (2010) veröffentlichten Ergebnisse zeigten, dass das APO-E4Vorkommen bei rpAD-Patienten niedrig ist. Dies lässt sich mit den Resultaten dieser Dissertation nicht bestätigen. In unserer Kohorte treten im Gegensatz zu Schmidts Patienten auch homozygote Probanden auf. Allerdings wurden die Patienten aus der Studie von 2010 mit anderen Kriterien untersucht. Es wurden 2010 retrospektiv die APO-E-Allele von Patienten betrachtet, deren AD mittels Autopsie gesichert worden war. Die mittlere Überlebenszeit betrug 26 Monate, sie verstarben also zeitnah an der Erkrankung. In der für diese Dissertation untersuchten Kohorte mussten Patienten mindestens zwei Follow-Up-Untersuchungen vorweisen, um in die Berechnungen miteinbezogen zu werden. Patienten, die innerhalb von Monaten bis wenigen Jahren an der Erkrankung verstarben, konnten meist aufgrund von unzureichender neuropsychologischer Testung nicht in die Berechnungen miteinbezogen werden. Bei näherer Betrachtung der Todeszeiten nach Beginn der Demenz ergaben sich in der Kohorte dieser Dissertation drei Patienten, die innerhalb von vier Jahren an der Erkrankung verstarben, von denen keiner das Allel 4/4 trug und einer das 3/4. In der gesamten rpADStudienkohorte fanden sich zehn Patienten, die höchstens vier Jahre mit der Erkrankung lebten. Die APO-E-Allele dieser kleineren Gruppe ähneln nun Schmidts Ergebnissen, es fand sich nur ein Patient mit homozygotem Allel 4/4 (10\%), die anderen trugen die Allele 3/4 (40\%) und 3/3 (50 \%). Bei Betrachtung der Patientendaten mit Schmidts Kriterien (Tod aufgrund AD nach höchstens vier Jahren), können seine Ergebnisse also reproduziert werden.

\subsubsection{APO-E2-Verteilung}

Das APO-E2 hingegen wird als Allel mit neuroprotektivem Effekt angesehen und ist mit einem reduzierten Verfall des episodischen Gedächtnisses vergesellschaftet. Bei Trägern des APO-E2Allels ist das Risiko an einer AD zu erkranken um $50 \%$ reduziert, verglichen mit Trägern des APO-E3-Allels (Benjamin et al. 1994; Conejero-Goldberg et al. 2014; Wilson et al. 2002).

Shinohara et al. (2016) veröffentlichten Ergebnisse einer großen amerikanischen Studie, welche die APO-E-Verteilung von 21.531 Patienten, registriert im „National Aløheimer's Coordinating Center", untersuchte. Im Verlauf wurden Untersuchungen an Mäusen durchgeführt, die menschliches APO-E exprimierten. Die Ergebnisse liefern direkte Beweise dafür, dass das APO-E2-Allel gegen kognitiven Verfall im Alter schützen kann, unabhängig von altersassoziierten synaptischen oder neuroinflammatorischen Veränderungen. Dabei wird 
vermutet, dass der protektive Effekt mit dem APO-E-Cholesterolmetabolismus zusammenhängt.

Auch Serrano-Pozo et al. (2015) untersuchten die Assoziation zwischen den APO-E-Allelen und intracerebralen Läsionen der AD-Pathologie in einer Autopsie-Kohorte mittels großer multizentrischer Studie. Verglichen mit APO-E 3/3 Trägern zeigte sich, dass Träger von APO-E2 niedrigere Levels von neurofibrillären tangles und weniger neuritischen Plaques im Hirngewebe aufwiesen. Um die Auswirkung von APO-E2- und APO-E4-Allelen auf den Schweregrad der pathologischen Läsionen zu untersuchen, wurden multivariable Modelle angewandt, die alle drei AD-typischen Läsionen und die Parameter Todesalter, Geschlecht, Bildung und Symptomdauer beinhalteten. Die Allelkombination 3/3 wurde stets als Referenz genutzt. Verglichen mit dem häufig vorkommenden APO-E 3/3 sind Träger des APO-E4Allels dem Risiko ausgesetzt eine stärkere klinische Ausprägung der AD zu entwickeln. Diese beinhaltet einen frühen Beginn der Erkrankung und eine schlechtere Kognition bis zum Tod. Träger des APO-E2-Allels neigen dazu, eine klinisch und pathologisch mildere Form der Erkrankung zu entwickeln.

In der rpAD-Studienkohorte entsprach die untersuchte Allelverteilung nicht den erwarteten Werten, da sich die Gruppen AD und rpAD nicht bedeutend in der APO-E4-Allelverteilung voneinander unterschieden. Hingegen ließ sich bei Beobachtung der Verteilung des APO-E2Allels ein interessanter Trend erkennen.

In der Gruppe AD ließen sich 11,7\% der Patienten mit mindestens einem APO-E2-Allel finden. Jeweils $1,9 \%$ hatten $2 / 2$ und $2 / 3$ und $7,9 \%$ besaßen das Allel 2/4.

In der rpAD-Gruppe trugen nur 1,8\% der Patienten das Allel 2/4. Allel 2/2 und Allel 2/3 kamen in dieser Kohorte nicht vor. Unter den 53 Patienten der rpAD-Gruppe kam also insgesamt nur ein Patient vor, der ein APO-E2-Allel in sich trug.

Eine Erklärungshypothese ist, dass der rapide Verlauf der AD nicht durch ein besonders hohes Vorkommen des APO-E4-Allels zu erklären ist, sondern möglicherweise durch ein Fehlen des als protektiv geltenden APO-E2-Allels. Dies könnte dazu führen, dass sich der Verlauf verschlimmert und die Patienten einen rapideren Abfall der Gedächtnisleistung zeigen. Es scheint nicht die gefährdende Rolle des APO-E4-Allels auf die Amyloidakkumulation eine Rolle zu spielen, sondern der fehlende bereinigende Effekt des APO-E2. Das Tragen eines APO-E2Allels kann zwar durch viele andere Faktoren auch zu einer AD führen, äußert sich dann aber in einem milderen Verlauf. Besonders auffällig ist das Fehlen von Allel 2/2 in der Studienkohorte, da sich bei dieser Allelkombination ein starker Schutz gegen pathologische Faktoren ergeben müsste. 
Da sich die Erkrankung Diabetes mellitus nach den Ergebnissen dieser Arbeit auf den Verlauf der AD auswirkt, wurde die APO-E4-Verteilung der Diabetes-Patienten genauer untersucht, um mögliche Zusammenhänge zwischen der Allelverteilung und dem möglichen protektiven Effekt der Erkrankung zu detektieren (vgl. S. 56). Von den acht bestimmten APO-E-Allelen der Patienten mit Diabetes mellitus zeigte keiner von ihnen ein APO-E2 in der Allelkombination, sodass sich ein Zusammenhang nicht bestätigen lässt. Diese Untersuchung müsste in einer größeren Patientengruppe wiederholt werden, um eine valide Aussage treffen zu können.

Die Theorie des schützenden APO-E2-Allels könnte sich bei weiterer Überprüfung zu einem möglichen Therapieansatz entwickeln. Zhao et al. (2016) veröffentlichten bereits Ergebnisse einer Studie, die sich ebenfalls den neuroprotektiven Effekt des intracerebralen APO-E2 zu Nutze machte.

\subsection{Kardiovaskuläre Risikofaktoren}

Die Ergebnisse vieler Studien sprechen für eine Assoziation zwischen AD und kardiovaskulären Risikofaktoren, die Vorhofflimmern, thromboembolische Ereignisse, Bluthochdruck, Herzinsuffizienz, KHK, das Vorliegen von APO-E4-Allelen und einige Weitere beinhalten (de la Torre 2012). Daher war es für diese Arbeit ebenfalls von Interesse, die kardiovaskulären Risikofaktoren in der beschriebenen Studienkohorte zu erheben.

Der Altersstruktur der Studienkohorte geschuldet, wiesen die Patienten zum Großteil kardiovaskuläre Risikofaktoren auf. Es zeigte sich bereits in einer anderen Studie, dass Patienten mit AD und einzelnen kardiovaskulären Risikofaktoren Nachteile in Bezug auf die kognitive Funktion zeigten. So fanden beispielsweise Helzner et al. (2009) heraus, dass höhere Cholesterol- und Low-Density-Lipoprotein (LDL)-Konzentrationen im Blut und eine Erkrankung mit Diabetes mellitus mit einem rapideren kognitiven Verfall bei Patienten mit AD assoziiert war.

Dass kardiovaskuläre Risikofaktoren und Erkrankungen häufig im Alter auftreten, ist ebenfalls an dieser Kohorte zu erkennen (vgl. S. 37). Die ungewöhnlich hohe Anzahl der Patienten mit Hyperlipoproteinämie ist unter anderem dadurch zu erklären, dass die Daten darüber lediglich anamnestisch erhoben wurden. Ein laborchemischer Grenzwert ist nicht festgelegt worden.

In der Kohorte zeigten die Variablen KHK und Diabetes mellitus signifikante Ergebnisse im p-Wert des Chi-Quadrat-Tests und des exakten Tests nach Fisher. Die beiden Erkrankungen werden in den folgenden Kapiteln genauer betrachtet. 
In anderen Untersuchungen wirkte sich bei Patienten mit AD die Behandlung von vaskulären Risikofaktoren günstig auf den Abfall im MMSE aus, sodass es sich als sinnvoll erweisen würde kardiovaskuläre Risikofaktoren bei Demenzpatienten zu behandeln (Deschaintre et al. 2009; Laukka et al. 2010).

In dem Review von Luchsinger und Mayeux (2004) wird deutlich, dass eine optimale Behandlung von kardiovaskulären Risikofaktoren wie Diabetes mellitus, Hyperlipidämie und Bluthochdruck im Alter sinnvoll ist, um Herzkreislauferkrankungen und Schlaganfällen vorzubeugen. Es wird empfohlen die Behandlung weiterzuführen, da zusätzlich ein günstiger Effekt auf die AD vermutet wird. Dabei unterscheidet sich Luchsingers Fragestellung allerdings von der unseren, da er die Auswirkung kardiovaskulärer Risikofaktoren vor Manifestation einer AD untersucht, während in dieser Dissertation untersucht wurde, wie sich Risikofaktoren auf eine bereits bestehende AD auswirkten.

Aufgrund der Häufigkeit kardiovaskulärer Risikofaktoren im Alter, wie sie auch erwartungsgemäß in dieser Kohorte zu finden ist, wäre es angemessen diese Entwicklung weiterhin zu beobachten und Therapiemöglichkeiten zu optimieren. Eine optimale Therapie der kardiovaskulären Risikofaktoren würde die AD-Patienten ebenfalls unterstützen.

\subsubsection{Diabetes mellitus}

Es waren zehn Patienten an Diabetes mellitus erkrankt, was 11,2\% der Gesamtkohorte entspricht (vgl. S. 37). Wie aus epidemiologischen Daten des Robert Koch-Instituts zur Prävalenz des Diabetes mellitus hervorgeht, sind 7,2 \% der Erwachsenen (4,6 Millionen) in Deutschland im Alter von 18 bis 79 Jahren von Diabetes mellitus betroffen (Heidemann und Scheidt-Nave 2017). Es zeigte sich, dass im Patientenkollektiv der rpAD-Studie Diabetes mellitus ebenfalls eine häufige Erkrankung des Alters darstellt.

Es wird vermutet, dass der Diabetes mellitus vor allem bei AD-Patienten gehäuft auftritt. In einer amerikanischen Studie wurde untersucht, wie häufig Diabetes mellitus Typ 2 oder eine gestörte Nüchternglukose bei AD-Patienten $\mathrm{zu}$ finden waren. Dies wurde mit einer Kontrollgruppe aus Nicht-AD-Patienten verglichen. In der Kohorte zeigte sich ein Diabetes mellitus Typ 2 und eine erhöhte Nüchternglukose deutlich häufiger bei Patienten mit AD. 34 \% der AD-Gruppe wiesen einen Diabetes mellitus Typ 2 auf, während es in der Kontrollgruppe mit Nicht-AD-Patienten nur 18,1 \% waren (Janson et al. 2004).

Die Daten der hier vorliegenden Arbeit zeigen einen höheren Anteil an Diabetikern unter den AD-Patienten, als es die epidemiologischen Zahlen erwarten lassen. Anhand der Berechnungen wird ersichtlich, dass der Diabetes mellitus den Krankheitsprogress protektiv zu beeinflussen 
scheint und zu einem milderen Verlauf führt. AD-Patienten, die gleichzeitig an Diabetes mellitus leiden, zeigten einen langsameren Abfall im MMSE als Patienten ohne Diabetes mellitus. Nur zwei von zehn Diabetikern konnten in die Gruppe rpAD eingeordnet werden.

Es zeigte sich, dass sieben der acht Diabetes-Patienten mindestens ein APO-E4-Allel in sich trugen (87,5\%), zwei der Patienten trugen das Allel 4/4 (25\%). In einer Dissertation aus dem Jahre 2011 der Universität Regensburg wurde ebenfalls die Verteilung von APO-E-Allelen bei Diabetikern mit Demenz untersucht, wobei eine größere Kohorte betrachtet wurde, ohne dabei zwischen den Demenzen zu unterscheiden (Zintl 2011). In der von Zintl untersuchten Kohorte trugen 7,1\% das Allel 4/4 und 45,2\% mindestens ein APO-E4-Allel in sich, was ebenfalls für ein hohes Vorkommen von APO-E4-Allelen spricht.

Patienten mit APO-E4-Allel haben nach einer aktuellen Studie ein höheres Risiko an Diabetes mellitus zu erkranken (Liu et al. 2019). Da auch das APO-E4-Allel ein Risikofaktor für die AD darstellt, ist durch diesen Effekt möglicherweise die hohe Anzahl an Diabetes-Patienten in der AD-Studienkohorte zu erklären.

Wie bereits in Kapitel 4.1.1 (vgl. S. 58) erwähnt, scheint das APO-E4-Allel bei bereits bestehender AD einen kognitiv rapiden Verfall zu begünstigen, was den Ergebnissen dieser Studie widerspricht (Cosentino et al. 2008). Es ist vermutlich in diesem Zusammenhang eher an der Entstehung der AD als an der Verbesserung der Gedächtnisleistung beteiligt (Chiappelli et al. 2006; Strittmatter und Roses 1996; Xie und Tanzi 2006). Keiner der Patienten trug ein APO-E2-Allel in sich, sodass die vorher aufgestellte Hypothese über einen protektiven Effekt des APO-E2-Allels ebenfalls nicht zur Erklärung des langsamen Verlaufs der DiabetesPatienten führen kann.

Ascher-Svanum et al. (2015) befassten sich mit einer ähnlichen Thematik. Es wurden innerhalb eines Zeitraums von 18 Monaten die Daten von Patienten mit einer milden AD mit und ohne Diabetes mellitus als Komorbidität verglichen. Eine milde AD wurde mit einem MMSE von 20 bis 26 Punkten festgelegt und die Gedächtnisleistung mittels MMSE und „Alø̧heimer's disease assessment scale - cognitive subscale، (ADAS-Cog14) ermittelt. Von den 972 eingeschlossenen Patienten wiesen 113 von ihnen zusätzlich einen Diabetes mellitus auf. Das entspricht 11,6 \% der Gesamtkohorte.

Die beiden Gruppen in Ascher-Svanums Studie unterschieden sich bezogen auf Bildungsjahre, Substanzkonsum (Alkohol, Kaffee, Tabak), APO-E-Trägerstatus, Arbeitsstatus und der Zeit seit AD-Diagnose nicht signifikant, was viele mögliche Störvariablen ausschließt. In den Untersuchungen für diese Dissertation wurden ebenfalls die Variablen „Alter“, „Geschlecht“ und „Bildungsgrad“ in die Regressionen aufgenommen und ihr Einfluss auf die Ergebnisse 
untersucht. In der Studie von 2015 zeigten die Patienten mit Diabetes mellitus und AD nach 18 Monaten einen nummerisch niedrigeren kognitiven Abfall im MMSE, was allerdings keine statistische Signifikanz erreichte. Der funktionelle Abfall erwies sich allerdings als statistisch signifikant. Patienten mit Diabetes mellitus und AD hatten einen besseren Outcome als Patienten mit $\mathrm{AD}$ ohne Diabetes mellitus. In den Berechnungen für die rpAD-Studie konnte mit einem $\mathrm{p}$-Wert $=0,001$ der statische Zusammenhang zwischen Diabetes mellitus und dem MMSE-Wert gezeigt werden. Aus den Ergebnissen der linearen Regression ist zu entnehmen, dass Patienten mit Diabetes mellitus einen langsameren Gedächtnisabfall aufwiesen (vgl. S. 40). Sanz et al. (2009) untersuchten 608 Patienten mit AD (MMSE-Testergebnis 10 bis 26 Punkte), die in eine prospektive multizentrische Studie eingeschlossen wurden. Es wurde zu Beginn nach Diabetes mellitus oder Diabetesmedikation gefragt und die kognitive Funktion wie in der rpADStudie halbjährlich mittels MMSE kontrolliert. 10,4\% (63) der Patienten litten an Diabetes mellitus. In einem gemischten Modell adjustiert auf Alter, Geschlecht, Bildung, Medikamente und kardiovaskuläre Risikofaktoren ergab sich kein Unterschied in den Gruppen bezüglich des MMSE-Baseline-Wertes. Jedoch zeigte sich ein im Vergleich langsamer kognitiver Verfall der Gruppe mit Diabetes mellitus, was sich ebenfalls mit den Ergebnissen dieser Arbeit deckt (Dominguez et al. 2012).

So zeigen sich trotz kleiner Kohorte der rpAD-Studie ähnliche Ergebnisse mit den eben genannten Berechnungen. Dies deutet daraufhin, dass es sich bei der in dieser Dissertation untersuchten Kohorte um ein repräsentatives Patientenkollektiv handelt.

Gherib (2016) entdeckte im Rahmen der gleichen Forschungsgruppe, in der auch diese Arbeit verfasst wurde, dass Diabetiker im Vergleich zu Patienten ohne Diabetes mellitus im Durchschnitt bessere MMSE-Werte erzielten. Die statistische Betrachtung ist jedoch nur deskriptiv erfolgt. Da die erwähnte Dissertation ebenfalls im Rahmen der rpAD-Studie verfasst wurde, ist es nicht ungewöhnlich, dass sich dieser Trend so fortsetzt. Jedoch wurde das Ergebnis in den Berechnungen für diese Arbeit durch Aufnahmen der Variablen „Alter“, „Geschlecht“, „Bildungsgrad“ und „MMSE-Baseline-Wert“ in die Regression detaillierter betrachtet.

Es bleibt die Frage, welche der vielen möglichen Faktoren den Verlauf verlangsamen beziehungsweise den Verfallsprozess aufhalten. Möglicherweise wurde dieses Ergebnis errechnet, weil eine Vorselektion der rpAD-Patienten durch die Einschlusskriterien stattfand. Es galt alle Patienten, die schon bei Einschluss eine Mischdemenz zeigten, aus der Studie auszuschließen. Somit sind in den Berechnungen nur Patienten mit reiner AD berücksichtigt worden. Die Risikofaktoren der Patienten mit Mischdemenz könnten sich bedeutend von jenen mit reiner AD unterscheiden, sodass die Ergebnisse dieser Arbeit nicht reproduzierbar wären. 
Einen weiteren Faktor könnte die Diabetesmedikation darstellen, die nachweislich verschiedene Effekte auf den Glukosestoffwechsel im Gehirn hat. Nach Durchführung zahlreicher Studien zu den molekularen Gemeinsamkeiten zwischen der AD und dem Diabetes mellitus ergab sich die Hypothese, dass sich aufgrund der Nutzung gleicher Stoffwechselwege eine Behandlung des Diabetes mellitus günstig auf die AD auswirken könnte (Kandimalla et al. 2017).

Schon 1994 wurde vermutet, dass synaptische Dysfunktionen mit einem erniedrigten Glukoseverbrauch in Cortex und Hippocampus vergesellschaftet waren. Fukuyama et al. (1994) zeigten mittels PET-Aufnahmen einen bis zu $45 \%$ erniedrigten Glukoseverbrauch bei ADPatienten im Gegensatz zur Kontrollgruppe.

In einem Review von 2014 wurde beschrieben, wie die löslichen Amyloid- $\beta$-Oligomere im Rahmen einer AD Insulinsignalwege im Gehirn mittels proinflammatorischer Signale stören. Es ergaben sich auch Ähnlichkeiten zwischen den biochemischen Veränderungen im Gehirn und denen, die im peripheren Gewebe bei einem Diabetes mellitus entstehen (De Felice et al. 2014).

Karki et al. (2017) untersuchten ebenfalls verschiedene Signalwege im Gehirn, unter anderem den PI3K/AKT-Signalweg, den Mammalian-Target-Of-Rapamycin (MTOR)-Signalweg und den Neurotrophin-Signalweg. Sie stellten die Vermutung auf, dass es Signalwege gibt, die sowohl in der Diabetes mellitus- als auch in der AD-Pathogenese eine Rolle spielen. Die beiden Erkrankungen sind also durch verschiedene überkreuzende Signalwege verbunden. Es handelt sich um Signalwege von Entzündungsmediatoren und Verursachern von oxidativem Stress, die gleichermaßen bei Diabetes mellitus, Adipositas und AD beobachtet wurden (Pugazhenthi et al. 2017).

Aufgrund der sich ähnelnden molekularen und zellulären Reaktionen, den gemeinsamen Signalwegen und pathophysiologischen Veränderungen wurde die Bezeichnung der AD als Diabetes mellitus Typ 3 diskutiert, um die Verbindung zwischen beiden Erkrankungen zu verdeutlichen (Kandimalla et al. 2017). Kritiker sprechen sich allerdings aufgrund der fehlenden Hyperglykämie im Liquor dagegen aus, da somit eines der Hauptkriterien für eine Diabeteserkrankung nicht erfüllt wäre (Talbot und Wang 2014).

Unter Berücksichtigung der genannten Studienergebnisse wäre es möglich, dass durch eine Behandlung des Diabetes mellitus auch Signalwege günstig beeinflusst werden, die in der ADPathogenese eine Rolle spielen.

In einer Studie der Universitätsklinik Bonn wurden 250.000 Patienten mit und ohne Diabetes mellitus Typ 2 untersucht, um das Risiko an einer Demenz zu erkranken zu erfassen. Im Falle einer Erkrankung mit Diabetes mellitus wurden ebenfalls die Medikamente dokumentiert und 
ihre Wirkung auf die AD untersucht. Es handelte sich um verschiedene Medikamente, bei denen ein besonderes Augenmerk auf das Medikament Pioglitazon gelegt wurde. Es zeigte sich hierbei unter anderem ein bedeutend geringeres Risiko an einer AD zu erkranken, falls Patienten mit Diabetes mellitus eine Langzeitbehandlung mit diesem oralen Antidiabetikum erhielten (Heneka et al. 2015). Zwar können wir mit den Berechnungen unserer Studie nicht darauf schließen, was das Risiko beeinflusst an einer Demenz zu erkranken, jedoch ergibt sich im Zusammenhang mit unseren Ergebnissen die Vermutung, dass die Diabetesmedikation auch im Verlauf der AD noch positive Auswirkung auf die neurokognitiven Leistungen haben könnte.

Auch in einem systematischen Review von 2018 stellt sich in einer Meta-Analyse heraus, dass höheres Alter, Medikamenteneinnahme und auch Diabetes protektive Faktoren für den Verlauf einer AD darstellen. Patienten mit Diabetes zeigten einen langsameren kognitiven Verfall. Bei AD-Patienten führte eine Komorbidität mit Diabetes zu einem zwischen $64 \%$ und $73 \%$ erniedrigtem Risiko für kognitiven Verfall (Song et al. 2018).

Die Medikation konnte in der rpAD-Studie nur unvollständig erfasst werden. So wurde bei den betroffenen Patienten bereits viele Jahre im Voraus eine Diabetesbehandlung initiiert, mutmaßlich auch mit wechselnder Medikation. Um einen möglichen Zusammenhang genauer zu eruieren, wäre eine Studie vonnöten, welche die einzelnen Medikamente mit Dosis und Zeiträumen bei den AD-Patienten genau dokumentiert und je nach Präparat auf Unterschiede im Outcome der Demenz untersucht. Des Weiteren wäre es sinnvoll, bei allen eingeschlossenen Patienten eine Nüchternglukosemessung durchzuführen, um eventuell nicht diagnostizierte Patienten zu entdecken.

\subsubsection{KHK}

Von den Patienten der untersuchten Kohorte litten 5,5\% an einer KHK. Alle fünf Patienten sind weiblich und lassen sich aufgrund ihrer MMSE-Ergebnisse in die Kategorie AD einordnen. In der logistischen Regression ergab sich ein signifikanter Einfluss der Erkrankung KHK auf den Verlauf der AD (p-Wert der logistischen Regression=0,023). Mittels Schätzer konnte eruiert werden, dass AD-Patienten mit einer KHK als Komorbidität dazu neigen in die langsam progressive Gruppe eingeordnet zu werden. Die Erkrankung scheint sich protektiv auf den Gedächtnisverfall auszuwirken.

Verglichen mit den Ergebnissen dieser Dissertation zeigen aktuelle Studien bisher gegensätzliche Ergebnisse. Aus der Meta-Analyse von Deckers et al. (2017) wird ein durch eine KHK bedingtes höheres Risiko ersichtlich, im Alter an kognitiven Einschränkungen oder einer 
Demenz zu leiden. Sie wird als wichtiger Risikofaktor für die Entstehung einer AD angesehen. Bei bereits bestehender Erkrankung zeigte eine Studie von Bleckwenn et al. (2017), dass die Erkrankung KHK einen signifikanten Einfluss auf den kognitiven Verfall bei älteren Patienten mit Late-Onset-AD nimmt. Dabei wurde der Gedächtnisverfall der Patienten alle sechs Monate mittels MMSE überprüft. Bei AD-Patienten ohne KHK betrug der MMSE-Verlust pro Jahr etwa 1,5 Punkte, während bei einer Komorbidität mit KHK der Verlust um $66 \%$ auf 2,5 Punkte pro Jahr anstieg.

In einer aktuellen Studie von Lin et al. (2019) konnte eine genetische Überlappung zwischen der AD und vaskulären Pathologien, vor allem durch das APO-E-Gen, gezeigt werden. APO-E ist neben der Rolle eines der Hauptrisikofaktoren für $\mathrm{AD}$ auch an der Entwicklung von Hyperlipoproteinämie sowie Artherosklerose beteiligt (Tai et al. 2016; Huang und Mahley 2014). Es wurden 5161 ältere Patienten untersucht, wobei als Einschlusskriterium in die Studie galt, dass keiner von ihnen bereits einen Schlaganfall erlitten haben durfte. Dabei wurden eine hohe Anzahl cerebraler Mikroblutungen, Hyperintensitäten der weißen Substanz und vermehrte Koronarsklerose mit schlechten Ergebnissen in Gedächtnistests und der globalen Kognition in Zusammenhang gebracht (Lin et al. 2019).

Bisher lassen die Ergebnisse aus vorherigen Untersuchungen vermuten, dass sich eine KHK eher ungünstig auf den Gedächtnisverfall im Rahmen einer AD auswirkt. Es ergibt sich die Frage, weshalb alle KHK-Patienten in der rpAD-Kohorte einen langsameren Verfall ihrer Gedächtnisleistung aufweisen. Bleckwenn et al. (2017) stellten die Vermutung auf, dass sich eine optimale Behandlung der kardiovaskulären Risikofaktoren auch protektiv auf die AD auswirken könnte. Auch andere Autoren verweisen auf den Profit der AD-Patienten durch Behandlung der kardiovaskulären Vorerkrankungen (Luchsinger und Mayeux 2004). Einige Medikamentenstudien brachten Ergebnisse hervor, die Verbesserungen der kognitiven Leistung mit Medikamenteneinnahmen in Zusammenhang brachten. Dazu zählten vor allem im Rahmen der KHK eingesetzte Antihypertensiva und Statine, welche beide zur Therapie bei KHK-Patienten eingesetzt werden.

Eine Meta-Analyse zeigte bei Statineinnahme ein signifikant niedrigeres Risiko an einer Demenz zu erkranken, allerdings konnte die Hoffnung mittels Statintherapie eine verbesserte kognitive Leistung bei AD zu erzielen nicht erfüllt werden (Poly et al. 2020; Mejias-Trueba et al. 2018).

Ziel einer Studie von 2009 war die Bewertung des Einflusses einer antihypertensiven Therapie auf die kognitive Funktion bei Patienten mit einer bereits bestehenden AD. Von den untersuchten AD-Patienten erhielten 54\% eine antihypertensive Therapie mit verschiedenen 
Präparaten, die Diuretika, $\beta$-Blocker, ACE-Hemmer, Calciumkanalblocker und Angiotensinrezeptorblockern beinhalteten. Hierbei zeigte sich ein geringerer kognitiver Zerfall bei Patienten mit medikamentöser antihypertensiver Behandlung im Vergleich zu jenen, deren Hypertonus nicht medikamentös eingestellt war (Duron et al. 2009).

Bei den in die rpAD-Studie aufgenommenen Patienten wurden keine exakten Daten zum Medikamentenverbrauch oder Therapiemaßnahmen zu einzelnen Risikofaktoren dokumentiert, sodass nicht nachzuvollziehen ist, ob die KHK-Patienten leitliniengerecht behandelt worden sind oder welche Medikamente sie einnahmen. Wenn davon ausgegangen wird, dass die KHKPatienten mit ihrer kardiovaskulären Erkrankung in regelmäßiger Behandlung und medikamentös gut eingestellt waren, lässt sich durch den möglicherweise protektiven Effekt der Pharmaka das Ergebnis erklären. Für eine genauere Untersuchung dieses Zusammenhangs wäre wie bei den Diabetes-Patienten eine genauere Dokumentation der medikamentösen Therapie vonnöten.

Ein weiterer Faktor in Bezug auf diesen Risikofaktor könnte der APO-E-Status darstellen. Es wurden die APO-E-Allele von vier der fünf KHK-Patientinnen bestimmt. Dabei ist auffällig, dass zwei von ihnen das Allel 2/4 (50 \%) trugen. Dieses Allel kam lediglich fünf Mal insgesamt in der für diese Dissertation untersuchte Kohorte vor. Keiner von ihnen trug das Allel 4/4, während $75 \%$ von ihnen ein APO-E4-Allel aufwiesen. Wie schon in Kapitel 4.1 erwähnt, gilt das APO-E4-Allel als Risikofaktor für eine AD, was sich in der hohen Anzahl der APO-E4Träger unter den KHK-Patientinnen widerspiegelt. Allerdings sind speziell in dieser Risikogruppe zwei Patienten mit einem APO-E2-Allel zu finden, was einem Drittel der Patienten in der Gruppe AD entspricht, die ein APO-E2-Allel in sich trugen. Die Vermutung, dass das APO-E2-Allel die bestehende Erkrankung möglicherweise protektiv beeinflusst, lässt sich in diesem Zusammenhang eventuell stützen. Dieser mögliche Zusammenhang sollte erneut mit einer größeren Patientenanzahl überprüft werden.

$\mathrm{Da}$ alle fünf KHK Patienten weiblichen Geschlechts waren, sind fragliche Geschlechtsunterschiede zwischen den AD-Patienten in Betracht zu ziehen. In einer retrospektiven Kohortenstudie wurden geschlechtsspezifische Untersuchungen bei $\mathrm{AD}$ Patienten mit dem Ergebnis durchgeführt, dass die Prävalenz und Inzidenz von AD bei Frauen höher ist, während Männer eine höhere Mortalität aufwiesen. Die Einjahres-Mortalität betrug $17 \%$ für Frauen und $31 \%$ für Männer. Frauen wiesen weniger Komorbiditäten, Medikamenteneinnahmen und Krankenhausaufenthalte auf, worauf ihr Überlebensvorteil möglicherweise zurückgeführt werden kann (Gambassi et al. 1999). Durch diese Beobachtung 
lässt sich möglicherweise die Tatsache erklären, dass in der KHK Gruppe nur Frauen zu finden sind. Diese überleben die Erkrankung länger.

\subsubsection{KHK und Diabetes mellitus als Komorbiditäten}

Nach Durchführung der linearen und logistischen Regressionen mit den signifikanten Ergebnissen von KHK und Diabetes mellitus zeigte sich ein langsamerer Verlauf der AD bei Patienten mit diesen Komorbiditäten. Es stellt sich die Frage, inwiefern die beiden Erkrankungen zusammenhängen und ob sich ein synergistischer Effekt auf die Gedächtnisleistung zeigt, wenn Patienten an beiden Risikofaktoren erkrankt sind.

Die rpAD-Studienkohorte, die als Auswertungsgrundlage dieser Dissertation diente, enthielt drei Patienten, die sowohl KHK als auch Diabetes mellitus als Komorbidität aufwiesen. Allesamt waren weiblich und in die Gruppe AD (langsamer Verlauf) eingeordnet. Die Patientinnen trugen die APO-E-Allele 3/4 und 3/3, bei einer Patientin wurde kein APO-EAllel bestimmt. Nach Anwendung einer logistischen Regression, in der sowohl Diabetes mellitus als auch KHK als Kovariablen einflossen, konnte sich die Vermutung über einen Zusammenhang nicht bestätigen ( $\mathrm{p}$-Wert $\mathrm{KHK}=0,144$, $\mathrm{p}$-Wert Diabetes=0,134). Es wurde ein signifikanter Einfluss durch die Variablen Achsenabschnitt $(p=0,014)$ und MMSE-BaselineWert ( $\mathrm{p}=0,035)$ auf die Risikofaktoren ausgeübt.

Eine aktuelle Studie zeigt, dass eine erhöhte Frequenz von APO-E 3/4 in Diabetes-Patienten mit KHK zu finden waren. Dabei war das Vorkommen des APO-E4-Allels bei KHK-Patienten ohne Diabetes mellitus und bei Diabetes-Patienten mit KHK höher als in den Kontrollgruppen. APO-E4 gilt als unabhängiger Risikofaktor sowohl für Diabetes mellitus Typ 2, als auch für KHK (Liu et al. 2019). Eine Patientin der rpAD-Studie trug das Allel 3/4, was sich mit den Studienergebnissen von Liu et al. deckt. Jedoch sollte dieser Zusammenhang in einer größeren Studienkohorte erneut untersucht werden, um eine valide Aussage treffen zu können.

Dass sich ein möglicher synergistischer Effekt der beiden Erkrankungen auf die Gedächtnisleistung nicht zu beobachten war, lässt sich möglicherweise durch die Ergebnisse einer Studie aus 2015 erklären. Aubert et al. (2015) testeten an einer retrospektiven Studienkohorte von AD-Patienten über 65 Jahren den Einfluss von Komorbiditäten auf die Gedächtnisleistung mittels „Charlson comorbidity index“ (CCI), einem Test zur Erfassung von Komorbiditäten und Korrelation zur Morbidität. Dabei ergab eine Multimorbidität einen rapiden kognitiven Verfall bei den AD-Patienten durch eine direkte Korrelation der Ergebnisse des Komorbiditätstests mit dem Gedächtnisabfall. Durch die Erkrankung an mehreren 
kardiovaskulären Risikofaktoren könnte sich der bereits diskutierte protektive Effekt der einzelnen Pathologien aufheben.

Es lässt sich anhand der Regression erkennen, dass Patienten mit beiden Risikofaktoren weiterhin in Richtung des langsameren Verlaufs tendieren, dieses Ergebnis ist jedoch nicht signifikant. Dies spricht möglicherweise für einen unabhängigen Effekt von KHK und Diabetes mellitus auf die Gedächtnisleistung der Patienten, wenn potentielle Einflüsse von APO-E, Geschlecht und Komorbiditäten miteinbezogen werden.

\subsection{Malignome}

In der untersuchten Kohorte litten 6,6\% aller Patienten an einer Krebserkrankung (sechs Patienten; vgl. S. 44). Es gestaltete sich als schwierig, die rpAD-Studienkohorte mit den Werten der Allgemeinbevölkerung zu vergleichen, da es sich bei diesem speziellen Risikofaktor um eine sehr kleine Gruppe handelte und die Patienten vorselektiert waren.

Die Ergebnisse zeigten mit einem p-Wert $=0,79$ im Chi-Quadrat-Test und p-Wert $=1,0 \mathrm{im}$ exakten Test nach Fisher keine Auswirkung auf den Verlauf einer AD bei Vorliegen einer Krebsanamnese (vgl. S. 45). Die Analyse wurde dahingehend vertieft, dass in der Kohorte die drei vorhandenen Krebserkrankungen näher mittels Gruppenvergleich untersucht wurden. Es handelte sich um gastrointestinale Tumoren, Mamma-Karzinome und Malignome der Nieren. Dabei ergab sich, dass sich auch die einzelnen Untergruppen nicht auf den Verlauf der AD auswirkten, was aufgrund der kleinen Patientenanzahl erneut getestet werden müsste. Bei einer erneuten Kontrolle der Ergebnisse wäre es auch sinnvoll nähere Daten zu den Krebserkrankungen zu erheben wie die Art des Tumors (Histologie), die Behandlung (Chemotherapie, Operation, Strahlentherapie etc.) und die Zeitspanne zwischen Krebserkrankung und Beginn der AD.

In einer prospektiven Studie von 2010 wurde ebenfalls der Zusammenhang zwischen Krebserkrankung und AD untersucht (Roe et al. 2010). Dabei wurde analysiert, ob eine bestehende Demenz mit einer zukünftigen Krebserkrankung assoziiert ist. Umgekehrt wurde auch untersucht, ob eine bestehende Krebserkrankung ein höheres Risiko für die Entwicklung einer AD darstellt. In der rpAD-Studie erhoben wir retrospektiv, ob die AD-Patienten an einer Krebserkrankung litten oder leiden.

Roe et al. (2010) testeten, ob eine AD-Diagnose im Gegensatz zu keiner AD-Diagnose die Zeit zwischen Aufnahme in die Studie und Hospitalisierung wegen Krebs beeinflusst. Die Ergebnisse wurden auf demographische Parameter adjustiert (Geschlecht, Rasse, Alter, Bildung etc.) und die zu den einzelnen Krebsarten assoziierten Risikofaktoren wurden 
einbezogen (Rauchen, Übergewicht, wenig Bewegung). Ob eine Krebsanamnese mit einer zukünftigen AD-Diagnose zusammenhängt war ebenfalls Gegenstand der Untersuchungen, wobei erneut auf demographische Parameter sowie Risikofaktoren für AD und vaskuläre Demenz adjustiert wurde (APO-E4-Allele, Bluthochdruck, Diabetes mellitus, KHK und damit verbundene Eingriffe). Von den 3020 ausgewählten Patienten waren 478 an Demenz erkrankt (15,8\%) und 376 aufgrund von Krebs hospitalisiert (12,4\%). Individuen mit AD hatten im Vergleich zu denjenigen ohne AD weniger Hospitalisierungen aufgrund von Krebs und hellhäutige Patienten mit einer Krebsanamnese zeigten ein niedrigeres Risiko an einer AD zu erkranken.

Zwar können die Analysen dieser Arbeit nicht direkt in Zusammenhang mit Roes Ergebnissen gebracht werden, dennoch werden sie von ihnen dahingehend gestützt, dass eine Krebserkrankung wahrscheinlich keinen Einfluss auf den Verlauf einer AD hat.

Untersuchungen aus dem Jahre 2017 zeigten einen ähnlichen Zusammenhang, indem 1515 Personen über eine mediane Follow-Up-Zeit von 18,5 Jahren auf die Inzidenz von Krebs und AD oder PD untersucht wurden (Prinelli et al. 2018). Die Frequenz von Krebspatienten war erneut niedriger bei den AD- oder PD-Patienten. 16,7\% der Patienten litten an einer Krebserkrankung, während es in der Kontrollgruppe ohne AD 24,5 \% waren. Das Risiko eine Krebserkrankung zu erleiden war erniedrigt, jedoch auf einem statistisch nicht signifikanten Niveau. Es ergab sich also erneut ein inverser Zusammenhang zwischen dem Krebsrisiko und der AD/PD.

In der Zusammenschau lassen die Ergebnisse vermuten, dass AD-Patienten durch bestimmte Faktoren in ihrer Gedächtnisfunktion nicht verstärkt beeinträchtigt sind, sobald neben der AD eine Krebserkrankung als Komorbidität auftritt. Durch die geringe Anzahl an Krebspatienten in der rpAD-Studienkohorte muss diese Berechnung in einer größeren Patientengruppe erneut stattfinden, um das Ergebnis zu überprüfen. Zudem wäre es interessant weitere Krebsarten zu untersuchen, um eventuelle Einflüsse der unterschiedlichen Tumore auf die Gedächtnisleistung zu detektieren. 


\subsection{Chirurgische Eingriffe}

Da die Annahme eines Zusammenhangs zwischen chirurgischen Eingriffen und kognitiver Dysfunktion bzw. AD bestand, nahmen sich diverse Arbeitsgruppen das Ziel dies zu prüfen.

Es stellte sich bezüglich dieser Arbeit die Frage, ob stattgefundene Operationen einen Einfluss auf den Verlauf der AD nehmen und ob die einzelnen Eingriffe sich unterschiedlich auswirken.

Evered et al. (2011) veröffentlichten eine Studie, in der postoperative kognitive Dysfunktion bei Patienten nach verschiedenen Eingriffen untersucht wurde. Dabei wurden Daten von 644 Patienten erhoben, die Kontrollgruppe umfasste 34 Personen. Es wurden direkt nach dem Eingriff, im Abstand von sieben Tagen und von drei Monaten postoperativ neuropsychologische Tests durchgeführt.

Während in der rpAD-Studie erhoben wurde an welchem Organsystem der Eingriff stattfand, untersuchte Evered drei spezifische Operationen. Er entdeckte, dass postoperative kognitive Dysfunktionen bei älteren Patienten am siebten postoperativen Tag nach Koronarbypässen häufiger vorkamen als beispielsweise nach Hüft-TEPs. Die kognitive Dysfunktion drei Monate nach Eingriff war unabhängig davon welcher Eingriff oder welche Form der Narkose durchgeführt wurde.

Die Daten der rpAD-Studie beziehen sich auf einen längeren Beobachtungszeitraum, da viele der Eingriffe bereits Jahre zurück lagen. Oft ergab sich allerdings in der Anamnese durch Familienmitglieder, dass der demenzielle Prozess nach einer Vollnarkose stark voranschritt, weshalb ein besonderes Augenmerk auf stattgefundene Eingriffe gelegt wurde. Dabei wurde zunächst überprüft, ob eine Operation generell eine Auswirkung auf den Verlauf der AD hat und später die Untergruppen der einzelnen Organsysteme untersucht.

In der Gesamtkohorte ließen sich im Laufe ihres Lebens 38,8 \% der Patienten (35 Patienten) einem oder mehrerer Eingriffe unterziehen (vgl. S. 46). Dabei ergab sich kein signifikanter $\mathrm{p}$-Wert mit einem Chi-Quadrat-Test mit $\mathrm{p}=0,23$ und einem exakten Test nach Fisher mit $p=0,28$ bei Betrachtung der „,chirurgischen Eingriffe“ im Allgemeinen. Dasselbe galt für die einzelnen Eingriffe oder die Eingriffe der Subgruppen.

Inwiefern Eingriffe mit der AD assoziiert sind, konnte nicht abschließend geklärt werden, weshalb dieser Themenbereich weiterer klinischer Forschung bedarf (Xie und Tanzi 2006). Im weiteren Verlauf der rpAD-Studie ist es vonnöten detailliertere Daten zu den Eingriffen zu erheben. Dadurch wäre es in Zukunft möglich zu untersuchen in welchem Alter Operationen einen besonderen Einfluss haben oder ob Eingriffe nach Einsetzen der AD einen anderen 
Effekt zeigen. Dies konnte in der für diese Arbeit untersuchten Kohorte aufgrund kleiner Patientenanzahlen nicht untersucht werden.

\subsection{Andere Vor- und Begleiterkrankungen}

Die retrospektiv erhobenen ,anderen Vor- und Begleiterkrankungen“ sind eine unsystematische Auflistung aus Erkrankungen, Risikofaktoren und laborchemischen Auffälligkeiten, die in der rpAD-Studienkohorte über die Untersuchungszeit aufgetreten sind und zur zusätzlichen Beobachtung in die statistische Berechnung miteinbezogen wurden. Einige dieser Erkrankungen wurden bereits in anderen Studien auf ihren Zusammenhang mit der AD untersucht.

\subsubsection{AD und Trauma}

Die Fähigkeit des Gehirns sich zu regenerieren und zu reorganisieren scheint sich im Alter zu verringern. Dies kann in gravierenden Konsequenzen für die kognitive Funktion resultieren, wenn Patienten eine Kopfverletzung in höheren Alter erleiden (Graves et al. 1990). Patienten, die ein Kopftrauma zehn Jahre vor Beginn der AD erlitten, hatten ein achtfach erhöhtes Risiko an einer Demenz zu erkranken. Dieses Risiko steigerte sich nochmals, wenn bereits ein Verwandter ersten Grades an einer Demenz litt (van Duijn et al. 1992). AD Patienten mit einer gravierenden Kopfverletzung vor dem 65. Lebensjahr zeigten früher einen Beginn der Symptome als AD-Patienten ohne Kopftrauma (Gedye et al. 1989).

In der in dieser Arbeit untersuchten Kohorte waren insgesamt elf Patienten mit einem Trauma in der Anamnese zu finden. Davon erlitten vier ein Kopf-/Halstrauma (4,4 \%) und sieben ein nicht Kopf-/Halstrauma (7,7 \%). Mit p= 0,333 im Chi-Quadrat-Test, $\mathrm{p}=$ 0,374 im exakten Test nach Fisher und $\mathrm{p}=0,816$ im Kruskal-Wallis-Test liefern die Ergebnisse dieser Arbeit keinen Anhalt dafür, dass Patienten mit Trauma einen Nachteil in ihrem Verlauf der AD erleben (vgl. S. 51). Die Ergebnisse dieser Arbeit widersprechen den kürzlich genannten Studienergebnissen. Eine mögliche Erklärung dafür könnte sein, dass die Kopfverletzung der Patienten der rpAD-Studie nur anamnestisch erhoben wurde. Es wurde nicht genau definiert, um welche Art von Kopfverletzung und um welche Schwere der Läsion es sich handelte. Die Patienten gaben lediglich an, ob sie im Verlaufe ihres Lebens eine Kopfverletzung erlitten. Dies führte dazu, dass in der Gruppe Traumata zum Beispiel sowohl Patienten mit einem schweren Autounfall in der Anamnese als auch Patienten mit einem leichten Sturz auf den Kopf zusammengefasst wurden. In den bereits genannten Studien von Graves et al. (1990) und van Duijn et al. (1992) war hingegen eine Kopfverletzung erst durch den Eintritt von 
Bewusstlosigkeit definiert, wodurch nur schwerwiegende Traumata in die Studien miteinbezogen wurden. Für einen besseren Vergleich der Ergebnisse müsste eine genauere Definition der Kopfverletzungen bei Einschluss in die rpAD-Studie erfolgen.

\subsubsection{AD und psychische Symptome}

Wilkosz et al. (2010) erhoben in ihrer Studie jährlich das Auftreten psychotischer Symptome bei Late-Onset-AD-Patienten. Dabei handelte es sich vor allem um Halluzinationen und Wahnsymptomatik, die bei bereits bestehender Erkrankung auftraten. Mittels latenter Klassenanalyse wurden sechs Graphen berechnet, die mögliche kognitive Verläufe darstellen. Unter Einbeziehung der Parameter MMSE-Baseline-Wert, Alter, Geschlecht, Bildung und APO-E4-Status wurde berechnet, welcher der sechs Verläufe am wahrscheinlichsten eingeschlagen werden würde. In einer zweiten Analyse wurde das Vorhandensein psychotischer Symptome miteinbezogen und eruiert, ob sich die Verläufe ändern würden. Zur genaueren Berechnung wurden beispielhaft die Daten für 68-jährige Patienten (jüngere) und 78-jährige Patienten (ältere) berechnet, während die MMSE-Baseline-Werte 26, 21 und 16 betrugen. Es wurden zwei Patienten gleichen Alters mit gleichem MMSE-Ergebnis verglichen, wobei einer von ihnen psychotische Symptome aufwies. Dabei betrafen diese Symptome ungefähr die Hälfte aller Late-Onset-AD Patienten. Sie wiesen einen rapiden kognitiven Verfall auf. Je größer die Belastung durch psychische Erkrankungen war, desto wahrscheinlicher zeigten die Patienten einen rapideren Verlauf. Dies war in allen Altersklassen und allen MMSE-Baseline-Werten zu beobachten. Ähnliche Ergebnisse lieferte eine weitere Studie aus dem Jahr 2007 (Buccione et al. 2007).

In der rpAD-Studienkohorte wurden ebenfalls Daten bezüglich psychischer Vorerkrankungen erhoben. 16 Patienten waren von einer Depression betroffen, was 17,7 \% der Gesamtkohorte darstellte. Mit $\mathrm{p}=0,83 \mathrm{im}$ Chi-Quadrat-Test und $\mathrm{p}=1,0 \mathrm{im}$ exakten Test nach Fisher ließen sich keine signifikanten Auswirkungen auf den Verlauf der AD durch eine Depression erkennen. Weitere vier Patienten litten an anderen psychischen Vorerkrankungen wie Angststörung, Zwangsstörung oder Schizophrenie (4,4\%), wobei sich hier ebenfalls keine signifikante Auswirkung erkennen ließ (vgl. S. 51).

Dieses Ergebnis widerspricht den eben genannten Studienergebnissen, in denen psychische Vorerkrankungen den Verlauf der AD negativ beeinflussten. Bei Einschluss in die rpAD-Studie gaben die Patienten an, ob bei ihnen im Laufe des Lebens eine psychische Erkrankung diagnostiziert wurde. Sie machten keine Angaben zu Medikation oder Therapien, sodass keine Informationen zu Akutsymptomatik oder Erfolg von Therapien vorlagen. Es besteht die 
Möglichkeit, dass Patienten bereits beschwerdefrei waren und sie trotzdem in die Gruppe der Patienten mit psychischen Erkrankungen eingeordnet wurden. Dies könnte zu dem vorliegenden Ergebnis führen, dass sich in der Patientenkohorte dieser Dissertation psychische Erkrankungen nicht auf den Verlauf der AD auswirken.

Es erscheint sinnvoll weiter auf diesem Themengebiet zu forschen, da auch die Diagnostik der AD durch psychische Vorerkrankungen erschwert wird. Oft lassen sich beginnende Demenzen schwierig von einer schweren Depression abgrenzen.

\subsubsection{AD und Schilddrüsenerkrankungen}

Es wurde lange angenommen, dass Schilddrüsenfehlfunktionen eine Ursache für reversible kognitive Dysfunktionen darstellten. Zudem sind sie mit einem erhöhten Risiko für eine irreversible Demenz in Zusammenhang gebracht worden (Tan et al. 2008).

Schilddrüsenhormone weisen die Fähigkeit auf die Produktion von verschiedenen APPIsoformen zu regulieren, wobei das Schilddrüsenhormon Trijodthyronin (T3) eine besondere Rolle spielen soll (Latasa et al. 1998). Besonders niedrige und hohe Thyroidea-stimulierendesHormon (TSH)-Level waren ebenfalls mit einem erhöhten Risiko an AD zu erkranken assoziiert, wovon allerdings nur Frauen betroffen waren. Es wird vermutet, dass Schilddrüsenhormone vaskuläre Risikofaktoren begünstigen und durch diesen Effekt das Risiko an einer AD zu erkranken erhöhen (Tan et al. 2008).

In der rpAD-Studienkohorte wiesen neun Patienten eine Schilddrüsenfehlfunktion auf, wovon vier eine Hypothyreose, einer eine Hyperthyreose, drei eine Hashimoto-Thyreoditis hatten und eine Person an einer nicht weiter definierten Schilddrüsenerkrankung litt. Mit $\mathrm{p}=0,666 \mathrm{im}$ Chi-Quadrat-Test, $\mathrm{p}=$ 0,798 im exakten Test nach Fisher und $\mathrm{p}=$ 0,278 im Kruskal-W allis-Test erwies sich keine signifikante Auswirkung von Schilddrüsenerkrankungen auf den Verlauf der AD (vgl. S. 51). Durch die kleinen Patientenzahlen im Gruppenvergleich können nur bedingt valide Aussagen bezüglich des Einflusses von Schilddrüsenerkrankungen auf den Verlauf der AD getroffen werden. In einer größeren Kohorte könnte ein besserer Vergleich zwischen den einzelnen Erkrankungen stattfinden.

\subsection{4 $\mathrm{AD}$ und Schlafapnoe}

Es existieren noch keine Beweise für einen kausalen Zusammenhang zwischen dem obstruktiven Schlafapnoesyndrom (OSAS) und der AD, allerdings kann das OSAS möglicherweise neurodegenerative Veränderungen durch unterbrochenen Schlaf und intermittierende Hypoxie herbeiführen. Dies kann zu Entzündungsprozessen und zellulärem 
Stress im weiteren Verlauf führen. Schlafunterbrechungen und intermittierende Hypoxie begünstigen die Proteinaggregation im Gehirn im Tier- und Zellmodell, was eine entscheidende Rolle in der Pathogenese der AD spielt. Chronische Schlafunterbrechungen erhöhen zudem die Amyloid-Plaque-Formation im Mausmodell. Ein andauerndes Schlafapnoesyndrom begünstigt also eine kognitive Dysfunktion, sodass eine frühe Behandlung des OSAS einen positiven Effekt auf die Einschränkungen haben könnte (Pan und Kastin 2014).

In dem untersuchten Patientenkollektiv litten vier männliche Patienten an einem OSAS (4,4 \%), davon drei in der Gruppe AD und einer in der Gruppe rpAD. Mit p= 0,21 im Chi-QuadratTest und $\mathrm{p}=0,32 \mathrm{im}$ exakten Test nach Fisher erwies sich in der Kohorte kein statistischer Zusammenhang zwischen dem OSAS und dem Verlauf der AD (vgl. S. 51). Für eine genauere Betrachtung dieses Zusammenhangs wäre es wichtig in Zukunft die Therapie des OSAS der Patienten bei der Anamnese zu erheben. Die Patienten gaben lediglich die Existenz eines OSAS an, jedoch fehlen jegliche Informationen bezüglich einer bestehenden Sauerstofftherapie. Eine solche Therapie könnte die Patienten in ihrer Gedächtnisleistung und Konzentrationsfähigkeit unterstützen, sodass ihre eher milden Verläufe zu den errechneten Ergebnissen passen würden.

\subsubsection{Andere Vor- und Begleiterkrankungen}

Zusammenfassend ließ sich erkennen, dass keine der ,anderen untersuchten Vor- und Begleiterkrankungen“ (Epilepsie, Hypakusis, Arthrose, Autoimmunerkrankung, chronische Infektionen, Asthma und andere neurologische Erkrankungen) eine Auswirkung auf den Verlauf der AD zeigte (vgl. S. 51). Dabei ist zu erwähnen, dass die Erkrankungen nicht explizit untersucht werden sollten, sondern nur hinzugezogen wurden, wenn sie mehr als zwei Mal in der Studienkohorte vorkamen. In dieser Gruppe finden sich die kleinsten Patientenanzahlen, wodurch viele Ergebnisse aufgrund der kleinen Gruppenanzahl nur bedingt aussagekräftig sind und mit einer größeren Anzahl erneut berechnet werden müssten.

Zur Übersicht der diskutierten Risikofaktoren finden sich in Tabelle 40 und 41 die

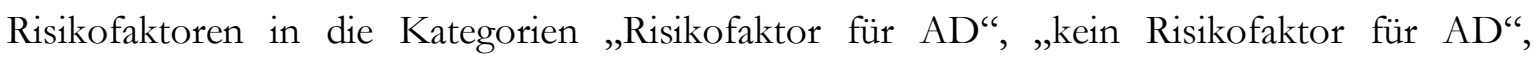
„Risikofaktor für klassischen Verlauf“ und „Risikofaktor für rapid progressiven Verlauf“ dargestellt. 
Tabelle 40: Übersicht über die Referenzen geordnet nach dem Kriterium „Risikofaktor für $\mathrm{AD}^{\prime}$ und „kein Risikofaktor für $\mathrm{AD}$ "

\begin{tabular}{|c|c|c|}
\hline Risikofaktor & Risikofaktor AD & Kein Risikofaktor AD \\
\hline $\begin{array}{l}\text { Kardiovaskuläre } \\
\text { Risikofaktoren }\end{array}$ & $\begin{array}{l}\text { Duthie et al. 2011, Laukka et al. 2010, Bhargava et al. } \\
\text { 2006, de la Torre 2012, Luchsinger und Mayeux 2004, } \\
\text { Lin et al. } 2019\end{array}$ & - \\
\hline Schlaganfall & Honig et al. 2003 & - \\
\hline pAVK & Newman et al. 2005 & - \\
\hline $\begin{array}{l}\text { medikamentöse } \\
\text { Therapie }\end{array}$ & - & $\begin{array}{l}\text { Poly et al. 2020, Mejias- } \\
\text { Trueba et al. } 2018\end{array}$ \\
\hline Diabetes & $\begin{array}{l}\text { Arvanitakis et al. 2004, Ott et al. 1996, McNay und } \\
\text { Recknagel 2011, Wu et al. 2008, Janson et al. 2004, } \\
\text { Fukuyama et al. } 1994 \\
\text { Deckers et al. 2017, Tai et al. 2016, Huang und Mahley } \\
2014\end{array}$ & $\begin{array}{l}\text { Hassing et al. 2002, } \\
\text { Kadohara et al. 2017, } \\
\text { Heneka et al. } 2015\end{array}$ \\
\hline Malignome & - & $\begin{array}{l}\text { Roe et al. 2010, Prinelli } \\
\text { et al. } 2018\end{array}$ \\
\hline Chir. Eingriffe & $\begin{array}{l}\text { Xie und Tanzi } 2006 \text { (möglicherweise) } \\
\text { Evered et al. } 2011 \text { (möglicheweise) }\end{array}$ & - \\
\hline Andere Vorerkr. & & - \\
\hline Traumata & $\begin{array}{l}\text { Mayeux et al. 1995, Graves et al. 1990, van Duijn et al. } \\
\text { 1992, Gedye et al. } 1989\end{array}$ & - \\
\hline Psychische-Erkr. & Bature et al. 2017 & - \\
\hline Schilddrüsen-Erkr. & Tan et al. 2008, Latasa et al. 1998 & - \\
\hline OSAS & Pan und Kastin 2014 & - \\
\hline \multicolumn{3}{|l|}{ APO-E } \\
\hline APO-E4 & $\begin{array}{l}\text { Jarvik et al. 1996, Slooter et al. 1998, Huang 2006, Caselli } \\
\text { et al. 2011, Tanzi und Bertram 2005, Chiappelli et al. 2006, } \\
\text { Strittmatter und Roses 1996, Xie und Tanzi 2006, Genin } \\
\text { et al. 2011, Blacker et al. 1997, Gomez-Isla et al. } 1996 \\
\text { Zintl 2011, Liu et al. } 2019 \text { (Risikofaktor für Diabetes } \\
\text { mellitus) }\end{array}$ & \\
\hline APO-E2 & - & $\begin{array}{l}\text { Benjamin et al. 1994, } \\
\text { Conejero-Goldberg et al. } \\
\text { 2014, Wilson et al. 2002, } \\
\text { Shinohara et al. } 2016\end{array}$ \\
\hline
\end{tabular}


Tabelle 41: Übersicht über die Referenzen geordnet nach „Risikofaktor für klassische $\mathrm{AD}$ " und „Risikofaktor für rapid progressive $\mathrm{AD}$ "

\begin{tabular}{|c|c|c|}
\hline Risikofaktor & Risikofaktor klassischer Verlauf & Risikofaktor rapid progressive $\mathrm{AD}$ \\
\hline $\begin{array}{l}\text { Kardiovaskuläre } \\
\text { Risikofaktoren }\end{array}$ & - & $\begin{array}{l}\text { Silvestrini et al. 2006, Helzner et al. } \\
\text { 2009, Deschaintre et al. 2009, Laukka } \\
\text { et al. } 2010\end{array}$ \\
\hline Diabetes & $\begin{array}{l}\text { Ascher-Svanum et al. 2015, Sanz et al. } \\
\text { 2009, Dominguez et al. 2012, Gherib } \\
\text { 2016, Kandimalla et al. 2017, Song et } \\
\text { al. } 2018\end{array}$ & Helzner et al. 2009 \\
\hline KHK & - & Bleckwenn et al. 2017 \\
\hline Antihypertensive Therapie & - & - \\
\hline Alter & Duron et al. 2009 & - \\
\hline Komorbiditäten & Gambassi et al. 1999 & Aubert et al. 2015 \\
\hline Malignome & - & - \\
\hline Chirurgische Eingriffe & - & - \\
\hline \multicolumn{3}{|l|}{$\begin{array}{l}\text { Andere } \\
\text { Vorerkrankungen. }\end{array}$} \\
\hline Traumata & - & - \\
\hline Psychische Erkrankungen & - & $\begin{array}{l}\text { Buccione et al. 2007, Wilkosz et al. } \\
2010\end{array}$ \\
\hline $\begin{array}{l}\text { Schilddrüsen- } \\
\text { Erkrankungen }\end{array}$ & - & - \\
\hline OSAS & - & - \\
\hline
\end{tabular}

\section{APO-E-Allelverteilung}

APO-E4

Schmidt et al. 2010, Cohen et al. 2015 Cosentino et al. 2008

APO-E2

Serrano-Pozo et al. 2015, Zhao et al.

2016 


\subsection{Vorzüge und Limitationen der Studie}

\subsubsection{Vorzüge}

Die Patienten der rpAD-Studie werden anhand fest definierter Ein- und Ausschlusskriterien in die Studie aufgenommen (vgl. S. 17). Mittels Blutuntersuchung, Bildgebung und neuropsychologischer Testung wird die Verdachtsdiagnose AD auf verschiedene Weise geprüft und es werden Differentialdiagnosen ausgeschlossen. Somit ist es sehr wahrscheinlich, dass die Patienten der rpAD-Studie tatsächlich an einer AD leiden. Die Verdachtsdiagnose kann jedoch erst durch Autopsie nach Tod des Patienten gesichert werden. In der UMG, ein Maximalversorgungszentrum für die Region Göttingen, sind sehr viele Patienten mit AD anzutreffen, was die Studie stets vergrößert. Seit nunmehr zehn Jahren läuft die Datenaufnahme, sodass neben den rpAD-Patienten auch viele Patienten mit klassischer AD eingeschlossen sind, was einen direkten Gruppenvergleich ermöglicht. Durch die intensiven Anamnesegespräche, die Vorbefunde, die neuropsychologische Testung, die genetische Untersuchung und die Gespräche mit Betreuern und Familienangehörigen ist es möglich vielseitige Informationen über die Patienten zu sammeln, sodass genetische Risikofaktoren sowie körperliche und psychische Erkrankungen erhoben werden können. Durch den Einschluss von mittlerweile über 300 Patienten ergibt sich ein vielseitiges Bild an Risikofaktoren, deren Einfluss auf die Grunderkrankung AD untersucht wird.

\subsubsection{Limitationen}

Da mindestens zwei Follow-Up-Untersuchungen nötig waren, um die Patientendaten für die statistische Auswertung zu nutzen, konnten nur die Daten von 90 Patienten für diese Arbeit genutzt werden. Durch die Beobachtung vieler Erkrankungen und Risikofaktoren sind in den einzelnen Gruppen relativ geringe Patientenzahlen zu finden, wodurch in einigen Gruppen Schwierigkeiten bei der statistischen Berechnung entstanden. Eine größere Gruppe würde genauere Ergebnisse vor allem für seltene Erkrankungen liefern.

Zudem könnten genauere Angaben zu einzelnen Vorerkrankungen (vor allem in den Kategorien „Malignome“ und „chirurgische Eingriffe“) oder Medikamenteneinnahmen die einzelnen Risikoprofile noch verfeinern. Je mehr Informationen bezüglich der Vorerkrankungen vorlägen, desto detaillierter könnten Erklärungsansätze für die beobachteten Effekte untersucht werden. Da es sich bei der Beobachtung um eine retrospektive Betrachtung der Daten handelte, konnten nur bestehende Datensätze genutzt werden und keine weiteren Informationen eingeholt werden. 
Noch dazu ist es möglich, dass die Einteilung in AD und rpAD nur anhand des MMSE-Wertes zu irrtümlichen Ergebnissen führt. Es besteht die Überlegung in Zukunft weitere Gedächtnistests oder die Überlebenszeit in die Einteilung in AD oder rpAD einzubeziehen, um mehr als ein Kriterium für die Einteilung in die zwei Gruppen zu nutzen.

\subsection{Ausblick}

Die AD-Forschung hat in den letzten Jahren viele interessante Ergebnisse hervorgebracht, die sich mit Biomarkern im Liquor, Risikofaktoren der AD und verbesserter Bildgebung beschäftigen (Jack et al. 2018). Mit Bezug auf diese Arbeit gilt es weiter zu verfolgen, welche Risikofaktoren dazu beitragen, dass sich eine AD in ihrem Verlauf verschlechtert, und welche Komorbiditäten die kognitiven Leistungen der Patienten beeinträchtigen. Dazu ist es sinnvoll die rpAD-Studie weiterzuführen, um eine größere Gruppe an Patienten zu erhalten. Des Weiteren wäre es interessant die Risikofaktoren Diabetes mellitus und KHK im Detail zu betrachten, da für die Ergebnisse dieser Arbeit lediglich die Information „am Risikofaktor erkrankt“ und „nicht am Risikofaktor erkrankt“ erhoben wurde. Es wäre von Interesse die Medikation, die Dauer der Erkrankung und im Falle des Diabetes mellitus den genauen Typ der Erkrankung miteinzubeziehen. Dies ermöglicht genauere Aussagen, warum Patienten mit Diabetes mellitus oder KHK einen langsameren Abfall der Gedächtnisleistung im MMSE zeigen. Ein besonderes Augenmerk sollte dabei auf die Medikamenteneinnahmen der Patienten gelegt werden, da sich eine Vielzahl von molekularen Gemeinsamkeiten von kardiovaskulären Risikofaktoren, der Erkrankung Diabetes mellitus und der AD ergeben haben und ein Eingriff in diese Stoffwechselwege weitreichende Folgen haben könnte (Pugazhenthi et al. 2017). 


\section{$5 \quad$ Zusammenfassung}

Die Alzheimer-Demenz ist die häufigste Ursache für ein demenzielles Syndrom in unserer alternden Gesellschaft und entwickelt sich auch zu einem sozioökonomischen Problem. Allerdings bleiben die Behandlungsergebnisse mit den heutigen Möglichkeiten bislang weit hinter den Erwartungen zurück, sodass die Weiterentwicklung der Demenz-Therapie ein großes Forschungsfeld einnimmt.

Durch Beobachtung einer Reihe von Alzheimer-Patienten mit extrem rapiden Krankheitsverläufen wurde 2009 die Rapidly-Progressive-Alzhbeimer's-Disease-Studie an der Universitätsmedizin Göttingen ins Leben gerufen. Das Ziel besteht darin, ein Patientenkollektiv mit rapid progressiver Alzheimer-Demenz und Patienten mit gewöhnlicher Alzheimer-Demenz zu vergleichen. Dafür werden die Patienten nach definierten Kriterien in die Studie eingeschlossen. Es wird eine umfassende Diagnostik wiederholt halbjährlich durchgeführt. Die Patientendaten werden asserviert und die Patienten werden je nach Ergebnis ihres Mini-Mental-StatusExamination-Tests in die Gruppe klassische Alzheimer-Demenz und rapid progressive Alzheimer-Demenz eingeteilt. Verliert ein Patient pro Jahr sechs oder mehr Punkte im MiniMental-Status-Examination-Test, wird er in die rapid progressive Gruppe eingeordnet.

In dieser Arbeit wurden die bei Einschluss in die Studie erhobenen Risikoprofile der AlzheimerPatienten untersucht und es wurde geprüft, ob sie sich auf den Verlauf der Alzheimer-Demenz auswirken. Die Risikofaktoren wurden in die vier Gruppen „kardiovaskuläre Risikofaktoren“, „Malignome“, „chirurgische Eingriffe“ und „,andere Vor- und Begleiterkrankungen“ eingeteilt und umfassend statistisch untersucht. Es wurde für jeden Patienten ein slope berechnet. Dieser stellt die Steigung der Geraden dar, wobei das Mini-Mental-Status-Examination-Ergebnis als abhängige Variable und die Zeit in Monaten als unabhängige Variable diente. Zu Beginn erfolgte die Erstellung der deskriptiven Statistik und die Testung der Daten auf Normalverteilung. Die Risikofaktoren wurden im Folgenden zunächst mit den Steigungen in Zusammenhang gebracht, um einen möglichen Effekt auf das Mini-Mental-Status-Examination-Ergebnis zu überprüfen (Welch-t-Test). Im Chi-Quadrat-Test und im exakten Test nach Fisher wurden die Risikofaktoren in Abhängigkeit von den dichotomisierten Steigungen auf stochastische Unabhängigkeit getestet. Zeigte einer der genannten Tests einen signifikanten p-Wert, wurde eine Regression durchgeführt, in welche verschiedene Variablen als mögliche Einflussfaktoren aufgenommen wurden. In der Studienkohorte konnten 90 Patienten in die statistische Berechnung miteinbezogen werden, wobei sich die Erkrankung Diabetes mellitus signifikant auf den Verlauf der Alzheimer-Demenz auswirkte (p-Wert=0,001, vgl. S. 40). 
Die Patienten mit Diabetes mellitus zeigten einen langsameren Abfall der Gedächtnisleistung als Patienten ohne Diabetes mellitus.

Bei der Erkrankung koronare Herzkrankheit ergab sich ebenfalls ein signifikantes Ergebnis (p-Wert= 0,023, vgl. S. 41). Auch Patienten mit koronarer Herzkrankheit tendierten statistisch signifikant zu einem langsameren Verlauf der Alzheimer-Demenz. Ein synergistischer Effekt der beiden Erkrankungen auf die Gedächtnisleistung ließ sich in einer logistischen Regression allerdings nicht bestätigen ( $\mathrm{p}$-Wert koronare Herzkrankheit=0,114, Diabetes mellitus= 0,134).

Die anderen Risikofaktoren wurden nach dem gleichen Ablauf untersucht, in den Kategorien „chirurgische Eingriffe“ und „Malignome“ wurden zusätzlich Subgruppen in die Berechnung miteinbezogen. Keiner der anderen Risikofaktoren, abgesehen von Diabetes mellitus und koronarer Herzkrankheit, wirkte sich signifikant auf den Verlauf der Alzheimer-Demenz aus.

In der Apolipoprotein-E-Allelverteilung ließ sich erkennen, dass die Gruppen AD und rpAD mit $57 \%$ und $55 \%$ eine ähnliche Anzahl an Patienten mit mindestens einem Apolipoprotein-E4-Allel aufwiesen. Es zeigte sich in beiden Gruppen eine hohe Anzahl an Apolipoprotein-E4-Trägern, was vorherige Studien in der Annahme bestätigt, dass dieses Allel einen Risikofaktor für die Alzheimer-Demenz darstellt.

Bezüglich der Apolipoprotein-E2 Verteilung der rapid progressiven Alzheimer-Gruppe trugen nur $2 \%$ der Patienten ein Apolipoprotein-E2-Allel, während es in der AD-Gruppe $12 \%$ waren. Daraus ergab sich die Vermutung, dass die rapid progressive AD durch das Fehlen des als protektiv geltenden Apolipoproteins-E2 begünstigt werden könnte.

Frühere Ergebnisse der Studie darüber, dass Patienten mit rapid progressiver AlzheimerDemenz eine niedrigere Anzahl an Apolipoprotein-E4-Trägern und Apolipoprotein-E4Homozygoten aufweisen, konnten mit den Ergebnissen dieser Dissertation nicht bestätigt werden. Allerdings handelt es sich bei den 2010 untersuchten Patienten um eine Gruppe von Patienten, die nach anderen Kriterien untersucht wurden (extrem rapide Verläufe von zwei bis drei Jahren Überlebenszeit), weshalb sich die Ergebnisse nicht uneingeschränkt vergleichen lassen. Nach erneuter Betrachtung der gesamten Kohorte mit Schmidts Kriterien gibt es zwar homozygote Patienten, jedoch viel weniger als nach den Berechnungen dieser Dissertation.

Im weiteren Verlauf ist es wichtig die Rapidly-Progressive-Aløheimer's-Disease-Studie weiterzuführen und im Verlauf die Berechnungen bei einer größeren Kohorte erneut zu überprüfen. Es bleibt die Frage, wie genau sich Diabetes mellitus und die koronare Herzkrankheit auf den Verlauf der Alzheimer-Demenz auswirken. Dies könnte in einer Studie untersucht werden, welche die genaue Medikation und eventuell noch andere Demenzformen miteinbezieht. 


\section{$6 \quad$ Literaturverzeichnis}

Abu-Rumeileh S, Capellari S, Stanzani-Maserati M, Polischi B, Martinelli P, Caroppo P, Ladogana A, Parchi P (2018): The CSF neurofilament light signature in rapidly progressive neurodegenerative dementias. Alzheimers Res Ther $\underline{10}, 3$

Ali R, Goubran M, Choudhri O, Zeineh MM (2015): Seven-Tesla MRI and neuroimaging biomarkers for Alzheimer's disease. Neurosurg Focus $\underline{39}$, E4

Arvanitakis Z, Wilson RS, Bienias JL, Evans DA, Bennett DA (2004): Diabetes mellitus and risk of Alzheimer disease and decline in cognitive function. Arch Neurol 61, 661-666

Ascher-Svanum H, Chen YF, Hake A, Kahle-Wrobleski K, Schuster D, Kendall D, Heine RJ (2015): Cognitive and Functional Decline in Patients With Mild Alzheimer Dementia With or Without Comorbid Diabetes. Clin Ther $\underline{37}$, 1195-1205

Aubert L, Pichierri S, Hommet C, Camus V, Berrut G, de Decker L (2015): Association between comorbidity burden and rapid cognitive decline in individuals with mild to moderate Alzheimer's disease. J Am Geriatr Soc $\underline{63}, 543-547$

Barage SH, Sonawane KD (2015): Amyloid cascade hypothesis: Pathogenesis and therapeutic strategies in Alzheimer's disease. Neuropeptides $\underline{52}, 1-18$

Barthel H, Meyer PT, Drzezga A, Bartenstein P, Boecker H, Brust P, Buchert R, Coenen HH, la Fougère C, Gründer G et al. (2015): Beta-Amyloid-PET-Bildgebung des Gehirns. S1-Leitlinie der Deutschen Gesellschaft für Nuklearmedizin e.V. https://www.awmf.org/uploads/tx_szleitlinien/031 052l_S1_Beta_Amyloid-PET-Bildgebung_Gehirn_2019-01.pdf; abgerufen am 24.04.2020

Bature F, Guinn BA, Pang D, Pappas Y (2017): Signs and symptoms preceding the diagnosis of Alzheimer's disease: a systematic scoping review of literature from 1937 to 2016. BMJ Open 7, e015746

Benjamin R, Leake A, McArthur FK, Ince PG, Candy JM, Edwardson JA, Morris CM, Bjertness E (1994): Protective effect of apoE epsilon 2 in Alzheimer's disease. Lancet $\underline{344}, 473$

Bhargava D, Weiner MF, Hynan LS, Diaz-Arrastia R, Lipton AM (2006): Vascular disease and risk factors, rate of progression, and survival in Alzheimer's disease. J Geriatr Psychiatry Neurol 19, 78-82

Blacker D, Haines JL, Rodes L, Terwedow H, Go RC, Harrell LE, Perry RT, Bassett SS, Chase G, Meyers $\mathrm{D}$ et al. (1997): ApoE-4 and age at onset of Alzheimer's disease: the NIMH genetics initiative. Neurology $\underline{48}, 139-147$

Bleckwenn M, Kleineidam L, Wagner M, Jessen F, Weyerer S, Werle J, Wiese B, Luhmann D, Posselt T, Konig HH et al. (2017): Impact of coronary heart disease on cognitive decline in Alzheimer's disease: a prospective longitudinal cohort study in primary care. Br J Gen Pract $\underline{67}$, e111-e117

Buccione I, Perri R, Carlesimo GA, Fadda L, Serra L, Scalmana S, Caltagirone C (2007): Cognitive and behavioural predictors of progression rates in Alzheimer's disease. Eur J Neurol $\underline{14}$, 440-446

Campdelacreu J (2014): Parkinson disease and Alzheimer disease: environmental risk factors. Neurologia $\underline{29}, 541-549$

Caselli RJ, Dueck AC, Locke DE, Sabbagh MN, Ahern GL, Rapcsak SZ, Baxter LC, Yaari R, Woodruff BK, Hoffman-Snyder C et al. (2011): Cerebrovascular risk factors and preclinical memory decline in healthy APOE epsilon4 homozygotes. Neurology $\underline{76}$, 1078-1084

Chiappelli M, Nasi M, Cossarizza A, Porcellini E, Tumini E, Pinti M, Troiano L, Franceschi M, Licastro F (2006): Polymorphisms of fas gene: relationship with Alzheimer's disease and cognitive decline. Dement Geriatr Cogn Disord 22, 296-300

Cohen ML, Kim C, Haldiman T, ElHag M, Mehndiratta P, Pichet T, Lissemore F, Shea M, Cohen Y, Chen W et al. (2015): Rapidly progressive Alzheimer's disease features distinct structures of amyloidbeta. Brain 138, 1009-1022 
Conejero-Goldberg C, Gomar JJ, Bobes-Bascaran T, Hyde TM, Kleinman JE, Herman MM, Chen S, Davies P, Goldberg TE (2014): APOE2 enhances neuroprotection against Alzheimer's disease through multiple molecular mechanisms. Mol Psychiatry $\underline{19}, 1243-1250$

Cosentino S, Scarmeas N, Helzner E, Glymour MM, Brandt J, Albert M, Blacker D, Stern Y (2008): APOE epsilon 4 allele predicts faster cognitive decline in mild Alzheimer disease. Neurology $\underline{70}, 1842-$ 1849

Cutler NR (1986): Cerebral metabolism as measured with positron emission tomography (PET) and [18F] 2-deoxy-D-glucose: healthy aging, Alzheimer's disease and Down syndrome. Prog Neuropsychopharmacol Biol Psychiatry $\underline{10}$, 309-321

Deckers K, Schievink SHJ, Rodriquez MMF, van Oostenbrugge RJ, van Boxtel MPJ, Verhey FRJ, Kohler S (2017): Coronary heart disease and risk for cognitive impairment or dementia: Systematic review and meta-analysis. PLoS One 12, e0184244

de Felice FG, Lourenco MV, Ferreira ST (2014): How does brain insulin resistance develop in Alzheimer's disease? Alzheimers Dement 10, 26-32

de la Torre JC (2012): Cardiovascular Risk Factors Promote Brain Hypoperfusion Leading to Cognitive Decline and Dementia. Cardiovasc Psychiatry Neurol 367516

Deschaintre Y, Richard F, Leys D, Pasquier F (2009): Treatment of vascular risk factors is associated with slower decline in Alzheimer disease. Neurology $\underline{73}$, 674-680

Desikan RS, Sabuncu MR, Schmansky NJ, Reuter M, Cabral HJ, Hess CP, Weiner MW, Biffi A, Anderson CD, Rosand J et al. (2010): Selective disruption of the cerebral neocortex in Alzheimer's disease. PLoS One $\underline{5}$, e12853

de Toledo-Morrell L, Stoub TR, Bulgakova M, Wilson RS, Bennett DA, Leurgans S, Wuu J, Turner DA (2004): MRI-derived entorhinal volume is a good predictor of conversion from MCI to AD. Neurobiol Aging 25, 1197-1203

DGN (2016): Demenzen. S3-Leitlinie der Deutschen Gesellschaft für Psychiatrie und Psychotherapie, Psychosomatik und Nervenheilkunde und der Deutschen Gesellschaft für Neurologie. https://www.awmf.org/uploads/tx_szleitlinien/038-0131_S3-Demenzen-2016-07.pdf; abgerufen am 24.04.2020

Dominguez RO, Marschoff ER, Gonzalez SE, Repetto MG, Serra JA (2012): Type 2 diabetes and/or its treatment leads to less cognitive impairment in Alzheimer's disease patients. Diabetes Res Clin Pract $\underline{98}$, 68-74

Drummond E, Nayak S, Faustin A, Pires G, Hickman RA, Askenazi M, Cohen M, Haldiman T, Kim C, Han X et al. (2017): Proteomic differences in amyloid plaques in rapidly progressive and sporadic Alzheimer's disease. Acta Neuropathol 133, 933-954

Dubois B, Feldman HH, Jacova C, Dekosky ST, Barberger-Gateau P, Cummings J, Delacourte A, Galasko D, Gauthier S, Jicha G, et al. (2007): Research criteria for the diagnosis of Alzheimer's disease: revising the NINCDS-ADRDA criteria. Lancet Neurol $\underline{6}, 734-746$

Dubois B, Feldman HH, Jacova C, Hampel H, Molinuevo JL, Blennow K, DeKosky ST, Gauthier S, Selkoe D, Bateman R et al. (2014): Advancing research diagnostic criteria for Alzheimer's disease: the IWG-2 criteria. Lancet Neurol $\underline{13}$, 614-629

Duron E, Rigaud AS, Dubail D, Mehrabian S, Latour F, Seux ML, Hanon O (2009): Effects of antihypertensive therapy on cognitive decline in Alzheimer's disease. Am J Hypertens 22, 1020-1024

Duthie A, Chew D, Soiza RL (2011): Non-psychiatric comorbidity associated with Alzheimer's disease. QJM 104, 913-920

Evered L, Scott DA, Silbert B, Maruff P (2011): Postoperative cognitive dysfunction is independent of type of surgery and anesthetic. Anesth Analg 112, 1179-1185 
Ferri CP, Prince M, Brayne C, Brodaty H, Fratiglioni L, Ganguli M, Hall K, Hasegawa K, Hendrie H, Huang Y et al. (2005): Global prevalence of dementia: a Delphi consensus study. Lancet $\underline{366}$, 2112-2117

Folstein MF, Folstein SE, McHugh PR (1975): "Mini-mental state". A practical method for grading the cognitive state of patients for the clinician. J Psychiatr Res $\underline{12}$, 189-198

Frisoni GB, Ganzola R, Canu E, Rub U, Pizzini FB, Alessandrini F, Zoccatelli G, Beltramello A, Caltagirone C, Thompson PM (2008): Mapping local hippocampal changes in Alzheimer's disease and normal ageing with MRI at 3 Tesla. Brain 131, 3266-3276

Fukuyama H, Ogawa M, Yamauchi H, Yamaguchi S, Kimura J, Yonekura Y, Konishi J (1994): Altered cerebral energy metabolism in Alzheimer's disease: a PET study. J Nucl Med $\underline{35}, 1-6$

Gambassi G, Lapane KL, Landi F, Sgadari A, Mor V, Bernabie R (1999): Gender differences in the relation between comorbidity and mortality of patients with Alzheimer's disease. Systematic Assessment of Geriatric drug use via Epidemiology (SAGE) Study Group. Neurology $\underline{53}$, 508-516

Gedye A, Beattie BL, Tuokko H, Horton A, Korsarek E (1989): Severe head injury hastens age of onset of Alzheimer's disease. J Am Geriatr Soc 37, 970-973

Genin E, Hannequin D, Wallon D, Sleegers K, Hiltunen M, Combarros O, Bullido MJ, Engelborghs S, De Deyn P, Berr C et al. (2011): APOE and Alzheimer disease: a major gene with semi-dominant inheritance. Mol Psychiatry 16, 903-907

Gherib K: MMSE-Präprogressionsrate als potentieller Prädikator des kognitiven und funktionellen Progresses der Alzheimer-Demenz. Med. Diss. Göttingen 2016

Goldberg RJ (2007): Alzheimer's disease. Compr Ther $\underline{33}$, 58-64

Gomez-Isla T, West HL, Rebeck GW, Harr SD, Growdon JH, Locascio JJ, Perls TT, Lipsitz LA, Hyman BT (1996): Clinical and pathological correlates of apolipoprotein E epsilon 4 in Alzheimer's disease. Ann Neurol $\underline{39}, 62-70$

Gomez-Isla T, Hollister R, West H, Mui S, Growdon JH, Petersen RC, Parisi JE, Hyman BT (1997): Neuronal loss correlates with but exceeds neurofibrillary tangles in Alzheimer's disease. Ann Neurol $\underline{11}$, $17-24$

Graves AB, White E, Koepsell TD, Reifler BV, van Belle G, Larson EB, Raskind M (1990): The association between head trauma and Alzheimer's disease. Am J Epidemiol 131, 491-501

Hampel H, Buerger K, Zinkowski R, Teipel SJ, Goernitz A, Andreasen N, Sjoegren M, DeBernardis J, Kerkman D, Ishiguro K et al. (2004): Measurement of phosphorylated tau epitopes in the differential diagnosis of Alzheimer disease: a comparative cerebrospinal fluid study. Arch Gen Psychiatry 61, 95-102

Hardy J, Allsop D (1991): Amyloid deposition as the central event in the aetiology of Alzheimer's disease. Trends Pharmacol Sci $\underline{12}$, 383-388

Hassing LB, Johansson B, Nilsson SE, Berg S, Pedersen NL, Gatz M, McClearn G (2002): Diabetes mellitus is a risk factor for vascular dementia, but not for Alzheimer's disease: a population-based study of the oldest old. Int Psychogeriatr 14, 239-248

Heidemann C, Scheidt-Nave C (2017): Prävalenz, Inzidenz und Mortalität von Diabetes mellitus bei Erwachsenen in Deutschland - Bestandsaufnahme zur Diabetes-Surveillance. J Health Monit 2, 98-121

Helzner EP, Luchsinger JA, Scarmeas N, Cosentino S, Brickman AM, Glymour MM, Stern Y (2009): Contribution of vascular risk factors to the progression in Alzheimer disease. Arch Neurol $\underline{66}$, 343-348

Heneka MT, Fink A, Doblhammer G (2015): Effect of pioglitazone medication on the incidence of dementia. Ann Neurol 78, 284-294

Honig LS, Tang MX, Albert S, Costa R, Luchsinger J, Manly J, Stern Y, Mayeux R (2003): Stroke and the risk of Alzheimer disease. Arch Neurol 60, 1707-1712 
Horwitz B, Grady CL, Schlageter NL, Duara R, Rapoport SI (1987): Intercorrelations of regional cerebral glucose metabolic rates in Alzheimer's disease. Brain Res 407, 294-306

Huang Y (2006): Molecular and cellular mechanisms of apolipoprotein E4 neurotoxicity and potential therapeutic strategies. Curr Opin Drug Discov Devel 9, 627-641

Huang Y, Mucke L (2012): Alzheimer mechanisms and therapeutic strategies. Cell $\underline{148}$, 1204-1222

Huang Y, Mahley RW (2014): Apolipoprotein E: structure and function in lipid metabolism, neurobiology, and Alzheimer's diseases. Neurobiol Dis $\underline{72 \mathrm{Pt} \mathrm{A}}, 3-12$

Hui JS, Wilson RS, Bennett DA, Bienias JL, Gilley DW, Evans DA (2003): Rate of cognitive decline and mortality in Alzheimer's disease. Neurology 61, 1356-1361

Ihl R, Grass-Kapanke B, Lahrem P, Brinkmeyer J, Fischer S, Gaab N, Kaupmannsennecke C (2000): Entwicklung und Validierung eines Tests zur Früherkennung der Demenz mit Depressionsabgrenzung (TFDD). Fortschr Neurol Psychiatr 68, 413-422

Iqbal K, Liu F, Gong CX, Grundke-Iqbal I (2010): Tau in Alzheimer disease and related tauopathies. Curr Alzheimer Res ㄱ, 656-664

Jack CR, Jr., Bennett DA, Blennow K, Carrillo MC, Dunn B, Haeberlein SB, Holtzman DM, Jagust W, Jessen F, Karlawish J et al. (2018): NIA-AA Research Framework: Toward a biological definition of Alzheimer's disease. Alzheimers Dement 14, 535-562

Janson J, Laedtke T, Parisi JE, O'Brien P, Petersen RC, Butler PC (2004): Increased risk of type 2 diabetes in Alzheimer disease. Diabetes $\underline{53}, 474-481$

Jarvik G, Larson EB, Goddard K, Schellenberg GD, Wijsman EM (1996): Influence of apolipoprotein E genotype on the transmission of Alzheimer disease in a community-based sample. Am J Hum Genet $\underline{58}, 191-200$

Jayaratnam S, Khoo AK, Basic D (2008): Rapidly progressive Alzheimer's disease and elevated 14-3-3 proteins in cerebrospinal fluid. Age Ageing $\underline{37}$, 467-469

Jorm AF, Scott R, Cullen JS, MacKinnon AJ (1991): Performance of the Informant Questionnaire on Cognitive Decline in the Elderly (IQCODE) as a screening test for dementia. Psychol Med 21, 785-790

Josephs KA, Ahlskog JE, Parisi JE, Boeve BF, Crum BA, Giannini C, Petersen RC (2009): Rapidly progressive neurodegenerative dementias. Arch Neurol 66, 201-207

Kadohara K, Sato I, Kawakami K (2017): Diabetes mellitus and risk of early-onset Alzheimer's disease: a population-based case-control study. Eur J Neurol 24, 944-949

Kandimalla R, Thirumala V, Reddy PH (2017): Is Alzheimer's disease a Type 3 Diabetes? A critical appraisal. Biochim Biophys Acta Mol Basis Dis 1863, 1078-1089

Kaplan E, Goodglass H, Weintraub S (Hrsg.): Boston naming test. 1. Auflage; Lea \& Febiger, Philadelphia 1983

Karki R, Kodamullil AT, Hofmann-Apitius M (2017): Comorbidity Analysis between Alzheimer's Disease and Type 2 Diabetes Mellitus (T2DM) Based on Shared Pathways and the Role of T2DM Drugs. J Alzheimers Dis $\underline{60}, 721-731$

Katz S (1983): Assessing self-maintenance: activities of daily living, mobility, and instrumental activities of daily living. J Am Geriatr Soc $\underline{31}, 721-727$

Kessler J, Calabrese P, Kalbe E, Berger F (2000): DemTect. Ein neues Screening-Verfahren zur Unterstützung der Demenzdiagnostik. Psycho $\underline{6}, 343-347$

Kim J, Basak JM, Holtzman DM (2009): The role of apolipoprotein E in Alzheimer's disease. Neuron $\underline{63}, 287-303$ 
Knopman DS, DeKosky ST, Cummings JL, Chui H, Corey-Bloom J, Relkin N, Small GW, Miller B, Stevens JC (2001): Practice parameter: diagnosis of dementia (an evidence-based review). Report of the Quality Standards Subcommittee of the American Academy of Neurology. Neurology $\underline{56}, 1143-1153$

Latasa MJ, Belandia B, Pascual A (1998): Thyroid hormones regulate beta-amyloid gene splicing and protein secretion in neuroblastoma cells. Endocrinology $\underline{139}, 2692-2698$

Laukka EJ, Fratiglioni L, Backman L (2010): The influence of vascular disease on cognitive performance in the preclinical and early phases of Alzheimer's disease. Dement Geriatr Cogn Disord 29, 498-503

Lawton MP, Brody EM (1969): Assessment of older people: self-maintaining and instrumental activities of daily living. Gerontologist $\underline{9}, 179-186$

Lin YF, Smith AV, Aspelund T, Betensky RA, Smoller JW, Gudnason V, Launer LJ, Blacker D (2019): Genetic overlap between vascular pathologies and Alzheimer's dementia and potential causal mechanisms. Alzheimers Dement 15, 65-75

Liu S, Liu J, Weng R, Gu X, Zhong Z (2019): Apolipoprotein E gene polymorphism and the risk of cardiovascular disease and type 2 diabetes. BMC Cardiovasc Disord 19, 213

Luchsinger JA, Mayeux R (2004): Cardiovascular risk factors and Alzheimer's disease. Curr Atheroscler Rep $\underline{6}, 261-266$

Mann DM (1991): The topographic distribution of brain atrophy in Alzheimer's disease. Acta Neuropathol $\underline{83}, 81-86$

Mann UM, Mohr E, Chase TN (1989): Rapidly progressive Alzheimer's disease. Lancet $\underline{2}, 799$

Mayeux R, Ottman R, Maestre G, Ngai C, Tang MX, Ginsberg H, Chun M, Tycko B, Shelanski M (1995): Synergistic effects of traumatic head injury and apolipoprotein-epsilon 4 in patients with Alzheimer's disease. Neurology $\underline{45}, 555-557$

McGeer EG, Peppard RP, McGeer PL, Tuokko H, Crockett D, Parks R, Akiyama H, Calne DB, Beattie BL, Harrop R (1990): 18Fluorodeoxyglucose positron emission tomography studies in presumed Alzheimer cases, including 13 serial scans. Can J Neurol Sci $\underline{17}, 1-11$

McKhann GM, Drachman D, Folstein M, Katzman R, Price D, Stadlan EM (1984): Clinical diagnosis of Alzheimer's disease: report of the NINCDS-ADRDA Work Group under the auspices of Department of Health and Human Services Task Force on Alzheimer's Disease. Neurology 34, 939-944

McKhann GM, Knopman DS, Chertkow H, Hyman BT, Jack CR, Jr., Kawas CH, Klunk WE, Koroshetz WJ, Manly JJ, Mayeux R et al. (2011): The diagnosis of dementia due to Alzheimer's disease: recommendations from the National Institute on Aging-Alzheimer's Association workgroups on diagnostic guidelines for Alzheimer's disease. Alzheimers Dement 7, 263-269

McNay EC, Recknagel AK (2011): Brain insulin signaling: a key component of cognitive processes and a potential basis for cognitive impairment in type 2 diabetes. Neurobiol Learn Mem $\underline{96}$, 432-442

Mega MS, Cummings JL, Fiorello T, Gornbein J (1996): The spectrum of behavioral changes in Alzheimer's disease. Neurology $\underline{46}, 130-135$

Mejias-Trueba M, Perez-Moreno MA, Fernandez-Arche MA (2018): Systematic review of the efficacy of statins for the treatment of Alzheimer's disease. Clin Med (Lond) 18, 54-61

Moher D, Liberati A, Tetzlaff J, Altman DG (2009): Preferred reporting items for systematic reviews and meta-analyses: the PRISMA statement. PLoS Med $\underline{6}$, e1000097

Morris JC, Heyman A, Mohs RC, Hughes JP, van Belle G, Fillenbaum G, Mellits ED, Clark C (1989): The Consortium to Establish a Registry for Alzheimer's Disease (CERAD). Part I. Clinical and neuropsychological assessment of Alzheimer's disease. Neurology 39, 1159-1165

Mortimer JA, Ebbitt B, Jun SP, Finch MD (1992): Predictors of cognitive and functional progression in patients with probable Alzheimer's disease. Neurology 42, 1689-1696 
Movement Disorder Society Task Force on Rating Scales for Parkinson's Disease (2003): The Unified Parkinson's Disease Rating Scale (UPDRS): status and recommendations. Mov Disord 18, 738-750

Murray ME, Graff-Radford NR, Ross OA, Petersen RC, Duara R, Dickson DW (2011): Neuropathologically defined subtypes of Alzheimer's disease with distinct clinical characteristics: a retrospective study. Lancet Neurol 10, 785-796

Nabers A, Perna L, Lange J, Mons U, Schartner J, Guldenhaupt J, Saum KU, Janelidze S, Holleczek B, Rujescu D et al. (2018): Amyloid blood biomarker detects Alzheimer's disease. EMBO Mol Med 10, e12853

Nasreddine ZS, Phillips NA, Bedirian V, Charbonneau S, Whitehead V, Collin I, Cummings JL, Chertkow H (2005): The Montreal Cognitive Assessment, MoCA: a brief screening tool for mild cognitive impairment. J Am Geriatr Soc $\underline{53}$, 695-699

Newman AB, Fitzpatrick AL, Lopez O, Jackson S, Lyketsos C, Jagust W, Ives D, Dekosky ST, Kuller LH (2005): Dementia and Alzheimer's disease incidence in relationship to cardiovascular disease in the Cardiovascular Health Study cohort. J Am Geriatr Soc 프, 1101-1107

Nikisch G, Wiedemann G, Kießling B, Hertel A (2008): Familiäre Alzheimer-Demenz mit Präsenilin 2 N141I Mutation. Fortschr Neurol Psychiatr $\underline{76}$, 606-609

Oswald WD (1979): Psychometrische Verfahren und Fragebögen für gerontopsychologische Untersuchungen. Z Gerontol 12, 341-350

Ott A, Stolk RP, Hofman A, van Harskamp F, Grobbee DE, Breteler MM (1996): Association of diabetes mellitus and dementia: the Rotterdam Study. Diabetologia $\underline{39}$, 1392-1397

Pan W, Kastin AJ (2014): Can sleep apnea cause Alzheimer's disease?. Neurosci Biobehav Rev $\underline{47}$, 656669

Petzold A (2005): Neurofilament phosphoforms: surrogate markers for axonal injury, degeneration and loss. J Neurol Sci 233, 183-198

Poly TN, Islam MM, Walther BA, Yang HC, Wu CC, Lin MC, Li YC (2020): Association between Use of Statin and Risk of Dementia: A Meta-Analysis of Observational Studies. Neuroepidemiology $\underline{54}, 214$ 226

Prinelli F, Adorni F, Leite MLC, Pettenati C, Russo A, Di Santo S, Musicco M (2018): Different Exposures to Risk Factors Do Not Explain the Inverse Relationship of Occurrence Between Cancer and Neurodegenerative Diseases: An Italian Nested Case-control Study. Alzheimer Dis Assoc Disord $\underline{32}, 76-82$

Pugazhenthi S, Qin L, Reddy PH (2017): Common neurodegenerative pathways in obesity, diabetes, and Alzheimer's disease. Biochim Biophys Acta Mol Basis Dis $\underline{1863}$, 1037-1045

Querfurth HW, LaFerla FM (2010): Alzheimer's disease. N Engl J Med 362, 329-344

Reiber H, Peter JB (2001): Cerebrospinal fluid analysis: disease-related data patterns and evaluation programs. J Neurol Sci $\underline{184}, 101-122$

Reisberg B, Ferris SH, de Leon MJ, Crook T (1982): The Global Deterioration Scale for assessment of primary degenerative dementia. Am J Psychiatry 139, 1136-1139

Roe CM, Fitzpatrick AL, Xiong C, Sieh W, Kuller L, Miller JP, Williams MM, Kopan R, Behrens MI, Morris JC (2010): Cancer linked to Alzheimer disease but not vascular dementia. Neurology 74 , 106-112

Sanz C, Andrieu S, Sinclair A, Hanaire H, Vellas B (2009): Diabetes is associated with a slower rate of cognitive decline in Alzheimer disease. Neurology $\underline{73}, 1359-1366$

Scheltens P, Barkhof F, Leys D, Pruvo JP, Nauta JJ, Vermersch P, Steinling M, Valk J (1993): A semiquantative rating scale for the assessment of signal hyperintensities on magnetic resonance imaging. J Neurol Sci $\underline{114}, 7-12$ 
Schmidt C, Redyk K, Meissner B, Krack L, von Ahsen N, Roeber S, Kretzschmar H, Zerr I (2010): Clinical features of rapidly progressive Alzheimer's disease. Dement Geriatr Cogn Disord 29, 371-378

Schmidt C, Wolff M, Weitz M, Bartlau T, Korth C, Zerr I (2011): Rapidly progressive Alzheimer disease. Arch Neurol 68, 1124-1130

Schmidt C, Artjomova S, Hoeschel M, Zerr I (2013): CSF prion protein concentration and cognition in patients with Alzheimer disease. Prion 7, 229-234

Serrano-Pozo A, Qian J, Monsell SE, Betensky RA, Hyman BT (2015): APOEepsilon2 is associated with milder clinical and pathological Alzheimer disease. Ann Neurol 77, 917-929

Shah M, Catafau AM (2014): Molecular Imaging Insights into Neurodegeneration: Focus on Tau PET Radiotracers. J Nucl Med $\underline{55}$, 871-874

Shinohara M, Kanekiyo T, Yang L, Linthicum D, Shinohara M, Fu Y, Price L, Frisch-Daiello JL, Han $\mathrm{X}$, Fryer JD et al. (2016): APOE2 eases cognitive decline during Aging: Clinical and preclinical evaluations. Ann Neurol 79, 758-774

Shulman KI (1993): Clock-drawing and dementia in the community: A longitudinal study. Int J Geriatr Psychiatry $\underline{8}, 487-496$

Silvestrini M, Pasqualetti P, Baruffaldi R, Bartolini M, Handouk Y, Matteis M, Moffa F, Provinciali L, Vernieri F (2006): Cerebrovascular reactivity and cognitive decline in patients with Alzheimer disease. Stroke $\underline{37}, 1010-1015$

Slooter AJ, Cruts M, Kalmijn S, Hofman A, Breteler MM, Van Broeckhoven C, van Duijn CM (1998): Risk estimates of dementia by apolipoprotein E genotypes from a population-based incidence study: the Rotterdam Study. Arch Neurol $\underline{55}$, 964-968

Song YN, Wang P, Xu W, Li JQ, Cao XP, Yu JT, Tan L (2018): Risk Factors of Rapid Cognitive Decline in Alzheimer's Disease and Mild Cognitive Impairment: A Systematic Review and Meta-Analysis. J Alzheimers Dis $\underline{66}, 497-515$

Soto ME, Andrieu S, Cantet C, Reynish E, Ousset PJ, Arbus C, Gillette-Guyonnet S, Nourhashemi F, Vellas B (2008a): Predictive value of rapid decline in mini mental state examination in clinical practice for prognosis in Alzheimer's disease. Dement Geriatr Cogn Disord 26, 109-116

Soto ME, Andrieu S, Arbus C, Ceccaldi M, Couratier P, Dantoine T, Dartigues JF, Gillette-Guyonnet S, Nourhashemi F, Ousset PJ et al. (2008b): Rapid cognitive decline in Alzheimer's disease. Consensus paper. J Nutr Health Aging 12, 703-713

Strittmatter WJ, Roses AD (1996): Apolipoprotein E and Alzheimer's disease. Annu Rev Neurosci 19, 53-77

Tai LM, Thomas R, Marottoli FM, Koster KP, Kanekiyo T, Morris AW, Bu G (2016): The role of APOE in cerebrovascular dysfunction. Acta Neuropathol 131, 709-723

Talbot K, Wang HY (2014): The nature, significance, and glucagon-like peptide-1 analog treatment of brain insulin resistance in Alzheimer's disease. Alzheimers Dement 10, 12-25

Tan ZS, Beiser A, Vasan RS, Au R, Auerbach S, Kiel DP, Wolf PA, Seshadri S (2008): Thyroid function and the risk of Alzheimer disease: the Framingham Study. Arch Intern Med 168, 1514-1520

Tanzi RE, Bertram L (2005): Twenty years of the Alzheimer's disease amyloid hypothesis: a genetic perspective. Cell $\underline{120}, 545-555$

van Duijn CM, Tanja TA, Haaxma R, Schulte W, Saan RJ, Lameris AJ, Antonides-Hendriks G, Hofman A (1992): Head trauma and the risk of Alzheimer's disease. Am J Epidemiol 135, 775-782

Wahlund LO, Barkhof F, Fazekas F, Bronge L, Augustin M, Sjogren M, Wallin A, Ader H, Leys D, Pantoni L et al. (2001): A new rating scale for age-related white matter changes applicable to MRI and CT. Stroke $\underline{32}, 1318-1322$ 
Wallin AK, Blennow K, Andreasen N, Minthon L (2006): CSF biomarkers for Alzheimer's Disease: levels of beta-amyloid, tau, phosphorylated tau relate to clinical symptoms and survival. Dement Geriatr Cogn Disord 21, 131-138

Walsh DM, Selkoe DJ (2004): Deciphering the molecular basis of memory failure in Alzheimer's disease. Neuron $\underline{44}, 181-193$

Wilkosz PA, Seltman HJ, Devlin B, Weamer EA, Lopez OL, DeKosky ST, Sweet RA (2010): Trajectories of cognitive decline in Alzheimer's disease. Int Psychogeriatr 22, 281-290

Wilson RS, Bienias JL, Berry-Kravis E, Evans DA, Bennett DA (2002): The apolipoprotein E epsilon 2 allele and decline in episodic memory. J Neurol Neurosurg Psychiatry $\underline{73}$, 672-677

Wimo A, Jonsson L, Bond J, Prince M, Winblad B (2013): The worldwide economic impact of dementia 2010. Alzheimers Dement $\underline{9}, 1-11 . e 3$

Wu W, Brickman AM, Luchsinger J, Ferrazzano P, Pichiule P, Yoshita M, Brown T, DeCarli C, Barnes CA, Mayeux R et al. (2008): The brain in the age of old: the hippocampal formation is targeted differentially by diseases of late life. Ann Neurol 64, 698-706

Xie Z, Tanzi RE (2006): Alzheimer's disease and post-operative cognitive dysfunction. Exp Gerontol $\underline{41}, 346-359$

Zerr I, Hermann P (2018): Diagnostic challenges in rapidly progressive dementia. Expert Rev Neurother $\underline{18}, 761-772$

Zhao L, Gottesdiener AJ, Parmar M, Li M, Kaminsky SM, Chiuchiolo MJ, Sondhi D, Sullivan PM, Holtzman DM, Crystal RG et al. (2016): Intracerebral adeno-associated virus gene delivery of apolipoprotein E2 markedly reduces brain amyloid pathology in Alzheimer's disease mouse models. Neurobiol Aging 44, 159-172

Zintl M: APOE im Zusammenhang mit Diabetes, Familienanamnese Demenz und Familienanamnese Diabetes. Med. Diss. Regensburg 2011 


\section{Danksagung}

Hiermit möchte ich Frau Prof. Dr. Zerr danken. Mit ihrer Betreuung konnte ich diese Arbeit verwirklichen und hatte die Möglichkeit zusammen mit meinem Betreuer Peter Hermann das Promotionsthema gemeinsam zu entwickeln. Des Weiteren konnte ich mich immer auf Unterstützung und Hilfestellung verlassen.

Herrn Prof. Dr. Friede aus dem Institut für Medizinische Statistik, meinem zweiten Betreuer, danke ich insbesondere für die Unterstützung bei den statistischen Berechnungen für diese Dissertation. Er nahm sich viel Zeit für die Sichtung der Daten, um die eleganteste Methode für die Berechnungen zu finden.

Auch möchte ich Peter Hermann für seine Arbeit als Betreuer danken. Er hat sich viel Mühe gegeben, meine Entwürfe zu korrigieren, und war bei Problemen immer gut erreichbar. Durch seine langjährige Erfahrung in der Forschung fühlte ich mich insbesondere beim Schreiben der Dissertation sehr gut aufgehoben.

Herrn Heiko Rembowski danke ich für die umfangreiche Unterstützung bei den Berechnungen für die Auswertung.

Zum Schluss möchte ich mich bei den Mitarbeitern des Nationalen Referenzzentrums für Transmissible Spongiforme Enzephalopathien bedanken, die mir einen Arbeitsplatz zur Verfügung stellten und bei organisatorischen Fragestellungen immer hilfsbereit waren. 